
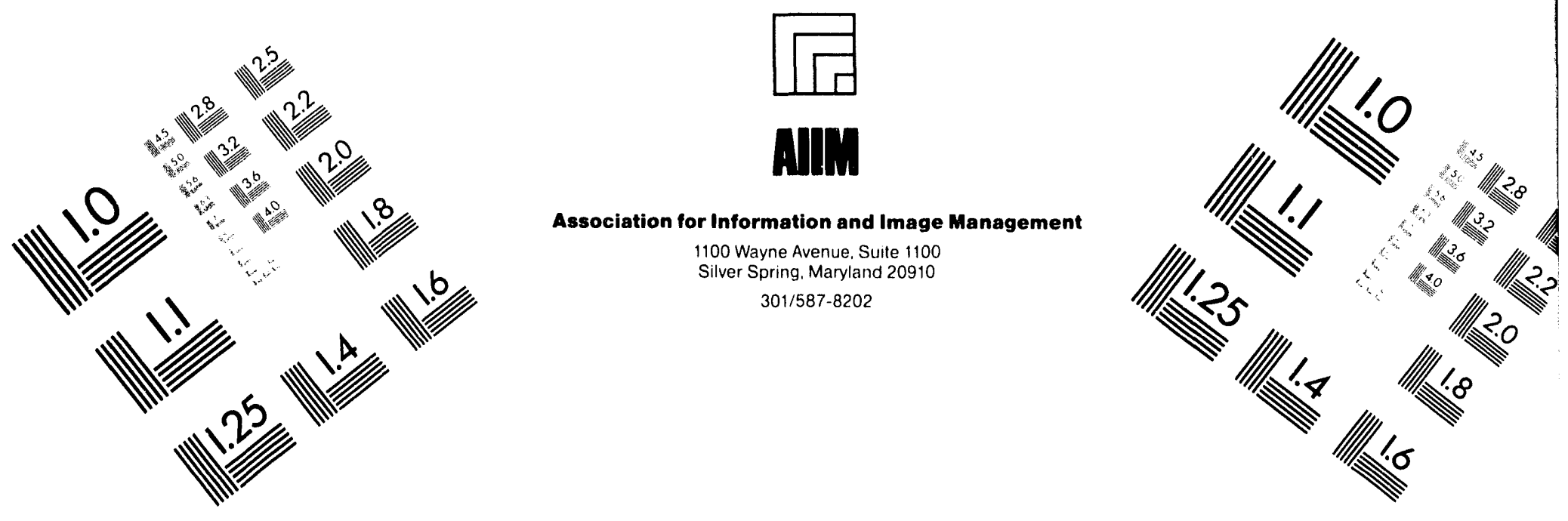

\title{
Centimeter
}

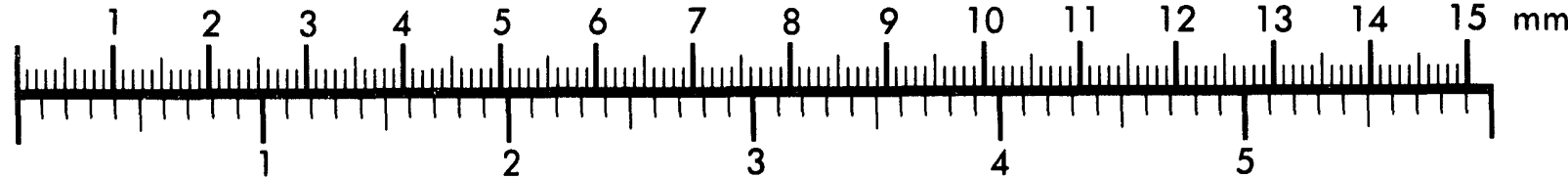
Inches
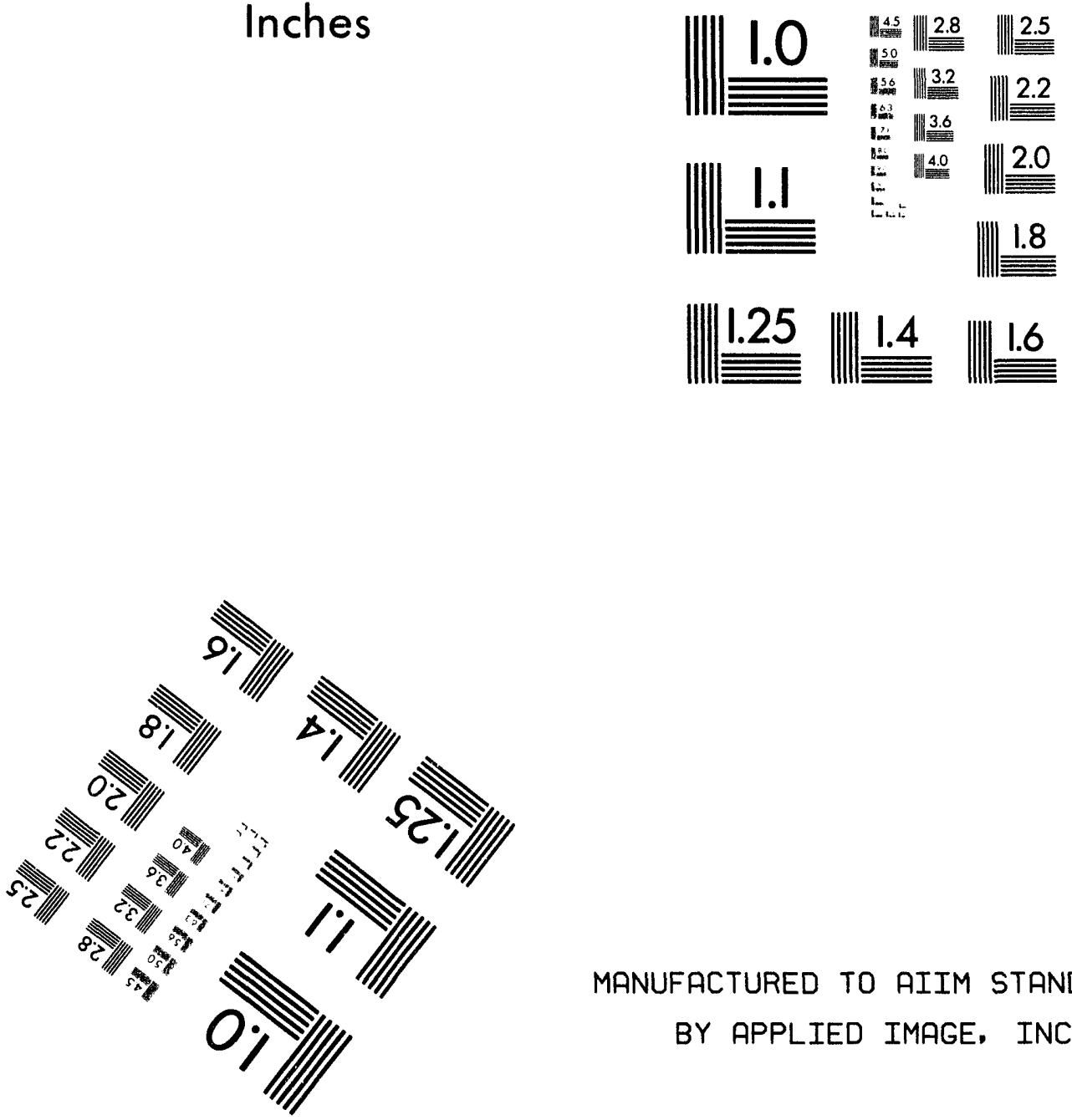

MANUFACTURED TO AIIM STANDARDS

BY APPLIED IMAGE, INC.

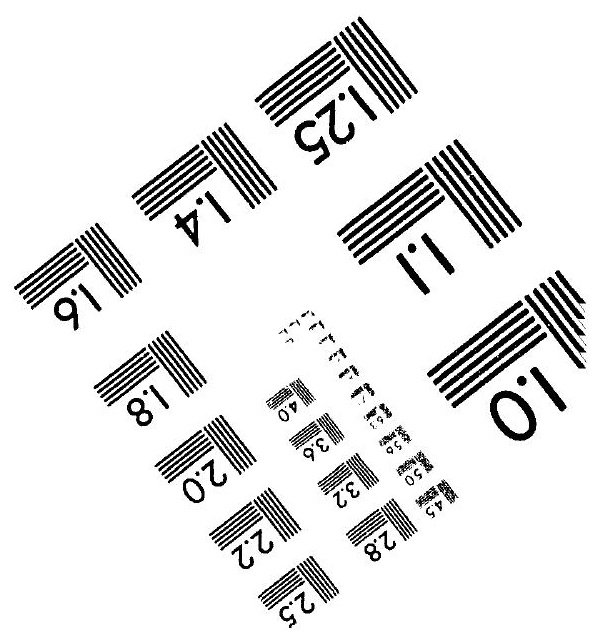



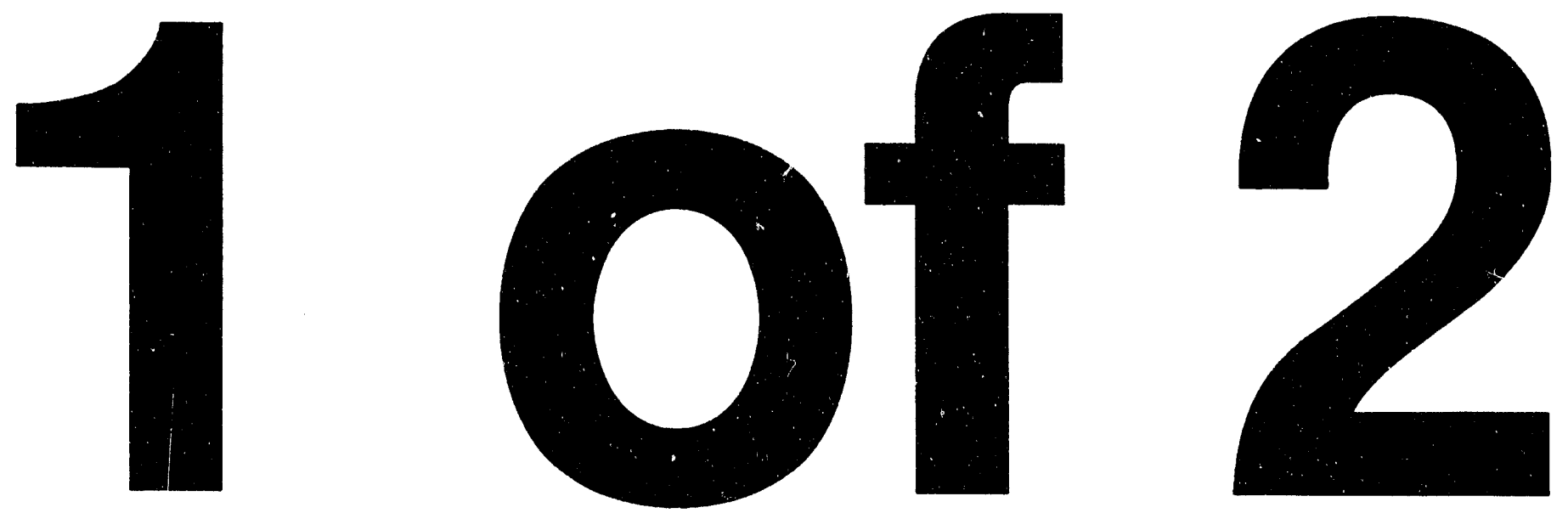
NUREG/CR-6086

BNL-NUREG-52385

\section{Selected Fault Testing of Electronic Isolation Devices Used in Nuclear Power Plant Operation}

Manuscript Completed: February 1994

Date Published: May 1994

\section{Prepared by}

M. Villaran, K. Hillman, J. Taylor, and J. Lara, Brookhaven National Laboratory

W. Wilhelm/Consultant

S. K. Aggarwal, NRC Program Manager

Brookhaven National Laboratory

Upton, NY 11973

\section{Prepared for}

Division of Engineering

Ofince of Nuclear Regulatory Research

U.S. Nuclear Regulatory Commission

Washington, DC 20555-0001

NRC FIN L2158 


\begin{abstract}
Electronic isolation devices are used in nuclear power plants to provide electrical separation between safety and non-safety circuits and systems. Major fault testing in an earlier program indicated that some energy may pass through an isolation device when a fault at the maximum credible potential is applied in the transverse mode to its output terminals. During subsequent field qualification testing of isolators, concerns were raised that the worst case fault, i.e., the Maximum Credible Fault (MCF), may not occur with a fault at the maximum credible potential, but rather at some lower potential. The present test program studies whether problems can arise when fault levels up to the maximum credible potential are applied to the output terminals of an isolator. The fault energy passed through an isolation device during a fault was measured, to determine whether the levels are great enough to potentially damage or degrade performance of equipment on the input (Class 1E) side of the isolator.
\end{abstract}




\section{CONTENTS}

Page

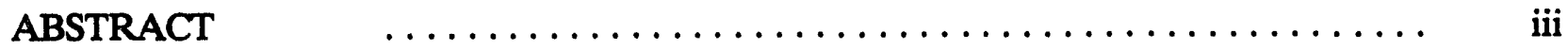

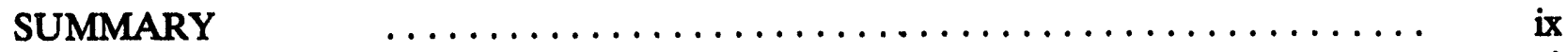

ACKNOWLEDGMENTS $\ldots \ldots \ldots \ldots \ldots \ldots \ldots \ldots \ldots \ldots \ldots \ldots \ldots \ldots \ldots \ldots \ldots$ xi

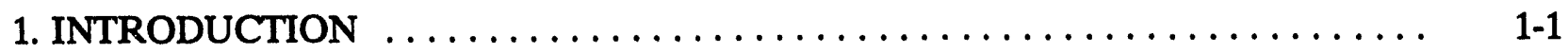

2. ELECTRONIC ISOLATION DEVICES $\ldots \ldots \ldots \ldots \ldots \ldots \ldots \ldots \ldots \ldots \ldots, 2-1$

2.1 Descriptions of Electronic Isolators $\ldots \ldots \ldots \ldots \ldots \ldots \ldots \ldots \ldots \ldots, 2-1$

2.2 Background of the Maximum Credible Fault Concerns ............ 2-4

2.3 Electronic Isolation Devices Tested $\ldots \ldots \ldots \ldots \ldots \ldots \ldots \ldots \ldots, 2-5$

2.3.1 Magnetically Coupled Isolators $\ldots \ldots \ldots \ldots \ldots \ldots \ldots \ldots \ldots, 2-6$

2.3.2 Optically Coupled Isolators $\ldots \ldots \ldots \ldots \ldots \ldots \ldots \ldots \ldots, \quad 2-14$

3. TESTING PROGRAM $\ldots \ldots \ldots \ldots \ldots \ldots \ldots \ldots \ldots \ldots \ldots \ldots \ldots \ldots \ldots \ldots \ldots \ldots, 3-1$

3.1 Objectives $\ldots \ldots \ldots \ldots \ldots \ldots \ldots \ldots \ldots \ldots \ldots \ldots \ldots \ldots \ldots \ldots \ldots \ldots \ldots \ldots, 3-1$

3.2 Test Procedures $\ldots \ldots \ldots \ldots \ldots \ldots \ldots \ldots \ldots \ldots \ldots \ldots \ldots \ldots \ldots, 3-1$

3.2.1 Baseline Electrical Tests .................... 3-1

3.2.2 Isolation Device Functional Test $\ldots \ldots \ldots \ldots \ldots \ldots \ldots \ldots \ldots, 3-3$

3.2.3 Fault Application to DUT ..................... 3-3

3.2.4 Multiple Channel Isolators $\ldots \ldots \ldots \ldots \ldots \ldots \ldots \ldots \ldots \ldots$ 3-6

3.3 Test Equipment Setup $\ldots \ldots \ldots \ldots \ldots \ldots \ldots \ldots \ldots \ldots \ldots \ldots \ldots \ldots \ldots \ldots \ldots \ldots, \quad 3-6$

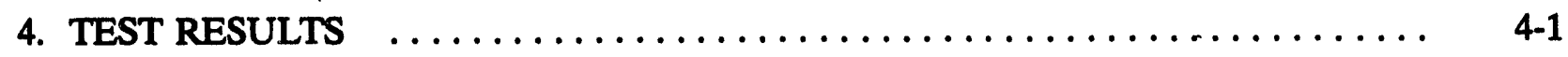

4.1 Reach-Through Energy $\ldots \ldots \ldots \ldots \ldots \ldots \ldots \ldots \ldots \ldots \ldots \ldots \ldots, 4,1$

4.2 Isolator Functional Tests $\ldots \ldots \ldots \ldots \ldots \ldots \ldots \ldots \ldots \ldots \ldots \ldots, 4-6$

4.3 Barrier Electrical Characteristics $\ldots \ldots \ldots \ldots \ldots \ldots \ldots \ldots \ldots \ldots, 4.7$

5. CONCLUSIONS AND RECOMMENDATIONS $\ldots \ldots \ldots \ldots \ldots \ldots \ldots \ldots, 5-1$

5.1 Conclusions and Observations $\ldots \ldots \ldots \ldots \ldots \ldots \ldots \ldots \ldots \ldots \ldots, 5-1$

5.2 Recommendations $\ldots \ldots \ldots \ldots \ldots \ldots \ldots \ldots \ldots \ldots \ldots \ldots \ldots, \quad 5-2$

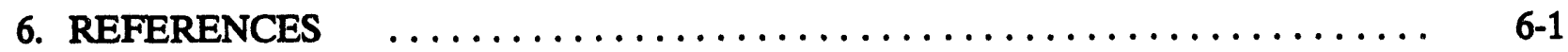

7. GLOSSARY $\quad \ldots \ldots \ldots \ldots \ldots \ldots \ldots \ldots \ldots \ldots \ldots \ldots \ldots \ldots \ldots \ldots \ldots \ldots \ldots,{ }^{7-1}$

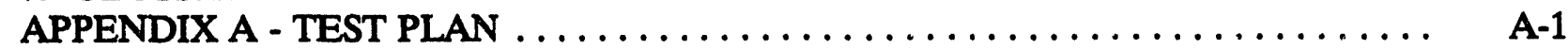

APPENDIX B - BNL ISOLATOR TEST FACILITY $\ldots \ldots \ldots \ldots \ldots \ldots \ldots \ldots$, B-1

APPENDIX C - TEST EQUIPMENT CERTIFICATIONS $\ldots \ldots \ldots \ldots \ldots \ldots \ldots$ C-1

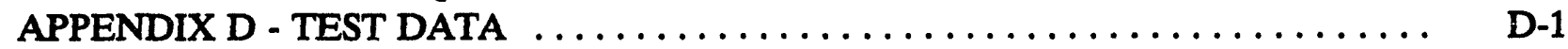




\section{FIGURES}

Page

2.1 Block diagram of transformer-coupled isolator $\ldots \ldots \ldots \ldots \ldots \ldots \ldots \ldots, 2-2$

2.2 Block diagram of optically-coupled isolator $\ldots \ldots \ldots \ldots \ldots \ldots \ldots \ldots, 2-2$

2.3 Transmation isolation transmitter $\ldots \ldots \ldots \ldots \ldots \ldots \ldots \ldots \ldots \ldots \ldots, 2-8$

2.4 Halliburton NUS isolation amplifier $\ldots \ldots \ldots \ldots \ldots \ldots \ldots \ldots \ldots \ldots, 2-8$

2.5 Devar isolated transmitter .......................... 2-10

2.6 Rochester Instruments isolated transmitters - front view and circuit board: I-to-I isolator (left) and V-to-V isolator (right) $\ldots \ldots \ldots \ldots, \quad 2-10$

2.7 Westinghouse isolator and loop power supply (NLP) card $\ldots \ldots \ldots \ldots \ldots, 2-11$

2.8 Foxboro isolators $\ldots \ldots \ldots \ldots \ldots \ldots \ldots \ldots \ldots \ldots \ldots \ldots \ldots \ldots \ldots \ldots \ldots \ldots, 2-11$

2.9 Halliburton NUS voltage-to-voltage isolation amplifier $\ldots \ldots \ldots \ldots \ldots \ldots .2-13$

2.10 Validyne isolator and support equipment shown undergoing fault testing in the BNL isolator test bed $\ldots \ldots \ldots \ldots \ldots \ldots \ldots, 2-13$

2.11 Technology for Energy single channel encapsulated digital signal isolator $\ldots \ldots \ldots \ldots \ldots \ldots \ldots \ldots \ldots \ldots \ldots \ldots, \quad 2-14$

2.12 Technology for Energy four-channel digital isolation module $\ldots \ldots \ldots \ldots \ldots .2-15$

2.13 Halliburton NUS eight-channel digital isolator card $\ldots \ldots \ldots \ldots \ldots \ldots \ldots, 2-15$

3.1 Isolation barrier resistance measurement $\ldots \ldots \ldots \ldots \ldots \ldots \ldots \ldots \ldots, 3-4$

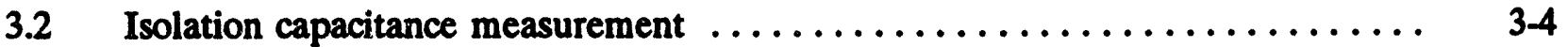

3.3 Voltage-to-voltage isolator functional test $\ldots \ldots \ldots \ldots \ldots \ldots \ldots \ldots \ldots, \quad 3-5$

3.4 Current-to-current isolator functional test $\ldots \ldots \ldots \ldots \ldots \ldots \ldots \ldots \ldots \ldots, 3-5$

3.5 Isolator incremental fault application test $\ldots \ldots \ldots \ldots \ldots \ldots \ldots \ldots \ldots \ldots, \quad 3.6$

3.6 Basic test equipment setup $\ldots \ldots \ldots \ldots \ldots \ldots \ldots \ldots \ldots \ldots \ldots \ldots \ldots, \quad 3-7$

3.7 DSO trace of the cosine fault waveform ..................... 3-9

3.8 Expanded timebase DSO trace of the leading edge (left) and the trailing edge (right) of the cosine fault waveform $\ldots \ldots \ldots \ldots \ldots \ldots \ldots . . .6$

4.1 Reach-through energy vs. fault level-isolator DA-3-1 $\ldots \ldots \ldots \ldots \ldots \ldots \ldots, \quad 4-2$

4.2 Reach-through energy vs. fault level-isolator FA-3-1A $\ldots \ldots \ldots \ldots \ldots \ldots \ldots, 4,2$

4.3 Reach-through energy vs. fault level-isolator RA-3-2 $\ldots \ldots \ldots \ldots \ldots \ldots \ldots$ 4.5

4.4 Reach-through energy vs. fault level-isolator HNA-3-1A $\ldots \ldots \ldots \ldots \ldots \ldots .4 .4 .5$

4.5 Estimation of the vulnerability of various components to ESD-induced damage $(\operatorname{Ref} 28) \ldots \ldots \ldots \ldots \ldots \ldots \ldots \ldots \ldots \ldots \ldots$ 


\section{TABLES}

Page

2.1 Typical Isolation Device Power Source and Signal Input

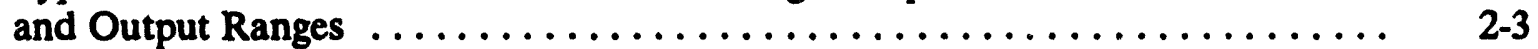

2.2 Electronic Isolators Tested $\ldots \ldots \ldots \ldots \ldots \ldots \ldots \ldots \ldots \ldots \ldots \ldots \ldots$

3.1 General Test Procedure Sequence $\ldots \ldots \ldots \ldots \ldots \ldots \ldots \ldots \ldots \ldots \ldots \ldots \ldots \ldots$

3.2 Equipment List for BNL Isolator Test Facility $\ldots \ldots \ldots \ldots \ldots \ldots \ldots \ldots \ldots$

4.1 Summary of Reach-Through Energy vs. Fault Level Testing $\ldots \ldots \ldots \ldots \ldots$ 


\section{SUMMARY}

Electronic isolation devices are used in nuclear power plants to provide electrical separation between safety and non-safety circuits and systems. Nuclear plant control and protection systems that rely heavily upon electronic and computerized instrumentation and controls make extensive use of isolation devices to maintain electrical separation. As older plants upgrade and modernize their designs to incorporate more electronics, computerized displays, and digital instrumentation and control systems, the already large population of isolation devices in nuclear plants will continue to increase. Proposed control systems for the next generation of advanced reactors will also depend heavily upon the use of electronic isolators.

With a large existing population of electronic isolation devices in nuclear power plants, most of which are used in PWR reactor protection systems (Ref. 5), and more being added as plants implement the requirement for a Safety Parameter Display System (Refs. 6,7), the US NRC initiated several activities to explore various aspects of the qualification, application, and risk significance of electronic isolation devices (Refs. 4,5,10.)

Major fault qualification testing in an earlier program (Ref.4) found that some energy may pass through an isolation device when a fault at the maximum credible potential is applied in the transverse mode to its output terminals. During subsequent field qualification testing of isolators (Refs. 8,9), concerns were raised that the worst case fault, i.e., the Maximum Credible Fault (MCF), may not occur as a result of a fault at the maximum credible potential but rather at some lower potential.
The present test program determines whether problems can arise when fault levels up to the maximum credible potential are applied to the output terminals of an isolator. The fault energy passed through an isolation device during a fault was measured to find out whether the levels are great enough to potentially damage or degrade performance of equipment on the input (Class 1E) side of the isolator.

A total of twelve models of isolation devices, representative of the major types found in nuclear power plants, were subjected to incremental fault testing. A series of faults, was applied in increasing increments of $10 \%$ of the maximum credible potential, from $10 \%$ up to $110 \%$ of the maximum credible potential, directly to the signal output terminals. Some of the major findings of this testing are:

- $\quad$ All of the devices tested demonstrated their ability to withstand and isolate a series of incremental faults without transferring significant quantities of energy across the isolation barrier to the input side.

- Peak 1/2 cycle reach-through energy measured at the input terminals of the isolation devices during fault application testing did not always occur at the level defined as the MCF potential. However, the magnitudes of the reach-through energies measured even at their peak were very small (less than 350 microjoules) and considered insignificant.

- Ten of the twelve models of isolators that were tested failed electronically, i.e., functionally lost the capability to transmit signals from input to output (their normal operating configuration), during the incremental fault testing process. 
- Three of the five multiple channel isolators tested failed electronically in all of their channels even though only one of the channels was subjected to the incremental applied fault testing process. The cause attributed to these failures was the loss of a common power supply on the output side used to power all of the isolator channels on a device.

Based on the results of this testing program, the worst case, or maximum credible, fault in regard to the reach-through energy, cid not always occur when a fault at the maximum credible potential was applied. The qualification of electronic isolators for a major fault by testing only at the maximum credible potential level is therefore not adequate if the intention is to assure that the isolators are qualified for worst case, credible fault conditions. In the future, the major fault qualification test should be expanded to test at several levels up to and including the maximum credible potential to ensure that a worst case condition is not missed.

It should be noted that the reachthrough energies measured during this testing program were considered insignificant, even in the worst case faults. Previous qualification tests for the twelve isolator models in this test program were adequate to demonstrate their acceptability as isolators even though all mechanisms were not explored. Consequently, expanded qualification testing for isolators already installed in nuclear plants is not considered necessary. 


\section{ACKNOWLEDGMENTS}

The authors wish to thank the NRC Program Manager, Mr. Satish K. Aggarwal, for his technical direction on this work. We also wish to thank Mr. Leo Beltracchi, Mr. Douglas Coe, Mir. Cliff Doutt, and Mr. Fred Ringland of NRC for the comments and information which they provided in support of this work.

The authors are grateful to various members of the Engineering Technology Division of Brookhaven National Laboratory, including Mr. Robert Hall, Mr. William Gunther, Dr. M.A. Azarm, Mr. Jeffrey A. Badger, Dr. Ralph Fullwood, Dr. Mano Subudhi, and Mr. Kenneth Sullivan for their technical comments and guidance, and assistance in the analysis of test data. We also thank Mr. Donald Sievers of the Reactor Division and Mr. Rod di Girolamo of the Alternating Gradient Synchrotron Dept. of Brookhaven National Laboratory for their technical comments and information.

We want to thank Mr. Sonny Kasturi, of MOS Services, for his technical guidance and comments throughout this project.

The authors wish to extend their gratitude to the personnel at the various manufacturers of isolation devices, utility users of isolation devices, and manufacturers of testing equipment for their cooperation in providing technical information, assistance, discussions, and guidance in support of this work. Among those providing support are the following:

Steve Guinta
James Rodgers
Don Chase
Dale Harkleroad
James Zachary
Les Kovacs
Anthony Ruscito
Terry Tomasko
David Potterton
Steve Bransfield
David R. Ringland
Daniel Nalepa
Joseph Gardiner
Ira Poppel
Laura Wolfson
Nick Lamberti
Wolf Shindler
Leo Lawrence
Holly Wallace
Victoria Keston
John Kirtland
Forrest Hatch
Paul Iaquinta
Don Waddoups

Steve Guinta

James Rodgers

Don Chase

Dale Harkleroad

James Zachary

Les Kovacs

Anthony Ruscito

Terry Tomasko

Steve Bransfield

David R. Ringland

Joseph Gardiner

Ira Poppel

Laura Wolfson

Nick Lamberti

Wolf Shindler

Leo Lawrence

Holly Wallace

Victoria Keston

John Kirtland

Forrest Hatch

Don Waddoups
Analog Devices

Analogics Corp.

Analogics Corp.

Bailey Controls

Bailey Controls

Devar Inc.

Devar Inc.

Devar Inc.

B.Dietz Associates (Transmation Inc.)

Electro-Mechanics (CE)

Foxboro Co.

Foxboro Co.

Foxboro Co.

General Electric

General Electric

General Electric

General Electric

General Electric

General Electric

General Electric

General Electric

General Electric

Gould, Inc.

Halliburton NUS (formerly Energy Inc.) 
Jay Monroe

Steve Vogel

Art Nolan

Ezra Gershon

John Nielsen

Thomas Roach

Steve Montgomery

Art Pini

Dennis Durand

Alex Sokolek

Dennis Ruppert

Michael Romagnolo

Raymond Cardella

Jill Graziano

William Harrold

Sergio Guerrero

Edward McConnell

Joseph Sheriff

William Tracey

Christopher Waters

Stacey Butler

James Botcher

James Avery

Daniel Drogo

Greg Bragdon

Carol Bailey

Anthony Franklin

Cynthia Bauer

Eugene Parberry

Rodger Swire

Joseph Kanzenberg

George Chambers

Robert Egan

William Crow

Douglas Fowble

Marjorie Van Ness

Jack Semon

Charles Griesacher

William Howell

William Miller

James Doyle

Wayne Steibel

Kevin Manchetti

Patrick Callahan
Industrial Test Equipment Co., Inc.

Industrial Test Equipment Co., Inc.

INEL

Integrated Technologies Solutions, Inc.

Isotec Co.

Keithley Instruments

LeCroy Corp.

LeCroy Corp.

LIICO

LIICO

LII Co

LILCO

LIICO

LIICO

National Instruments

National Instruments

National Instruments

Newark Electronics

Opto-22

Pearson Electronics, Inc.

Pearson Electronics, Inc.

Rochester Instruments

Rochester Instruments

Rochester Instruments

Sipex Corp. (formerly Hybrid Systems Corp.)

Technology for Energy Corp.

Technology for Energy Corp.

Transmation Inc.

Validyne Engineering Corp.

Validyne Engineering Corp.

WESCO

Westinghouse Electric Corp.

Westinghouse Electric Corp.

Westinghouse Electric Corp.

Westinghouse Electric Corp.

Westinghouse Electric Corp.

Westinghouse Electric Corp.

Westinghouse Electric Corp.

Westinghouse Electric Corp.

Westinghouse Electric Corp.

Westinghouse Electric Corp.

Westinghouse Electric Corp.

Westinghouse Electric Corp.

Westinghouse Electric Corp. 
We thank Ms. Helen Todosow and the staff of Energy and Technology Information Resources at Brookhaven National Laboratory for their efforts and assistance in support of this work.

We also wish to thank Ms. Patty Ennis for her help in the preparation of this manuscript. 


\section{INTRODUCTION}

The "Adequacy of Electrical Isolation Device Acceptance Criteria" Program was funded by the U.S. Nuclear Regulatory Commission through FIN L-2158. The purpose of this program was to develop and implement an electrical isolation device major fault testing program that explores the effects of fault voltage and current levels of lesser magnitude thar used in previous maximum credible potential testing. The results of this testing program, together with previous major fault testing, will determine whether a revision to the current NRC acceptance criteria is required.

Electrical isolation devices are used to maintain electrical separation between safety (Class 1E) and non-safety related circuits and systems in nuclear power plants. Isolation devices are required wherever signals from nuclear safety protection systems are transmitted to non-safety related controls or display systems. Their purpose is to ensure that any credible fault or transient occurring on the non-Class 1E side will not degrade the circuits connected to the device Class 1E or associated side below an acceptable level (Ref.1).

The criteria for qualification of electrical isolation devices to be used in nuclear power plants are sandated by the U.S. Code of Federal Regulations 10 CFR 50, Section 50.55a, paragraph (h) for protection systems (Ref. 2), which states:

"For construction permits issued after January 1, 1971, protection systems shall mest the requirements set forth in editions or revisions of the Institute of Electrical and Electronics Engineers Standard: "Criteria for Protection Systems for Nuclear Generating Stations," (IEEE-279) in effect on the formal docket date of the application for a construction permit. Protection systems may meet the requirements set forth in subsequent editions or revisions of IEEE-279 which become effective."

Section 4.7.2 of IEEE Standard 279. 1971 (Ref. 3) entitled Isolation Devices states:

The transmission of signals from protection system equipment for control system use shall be through isolation devices which shall be classified as part of the protection system and shall meet all the requirements of this document. No credible failure at the output of an isolation device shall prevent the associated protection system from meeting the minimum performance requirements specified in the design bases.

"Examples of credible failures include short circuits, open circuits, grounds, and application of the maximum credible ac or de potential. A failure in an isolation device is evaluated in the same manner as a failure of other equipment in the protection system."

Issues related to the adequacy of isolation devices acceptance criteria and performance of isolators in nuclear plants have been studied by the U.S. Nuclear Regulatory Commission for over a decade. Earlier major fault testing performed as part of the NRC's Isolation Devices Evaluation Criteria Program, and reported by Neilsen in NUREG/CR-3453 (Ref. 4), indicated that electronic isolation devices may experience severe damage and may pass some energy across the isolation barrier when subjected to faults at the maximum credible AC or DC voltage and current levels applied to the output side of the energized device. During subsequent field qualification testing, concems were raised that similar or more severe problems might be realized at fault voltages 
and currents less than maximum credible levels (Ref. 5). Specifically, the worst case fault condition may not occur as the result of a fault at the maximum credible potential, but rather at some lower potential. The actual "reach-through" energy, passed across the isolation device during a fault condition, expressed by $\int V(t)^{*} I(t) d t$, even while not attaining maximum credible voltage potentials, might still be large enough to inflict damage on sensitive electronic components. The maximum credible fault (MCF) for a given isolation device and application may thus be defined as that fault potential and waveform at which the maximum reach-through energy is passed across the isolation barrier.

The objective of this testing program is to determine whether the worst case fault, in regard to the reach-through energy, occurs when a high speed fault is applied to an isolator's output terminals at the maximum credible potential of $120 \mathrm{Vac}, 60 \mathrm{~Hz}$, or rather at some lower potential. Isolation barrier characteristics such as resistance and capacitance, and isolator function are monitored during the testing for significant changes or trends. Resources were not available to expand the testing to explore the effects of higher fault potentials, inter-channel reach-through energy (multiple channel isolators), sustained applied faults, nor a range of fault frequencies.

A review of the applicable standards, regulatory guides, previous testing work, and nuclear industry operating experience with isolation devices was performed to identify the problem areas and develop a testing program to address the concerns associated with major fault qualification testing. A group of isolators representative of the types and models found in nuclear plants was purchased and tested in accordance with the detailed test procedures developed.

The test report is organized into five major sections plus a references section and appendices. Section 1 is an introduction describing the purpose and objectives for the testing program, some of the regulatory background concerning isolation devices, and an outline of the report organization. Section 2 provides a brief description of the major types of electronic isolation devices, their basic operating principles, their application in nuclear plants, and the background of the concerns in the area of maximum credible fault testing. The details of the major fault testing program are presented in Section 3. The discussion includes the test objectives, relation to previous isolation device testing, test procedures, test equipment, and conduct of the test. The results of the testing are presented in Section 4 along with an analysis of the data. Recommendations and conclusions based upon the findings of the testing program are given in the 5th Section. A glossary of terms and phrases that are used throughout this report is provided at the end of the report. Appendix A is the test plan for the work, Appendix B contains the details of the test setup, Appendix C contains copies of the test equipment certifications for the measuring equipment used in the test program and Appendix D presents the test data in graphical form. 


\section{ELECTRONIC ISOLATION DEVICES}

This section provides a brief description of the major types of electronic isolation devices used in nuclear power plants to provide signal isolation between Class 1E sensors, instrumentation and controls and non-Class 1E instrumentation, controls, and displays. The basic operation of each type is described. Some of the applications in which electronic isolators are utilized in nuclear plants is covered along with some of the major problem areas that have been encountered as revealed in the operating experience records. The origins of the concerns about maximum credible fault tests and faults at less than maximum credible potential are covered.

\subsection{Descriptions of Electronic Isolators}

There are two basic methods of electronic signal isolation commonly found in the isolation devices used in nuclear power plants: magnetically-coupled isolation and optically-coupled isolation. In the first method, input signals into the device are conditioned and modulated, passed through a transformer that serves as the isolating barrier, and then demodulated, filtered, and conditioned before being sent out of the device. In the latter method, the input signal is conditioned or converted to a digital signal, which in turn is converted to an optical signal. This optical signal is passed across an optical isolation barrier to an optical receiver, where it is conditioned for output from the device."

The basic components of a typical magnetically-coupled (transformer-coupled) electronic isolator are shown in Figure 2.1. The isolator may be either an analog device or a digital device depending upon the nature of the input and output signals which it is designed to handle.
The analog isolation device will be used in applications where the input signal is either an analog voltage signal or an analog current signal as would be found in an instrumentation loop. Digital isolation devices are used to isolate computer systems that are communicating via digital signals, or to accept and isolate the signals supplied from digital sensors. Typical voltage or current input and output ranges for analog and digital isolators encountered during research for this test program are listed in Table 2.1.

Upon entering the input terminals of an analog isolation device, the analog input signal will be conditioned, filtered, and amplified. The signal is then modulated and passed through a transformer which serves as the electrical isolation barrier, the signal being transferred via magnetic-coupling. The output signal is demodulated, filtered, and conditioned for output from the isolation device.

The power supplied to the isolation device to drive the active electronic subcomponents is usually a non-Class $1 E$ source. It is therefore isolated from the input signal by an isolating transformer as well, as shown in Figure 2.1. Some of the typical power supply voltages levels found during this research are listed in Table 2.1.

The basic components of an opticallycoupled electronic isolator are shown in Figure 2.2. The optical isolator is normally a digital signal device in which the electrical isolation is achieved by the conversion of the electrical signal into an optical signal that is transmitted through an optical dielectric medium. This optical link serves as the isolating barrier in this type of device. It may consist of: a phototransmitter and optical receiver back-to-back on a single optoisolator integrated circuit; a phototransmitter and 


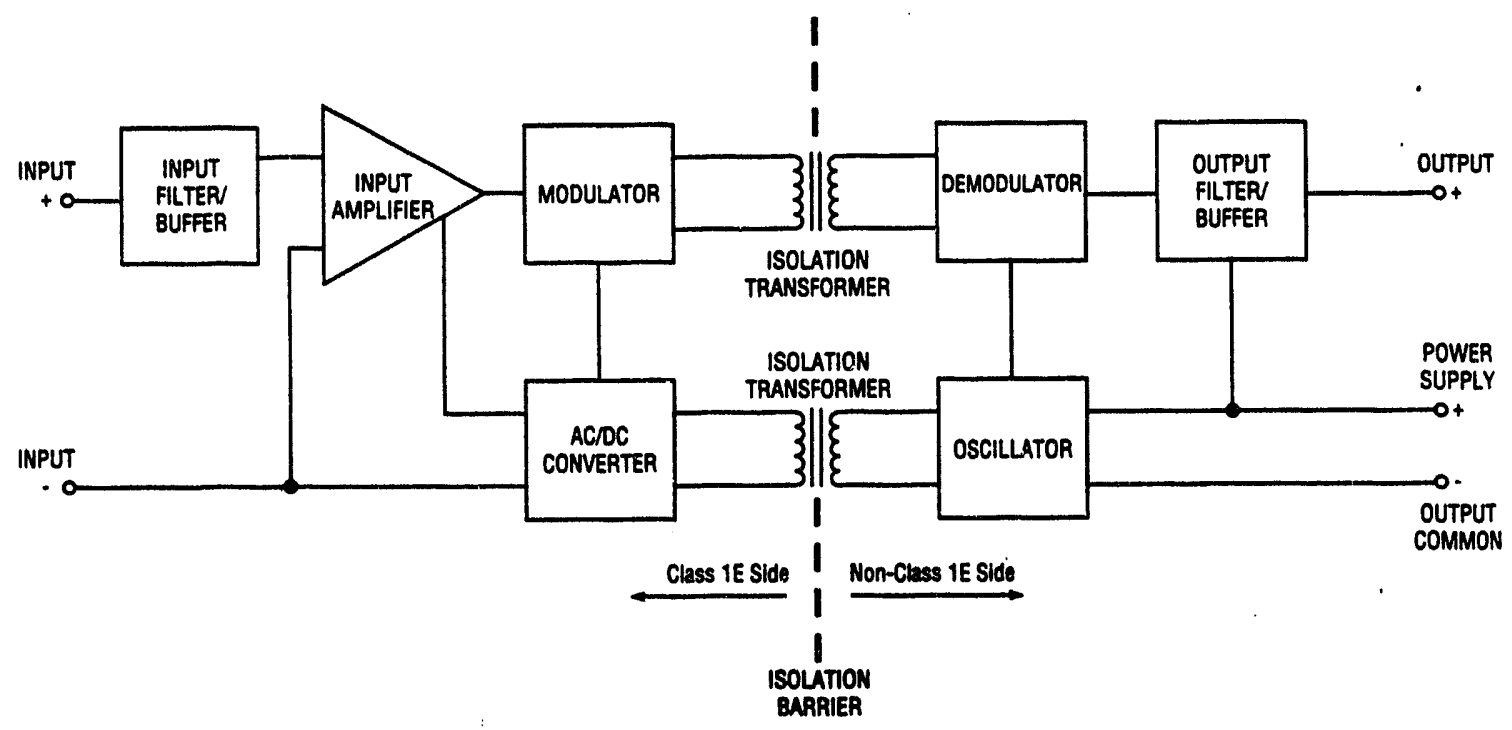

Figure 2.1 Block diagram of transformer-coupled isolator

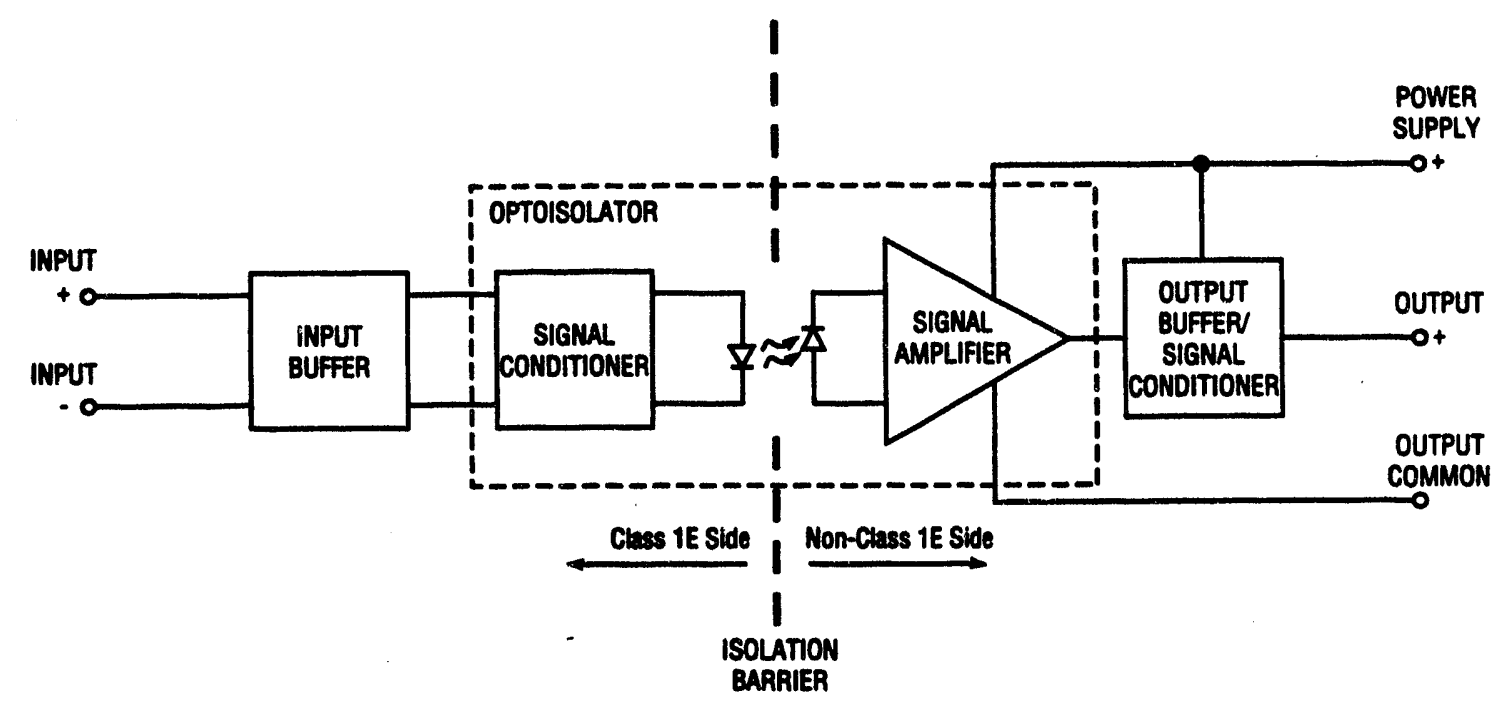

Figure 2.2 Block diagram of optically-coupled isolator 
Table 2.1 Typical Isolation Device Power Source and Signal Input and Output Ranges

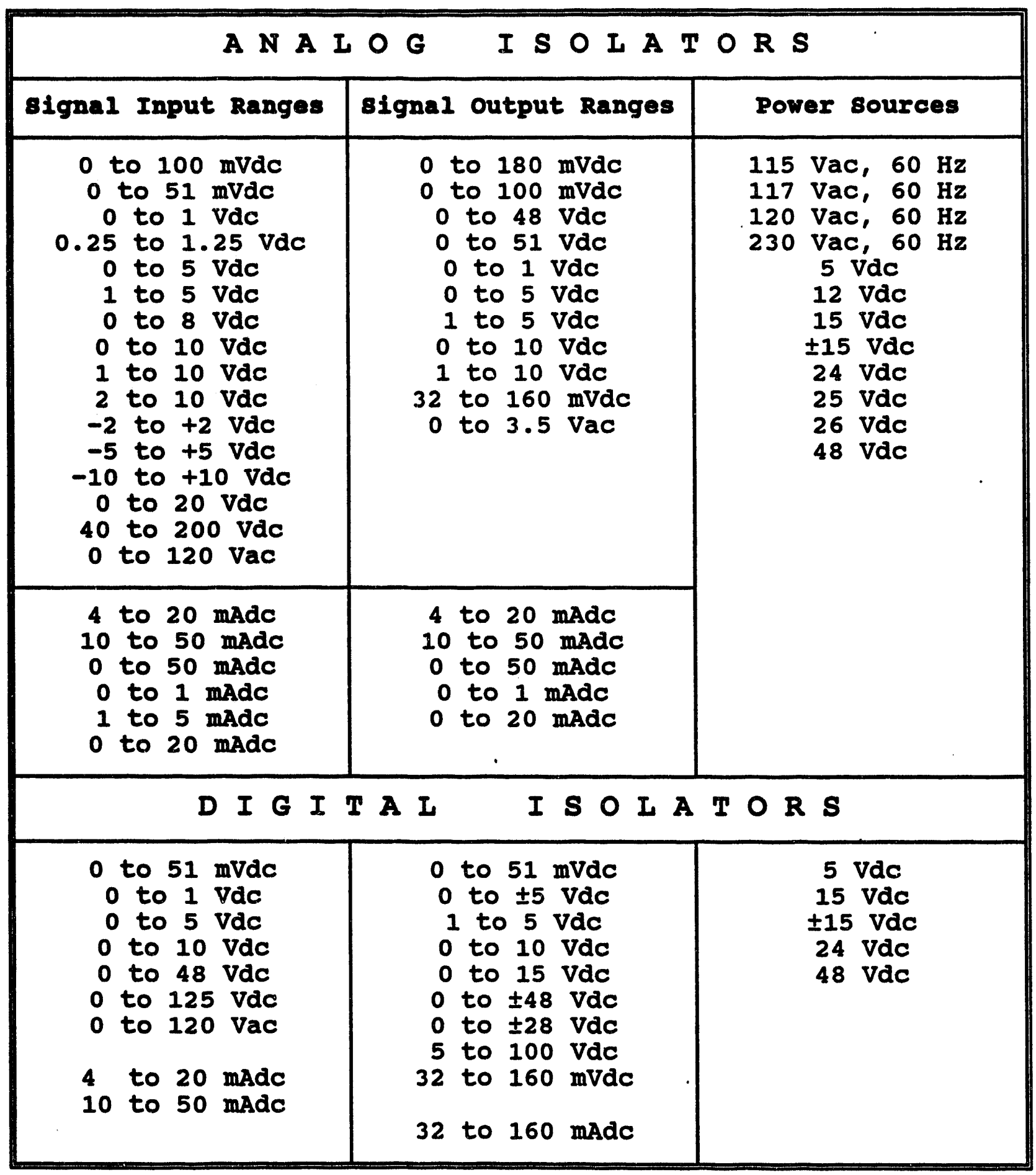


receiver connected by a short, optically conducting, quartz rod or some other type of fiber optic link on the same circuit board; or a fiber optic link ranging anywhere from a fraction of an inch to hundreds of feet.

The digital input signals to an optically coupled isolator are first buffered and conditioned upon entering the device, shown in Figure 2.2. If the input signal is analog. then it is converted to an equivalent electrical digital signal. The digital signals are converted to optical digital pulses for transmission through the optical coupler. As mentioned previously, the optical link may be a phototransmitter and receiver back-to-back, or separated by some distance, and in communication through an optical transmission medium. On the output side, the optical digital pulses are converted back to electrical digital signals, amplified, and conditioned prior to being sent out of the isolator. If the output is to be an analog signal, circuitry is provided on the output side of the optical coupling to convert the digital signals back to analog as required.

\subsection{Backenond of the Marimum Credible Eanlt Concerns}

Electronic isolation devices are used in nuclear power plants to maintain electrical separation between safety related and nonsafety related systems. They provide electrical isolation of Class $1 \mathrm{E}$ electrical circuits and instrumentation from non-Class $1 E$ circuits and equipment.

Isolators are used most extensively in Westinghouse and Combustion Engineering PWR's due to the design philosophy and the nature of the instrumentation and controls designs for the safety systems in these plants (Ref.5). Electronic process control systems are used extensively in the designs of these plants. Among the systems in PWR plants that utilize isolation devices are:
- $\quad$ Reactor Protection (RPS)

- Engineered Safety Features Actuation (ESFAS)

- Reactor Coolant (RCS)

- Main Steam

- Main Feedwater

- Chemical and Volume Control (CVCS)

- Residual Heat Removal/Low Pressure Safety Injection

- Auxiliary (Emergency) Feedwater (AFW)

Electronic isolators are also used in BWR designs, but to a more limited extent than in PWRs. In the BWR, the design approach applied to the control, logic, and instrumentation circuits for the reactor protection system, emergency core cooling system actuation, containment isolation system, and other safety systems relies more heavily on electromechanical relays with redundant hard wired circuits. The electromechanical relay itself then serves as a type of isolation device. Among the systems in BWR plants that sometimes utilize electronic isolation devices are:

\section{- Reactor Protection (RPS) \\ - Reactor Recirculation \\ - Reactor Core Isolation Cooling (RCIC) \\ - Residual Heat Removal/Low Pressure Coolant Injection (LPCI) \\ - Feedwater \\ - Control Rod Drive (CRD) \\ - Nuclear Steam Supply Shutoff (NSSS)}

Following the accident at Three Mile Island Unit 2, the NRC developed the TMI Action Plan NUREG-0660 (Ref. 6) and clarification NUREG-0737 (Ref. 7). Among its requirements, the TMI Action Plan included the implementation of a Safety Parameter Display System (SPDS) Console. To comply, each nuclear plant applicant and licensee was required to install an SPDS that could display to operating personnel in the 
control room, and to personnel in the Technical Support Center (TSC) and Emergency Operations Facility (EOF), a minimum set of parameters that define the safety status of the plant. Implementation in nuclear plants of the non-Class IE SPDS in most designs necessitated the use of a number of electronic isolators to allow tapping into Class 1E instrumentation and controls loops in order to drive SPDS displays without compromising the integrity of the plant safety systems. This requirement significantly increased the number of electronic isolators found in all nuclear power plants.

During the testing and review of electronic isolation devices for use in SPDS systems, NRC raised concems that isolation devices, when subjected to.fault voltages or currents less than the maximum credible fault levels, may pass potentially significant levels of energy, but the same devices performed acceptably at the maximum credible fault level (Refs. 5,8,9).

As a result of the aforementioned observations made during SPDS evaluation tests, the problem was formally identified as Generic Safety Issue 142, Leakage Through Electrical Isolators in Instrumentation Circuits, in June 1987 (Ref. 10):

"Recent observations have shown instances in which isolation devices subjected to failure voltages and/or currents less than maximum credible fault levels passed significant levels of voltage and current, but the same devices performed acceptably at maximum credible levels. The safety system on the Class 1E side of the isolation device may be affected by the passage of small luvels of electrical energy, depending upon the design and function of the safety system."
"In the event that safety systems are affected by less than maximum credible faults on the ron-Class $1 \mathrm{E}$ side of isolators, the effects can range from degradation to failure of single or multiple trains of safety systems resulting in failure on demand or inadvertent operation. In one reported incident, a voltage transient induced by a power line fault caused a false indication that the turbinegenerator output breaker had tripped, resulting in a reactor scram."

The present testing program was initiated to investigate the hypothesis that energy may leak across, or reach through, the isolation barrier in an electronic isolation device at fault levels less than the maximum credible fault. By measuring and quantifying the extent of the leakage problem, an assessment can then be made of the potential damage that could occur to various types of electronic and electrical devices that are used on the Class $1 \mathrm{E}$ side of isolation devices.

\subsection{Electronic Isolation Devices Tested}

NPRDS searches and sorts of reported failures that involved isolation devices were used to develop lists of isolation device model numbers that were considered as candidates for this testing program. This search provided information on the relative populations of the various isolators, and the types and model numbers that were in service in nuclear power plants. In addition, the isolators that were tested previously under NUREG/CR-3453 (Ref. 4), were given strong consideration, particularly those that were found to pass energy across the isolation barrier during the testing reported by Neilsen. Information obtained during discussions with manufacturers of electronic isolators and with nuclear plant personnel also contributed to the selection process. 
Based upon the data and information gathered, a representative group of twelve isolators was established for testing. The final selection of isolators was based upon frequency of appearance in NPRDS reports, models specified by NRC, procurement availability, technical information availability, budget constraints, and schedule constraints.

One or more models of isolators manufactured by the following vendors were subjected to testing in this program. The models tested are identical to units used in nuclear power plants, and they present a representative sample of the major types of isolators. After BNL had completed its testing, Devar indicated that a nuclear service version of their isolators was available that included zener diodes and a fuse at the output to limit fault damage. This version of the Devar isolator was not tested by BNL. The Validyne isolators and their supporting equipment were obtained from a nuclear power plant where they had seen eight years of service as part of the isolation system interfacing with the plant's emergency response facilities. All the other equipment was purchased new;

\section{Devar}

Halliburton NUS

Foxboro

Rochester Instruments

Technology for Energy

Transmation

Validyne

Westinghouse Electric Corp.

The basic operating specifications for the isolation devices tested under this program are given in Table 2.2. The group tested included both magnetically and optically coupled isolators, and both analog and digital types. As indicated in the table, five units were multiple-channel devices.

\subsubsection{Magnetically Coupled Isolators}

The magnetically coupledisolators that were tested included three current-to-current analog isolators, five voltage-to-voltage analog isolators, and one digital isolator: These units are described briefly in this section.

Two of the current-to-current analog isolators tested, one manufactured by Transmation, Inc and the other by Halliburton NUS Corp. are shown in Figure 2.3 (with and without the protective barrier covering the terminations). Both units are completely enclosed in metal cases with mounting provisions to allow installation in control panels throughout a plant.

Internally, the Transmation isolation transmitter consists of three individual circuit boards: the power supply board, the transmitter/signal conditioner board and the isolator board, each handling a major subfunction of the device. The Transmation isolators tested in this program were currentto-current units, which are identical to the voltage-to-voltage versions of the device also available, with the exception of factory installed resistors at the device input to adjust the voltage levels (Ref. 11, 12).

The Halliburton NUS isolation amplifier tested was a four-channel, encapsulated. surface-mount isolation device taking 4-20ma analog input signals and providing a 4-20ma output signal. This isolator is available in voltage-to-voltage configurations at a variety of input and output levels, and single, dual, or three channel versions are also available using the same operating principle. The major components are a I/O signal conditioning circuit board and a power supply circuit board, that are embedded in a potting matrix for seismic protection. The individual channel outputs and the power supply are protected by fuses accessible from the face of the unit as shown in Figure 2.4, and surge protection is provided on the power input and the signal inputs and outputs (Ref. 13). 
Table 2.2 Electronic Isolators Tected

\begin{tabular}{|c|c|c|c|c|c|c|c|c|c|c|c|}
\hline $\begin{array}{l}\text { Isolator } \\
10 \text { No. }\end{array}$ & Type of Isolation & $\begin{array}{c}\text { Physical } \\
\text { Configuration }\end{array}$ & $\begin{array}{l}\text { No. of } \\
\text { Channels } \\
=\sin =x==\end{array}$ & $\begin{array}{l}\text { Signal } \\
\text { Type } \\
\text { zxamex= }\end{array}$ & $\begin{array}{l}\text { Signal } \\
\text { Input } \\
\text { extex=mex }\end{array}$ & $\begin{array}{l}\text { Renge } \\
\text { Output } \\
\text { =xx=man=s }\end{array}$ & $\begin{array}{l}\text { Power } \\
\text { Supply }\end{array}$ & $\begin{array}{l}\text { Used } \\
\text { Bur } \\
=2=\end{array}$ & & $\begin{array}{l}\text { Freq of } \\
\text { Occurrence } \\
\text { in wpros } \\
\text { Reports }\end{array}$ & $\begin{array}{c}\text { Tested in } \\
\text { meres/CR- } \\
3453 \\
==-2\end{array}$ \\
\hline $\begin{array}{l}\text { con-3-1 } \\
F A-3-1 A / B \\
m a-3-2 \\
=\operatorname{man}-3-1 A / D \\
V D-3-1 \\
m a-3-1\end{array}$ & $\begin{array}{l}\text { Magnetic Coupl ing } \\
\text { Magnetic Coupl ing } \\
\text { Magnetic Coupl ing } \\
\text { Magnetic Coupl ing } \\
\text { Magnetic Coupl ing } \\
\text { Magnetic Coupl ing }\end{array}$ & $\begin{array}{l}\text { Enclsd Metal Case } \\
\text { Circuit Card } \\
\text { Enclsd Metal case } \\
\text { Circuit Card } \\
\text { Potted, Metal case } \\
\text { Circuit Card }\end{array}$ & $\begin{array}{l}\text { one } \\
\text { Two } \\
\text { one } \\
\text { four } \\
\text { one } \\
\text { one }\end{array}$ & $\begin{array}{l}\text { Analog } \\
\text { Analog } \\
\text { Analog } \\
\text { Analog } \\
\text { Digital } \\
\text { Analog }\end{array}$ & $\begin{array}{l}1-5 \text { vde } \\
1-10 \text { vde } \\
1-5 \text { vde } \\
0-5 \text { vde } \\
0-5 \text { vde } \\
0-10 \text { vde }\end{array}$ & $\begin{array}{l}1-5 \text { vde } \\
1-10 \text { vde } \\
1-5 \text { vde } \\
0-5 \text { vde } \\
0-2 \text { avde } \\
0-10 \text { vde }\end{array}$ & $\begin{array}{l}\text { 120vac, 6OHz } \\
+/-15 \mathrm{vdc} \\
115 \mathrm{vac}, 60 \mathrm{~Hz}, 5 \mathrm{H} \\
+/-15 \mathrm{vdc} \\
5 \mathrm{vac}, 3 \mathrm{KHz} \\
26 \mathrm{vdc}\end{array}$ & $\begin{array}{l}x \\
x \\
x \\
x \\
x\end{array}$ & $\begin{array}{l}x \\
x \\
x \\
x\end{array}$ & $\begin{array}{l}\text { L } \\
\text { H } \\
L \\
\text { Mone } \\
\text { Mone } \\
\text { H }\end{array}$ & $\begin{array}{l}x \\
x \\
x \\
x \\
x\end{array}$ \\
\hline $\begin{array}{l}\operatorname{coma-2-3} \\
+\operatorname{tana-2}-1 A N D \\
\operatorname{TRA}-2-2\end{array}$ & $\begin{array}{l}\text { Magnetic Coupl ing } \\
\text { Magnetic Coupl ing } \\
\text { Magnetic Coupl ing }\end{array}$ & $\begin{array}{l}\text { Enclsd Metal Case } \\
\text { Potted, Metal Case } \\
\text { Enclsd Metal Case }\end{array}$ & $\begin{array}{l}\text { one } \\
\text { four } \\
\text { one }\end{array}$ & $\begin{array}{l}\text { Analog } \\
\text { Analog } \\
\text { Analog }\end{array}$ & $\begin{array}{l}4-20 \mathrm{ma} \\
4-20 \mathrm{ma} \\
4-20 \mathrm{ma}\end{array}$ & $\begin{array}{l}4-20 \mathrm{ma} \\
4-20 \mathrm{ma} \\
4-20 \mathrm{ma}\end{array}$ & $\begin{array}{l}120 \mathrm{vac}, 60 \mathrm{~Hz} \\
117 \mathrm{vac}, 60 \mathrm{~Hz} \\
120 \mathrm{vac}, 60 \mathrm{~Hz}, 5 \mathrm{H}\end{array}$ & $\begin{array}{l}x \\
x \\
x\end{array}$ & $\begin{array}{l}x \\
x \\
x\end{array}$ & $\begin{array}{l}\text { Lone } \\
\text { N }\end{array}$ & $8 x$ \\
\hline $\begin{array}{l}T D-4-1 \\
T D-4-3 A / D\end{array}$ & $\begin{array}{l}\text { Optical Coupling } \\
\text { optical coupl ing } \\
\text { optical coupl ing }\end{array}$ & $\begin{array}{l}\text { Circuit Card } \\
\text { Sealed, Metal case } \\
\text { Circuit Card }\end{array}$ & $\begin{array}{l}\text { Eight } \\
\text { One } \\
\text { four }\end{array}$ & $\begin{array}{l}\text { Digital } \\
\text { Digital } \\
\text { Digital }\end{array}$ & $\begin{array}{l}0-120 \text { vac } \\
1-5 \text { vde } \\
1-5 \text { vdc }\end{array}$ & $\begin{array}{l}=0-48 \mathrm{vdc} \\
1-5 \mathrm{vdc} \\
1-5 \mathrm{vdc}\end{array}$ & $\begin{array}{l}48 \mathrm{vde} \\
24 \mathrm{vde} \\
15 \mathrm{vde}\end{array}$ & $\begin{array}{l}x \\
x \\
x\end{array}$ & $\begin{array}{l}x \\
x \\
x\end{array}$ & $\begin{array}{l}\text { Mone } \\
\text { Mone } \\
\text { Mone }\end{array}$ & $\begin{array}{l}x \\
x\end{array}$ \\
\hline
\end{tabular}

a sinilar to nuclear service unit but w/o output diodes and fuse

- Passed energy during testing for MUREG/CR-3453

* Isoletor model sinilar to those used at Palo Verde

+ Four chanel version of isolator requested for testing by MRC

$z$
8
8
8
8
8
8

2. Model tested repleces earlier model tested for inneg/ch-3453 


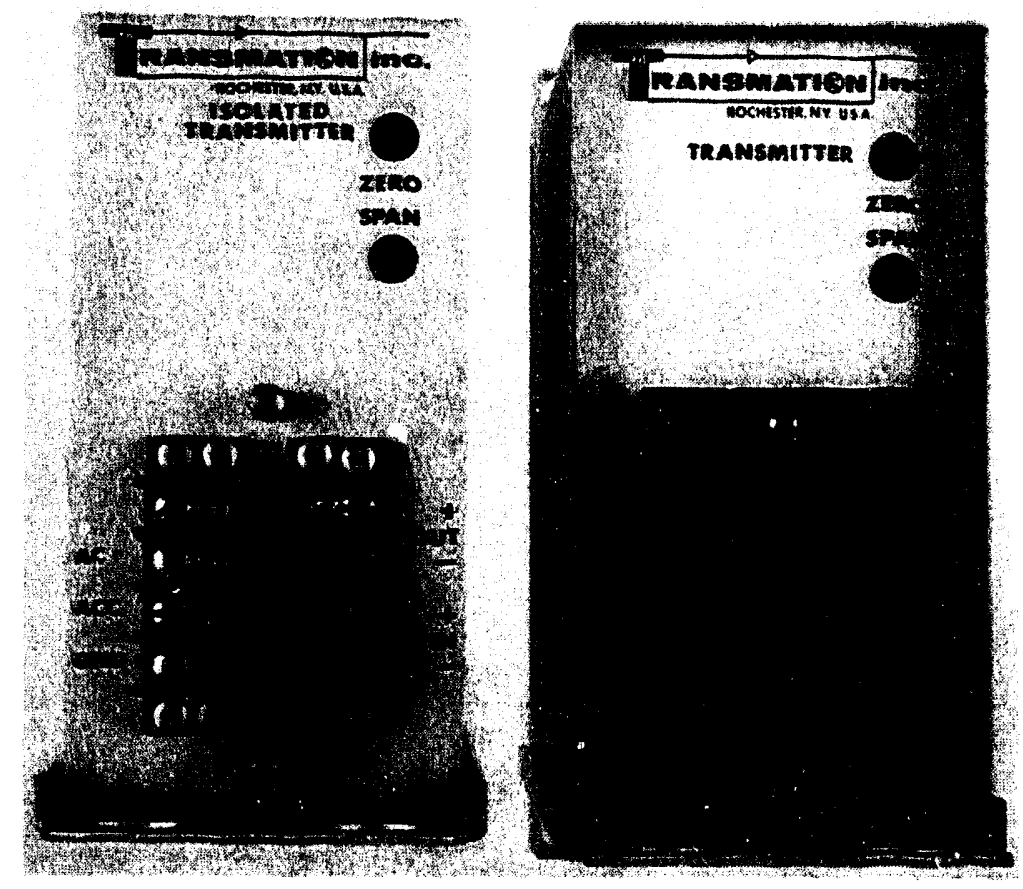

Figure 23 Transmation isolation transmitter

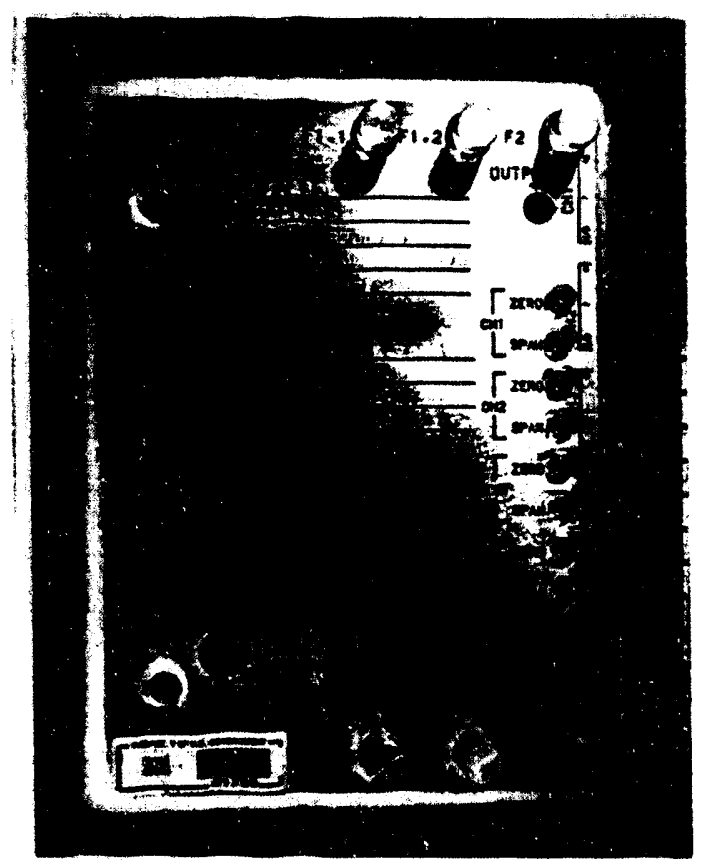

Figure 2.4 Halliburton NUS isolation amplifier 
The third current-to-current analog isolator tested, manufactured by Devar, is shown in Figure 2.5. It is discussed later in this section along with the voltage-to-voltage version of this unit.

The voltage-to-voltage, magnetically coupled isolators tested included devices from Devar, Rochester Instruments, Foxboro, Halliburton NUS, Westinghouse, and Validyne. The Devar isolated transmitter, similar to the device pictured in Figure 2.5, and the Rochester Instruments isolated transmitter, shown in Figure 2.6 are both enclosed, single channel, surface mount units similar to the Transmation isolator discussed above. Both of these units are available in current-to-current configurations with the addition of selected input and output resistors.

Externally, the voltage-to-voltage and current-to-current (Figure 2.5) Devar isolators both appear to be physically identical. However, internal inspection reveals the selected calibrating resistors and jumpers required to convert the isolator from voltage to current output. These can be seen at the back of the circuit board (Ref. 14). As mentioned in Section 2.3, Devar also offers these units in a nuclear service version, with zener diodes and a fuse at the output to limit fault damage. This version of the isolator was not tested.

Similarly, the Rochester Instruments current-to-current isolator and the voltage-tovoltage isolator (left and right, respectively, in Figure 2.6) are identical in appearance extemally. The minor differences can be seen on the circuit boards, where the voltage-tovoltage unit has modified values on some of the resistors and an additional shunt resistor at the output (Ref. 15).

The Westinghouse and Foxboro isolators are both open circuit card configured isolators with edge connectors designed for use as part of a large electronic process control system. In the case of the Westinghouse isolator, it is mounted in a card rack in the Westinghouse $\mathbf{7 3 0 0}$ Series or $\mathbf{7 1 0 0}$ Series Control Systems. Known as the Isolator and Loop Power Supply Card, or NLP Card, it provides an isolated, 0 to $10 \mathrm{Vdc}$ signal output proportional to a 0 to $10 \mathrm{Vdc}$ differential input signal. The normal primary power requirement for the card is $26 \mathrm{Vdc} \pm 1$ V (Ref. 16,17).

The Westinghouse Isolator and Loop Power Supply Card is shown in Figure 2.7. The 42-pin edge connector can be seen at the right in the figure. At the left in the figure are a red LED status indicator and various input and output signal test points as labeled. These are visible and accessible from the front of the 7300 or 7100 Series Control System equipment racks to facilitate maintenance testing and monitoring when the card is installed (Ref. 16,17).

The Foxboro dual output converter is a dual channel, rack mounted device designed for use in Foxboro's SPEC 200 control system. The standard version of this isolator converts inputs with spans from 2.5 to $10 \mathrm{Vdc}$ within the limits of 0 and $10 \mathrm{~V}$ to proportional 4 to 20 mAdc output signals. The output is transformer isolated from the input. Decreasing output for increasing input is achieved by reversing input leads. Output is normally powered from an internal isolated 24 Vdc source. The units tested were modified by the factory to function as an isolated voltage-to-voltage converter (Ref. 18,19).

The Foxboro isolators are shown in Figure 2.8 in a frontal view (right) and from the side (left) revealing the face of the circuit board. The isolator slides into the SPEC 200 nest assembly and is held by two captive screws at the top and bottom. A power bus plug for field testing the unit is seen at the bottom of the left isolator in Figure 2.8. When installed the isolator receives its power at this point from the supply bus in the nest 


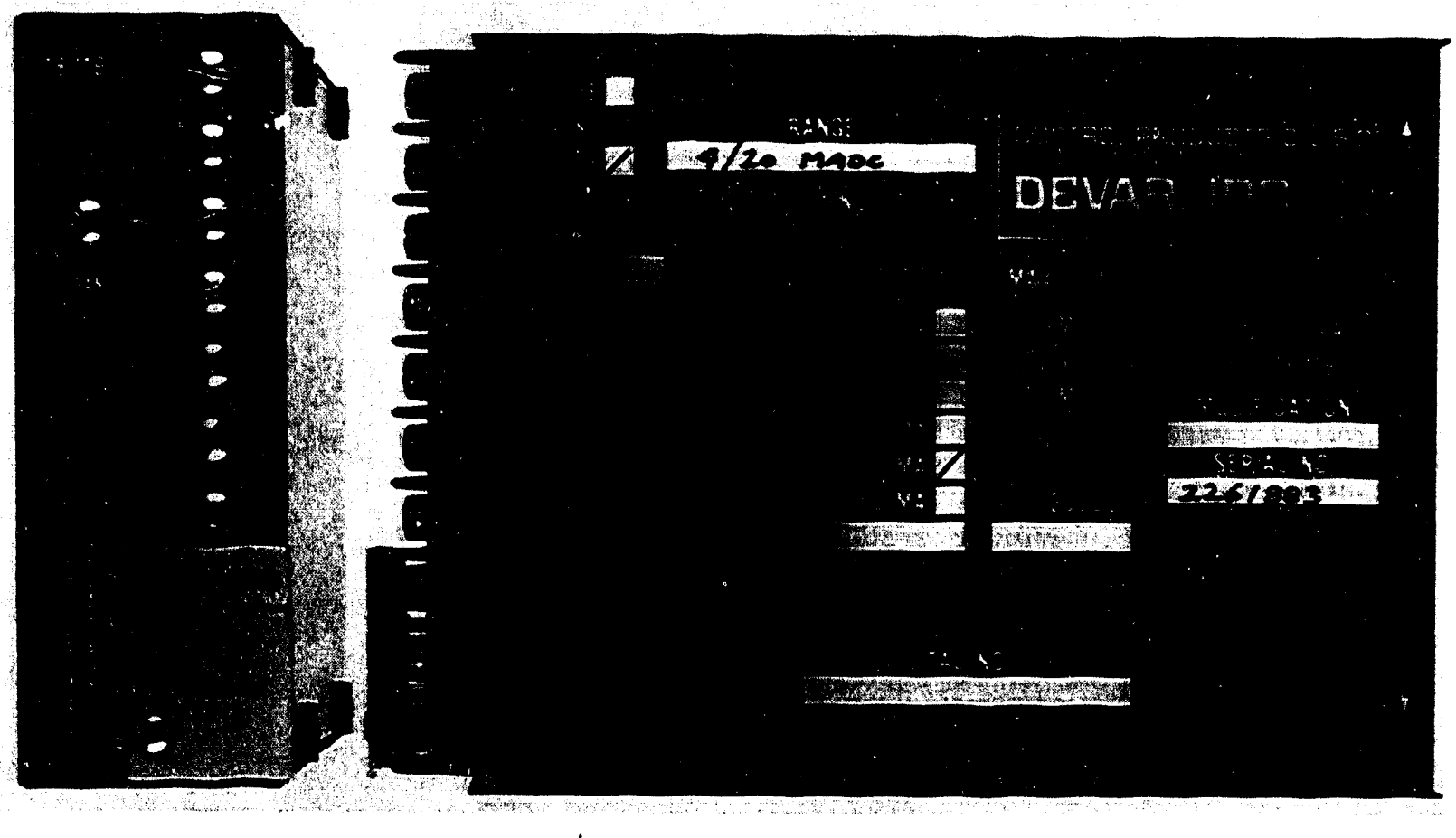

Figure 2.5 Devar isolated transmitter

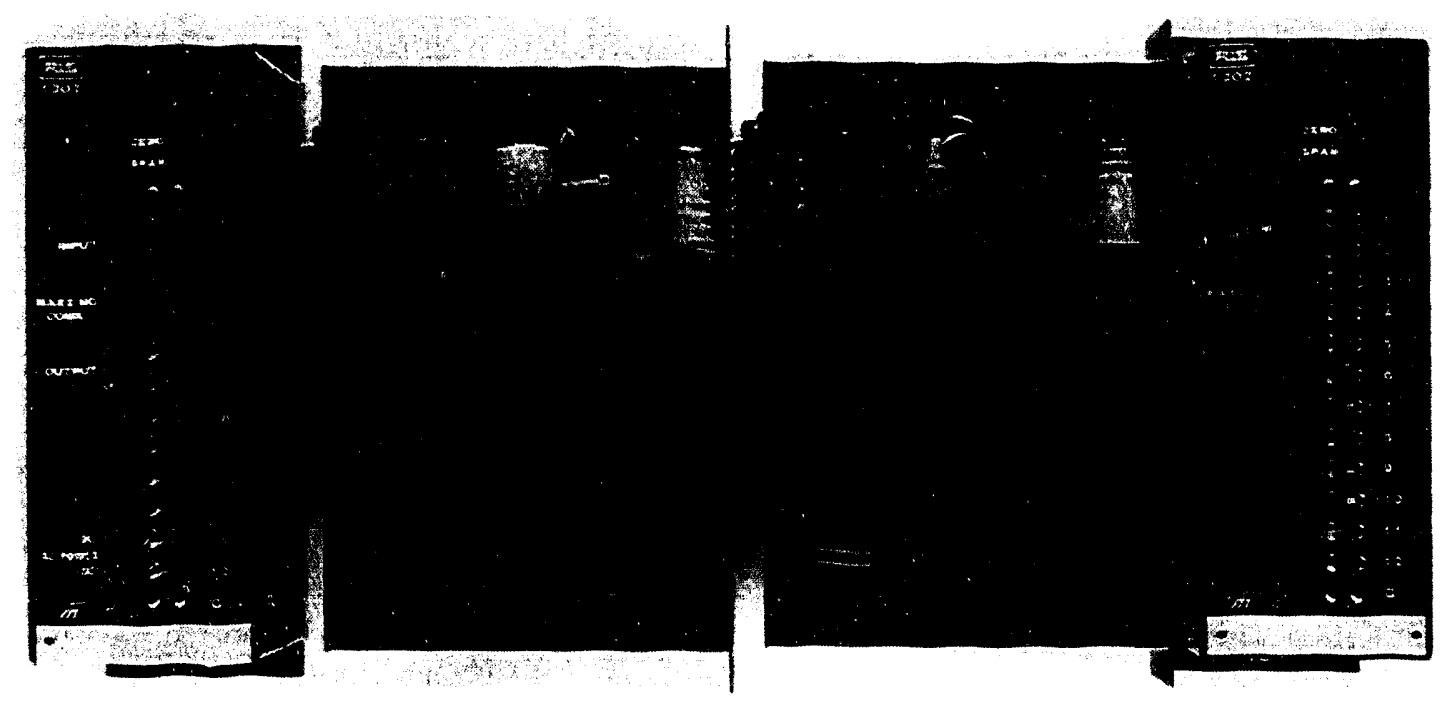

Figure 2.6 Rochester Instruments isolated transmitters-front view and cireuit board: I-to-I isolator (left) and V-to.V isolator (right) 


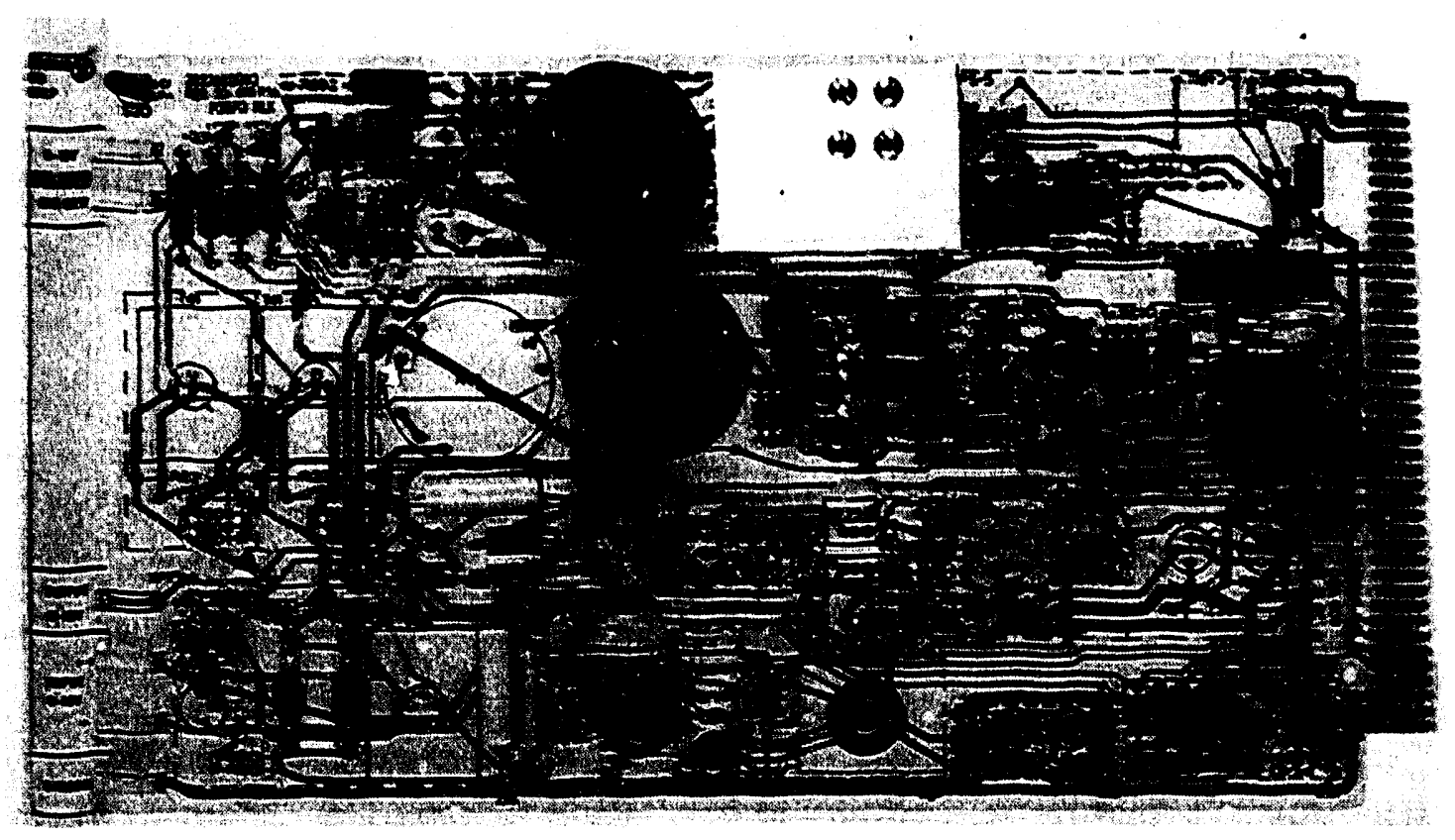

\section{Fienre 2.7 Westinghouse isolator and loop power supply (NLP) card}

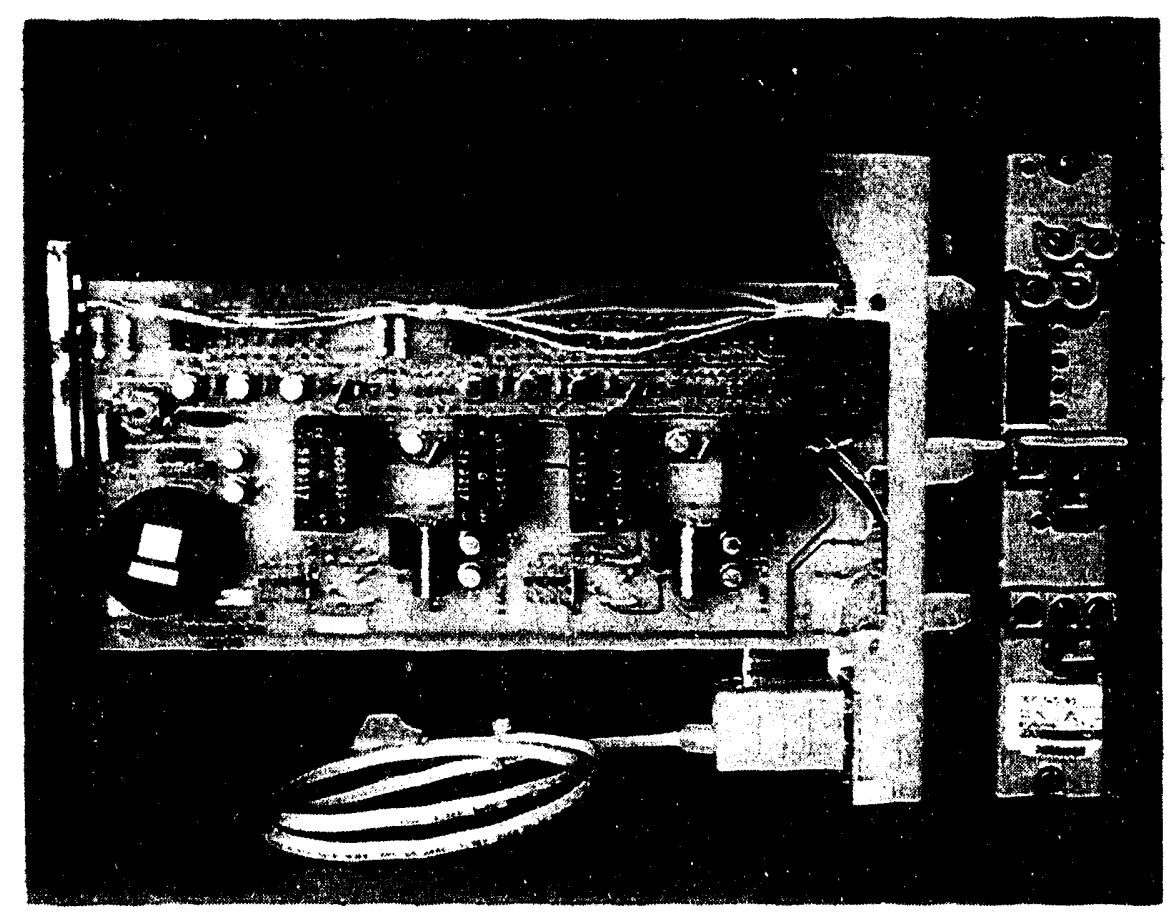

Fizure 2.8 Foxboro isolators 
assembly. The signal connections and calibration adjustments are accessible on the front plate of the device when it is installed (Ref. 19,20).

The Halliburton NUS analog isolator card, formerly built by Energy Incorporated (EI), is a four-channel analog isolation device with an open circuit card configuration, as shown in Figure 2.9. Isolation between the input and the output on the circuit board is provided by physical separation of the input and output circuits and a hybrid-circuit, transformer coupled isolation amplifier made by Burr-Brown. Input and output signals, and power sources are connected to the card through a 2x22-pin edge connector shown at the left (rtar) in the figure. Calibration adjustment pots for each channel are accessible from the front (upper right in the figure) when the isolator card is installed in an isolator circuit card rack as part of a system. In addition, output signals from each channel are brought out to test points which are accessible from the front (lower right in the figure) to facilitate calibration and maintenance testing (Ref. 21).

The Validyne Engineering Corp. isolator, or Remote Carrier Modulator, is used to convert a DC or low frequency AC input to a High-Gain Carrier Demodulator card. It is designed for remote location at the signal source and derives its operating power from the 3kHz carrier excitation supply of the Carrier Demodulator. The Remote Carrier Modulator provides isolation to protect the signal conditioning system from damage and its low output impedance allows it to be operated with long signal cables. In the configuration tested in this program, the Remote Carrier Modulator served as a voltage-to-voltage digital signal isolator (Ref. 22).

The High-Gain Carrier Demodulator Plug-In Module is used to excite, amplify, and demodulate the output of the Remote Carrier Modulator signal isolator units. The Carrier Demodulator Plug-In Module is a circuit card device located in the Remote Multiplexer Module/ Case (or Module Case). The Module Case provides plug-in capability for up to 25 signal conditioning modules plus a Power Supply Module and supplies the necessary dc operating voltages and $3 \mathrm{kHz}$ carrier for the modules and their associated transducers. The Module Case serves as the center of an isolation system with its capability to convert analog dc signals received from signal conditioning modules and directly from external sources, into serial digital data for transmission to a remote Master Receiver via a fiber optic link. It contains a built-in multiplexer that can sequentially sample up to 32 inputs for subsequent data transmission (Ref. 23,24).

The various components of the Validyne isolator and support equipment are shown set up in the BNL isolator test bed in Figure 2.10. The Module Case is the large electronic circuit card rack in the center of the photograph. The Power Supply Module is the plug-in unit at the right end of the card rack. The multiplexed circuitry and associated analog and digital electronics are enclosed in the upper part of the Module Case above the open circuit card racks. Signal connections are made at the rear of the unit via plug connectors or terminal blocks; power is provided through edge connectors to a power bus in the circuit card plug-in slots. The High-Gain Carrier Demodulator Plug-In Module undergoing fault testing is shown mounted in plug-in slot \#1 at the left end of the card rack. Test points and calibration adjustments for the Carrier Demodulator are brought out to the end plate of the plug-in module so they are accessible while the unit is installed in the Module Case. The Remote Carrier Modulator signal isolator unit under test (labeled ERF B) is seen sitting upright on top of the Module Case. 


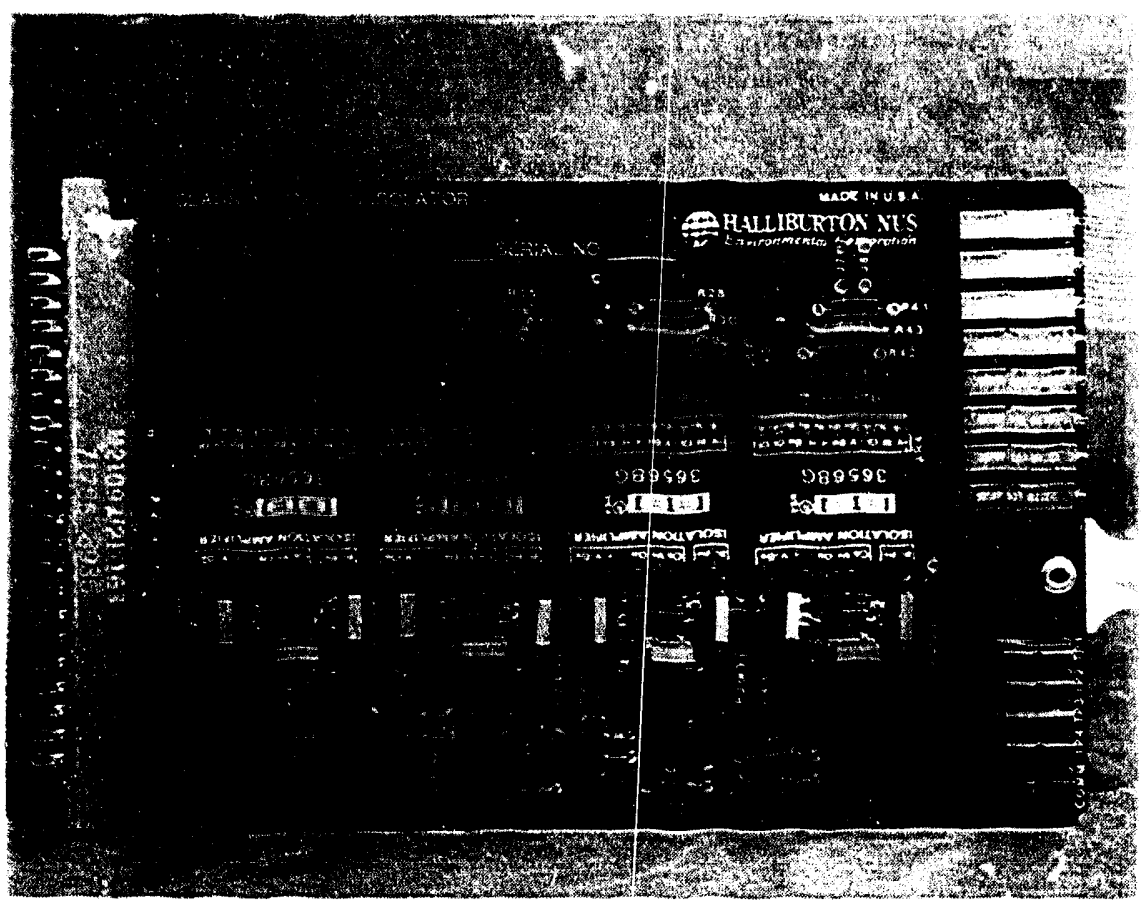

Figure 2.9 Halliburton NUS voltagato-voliage isolation amplifier

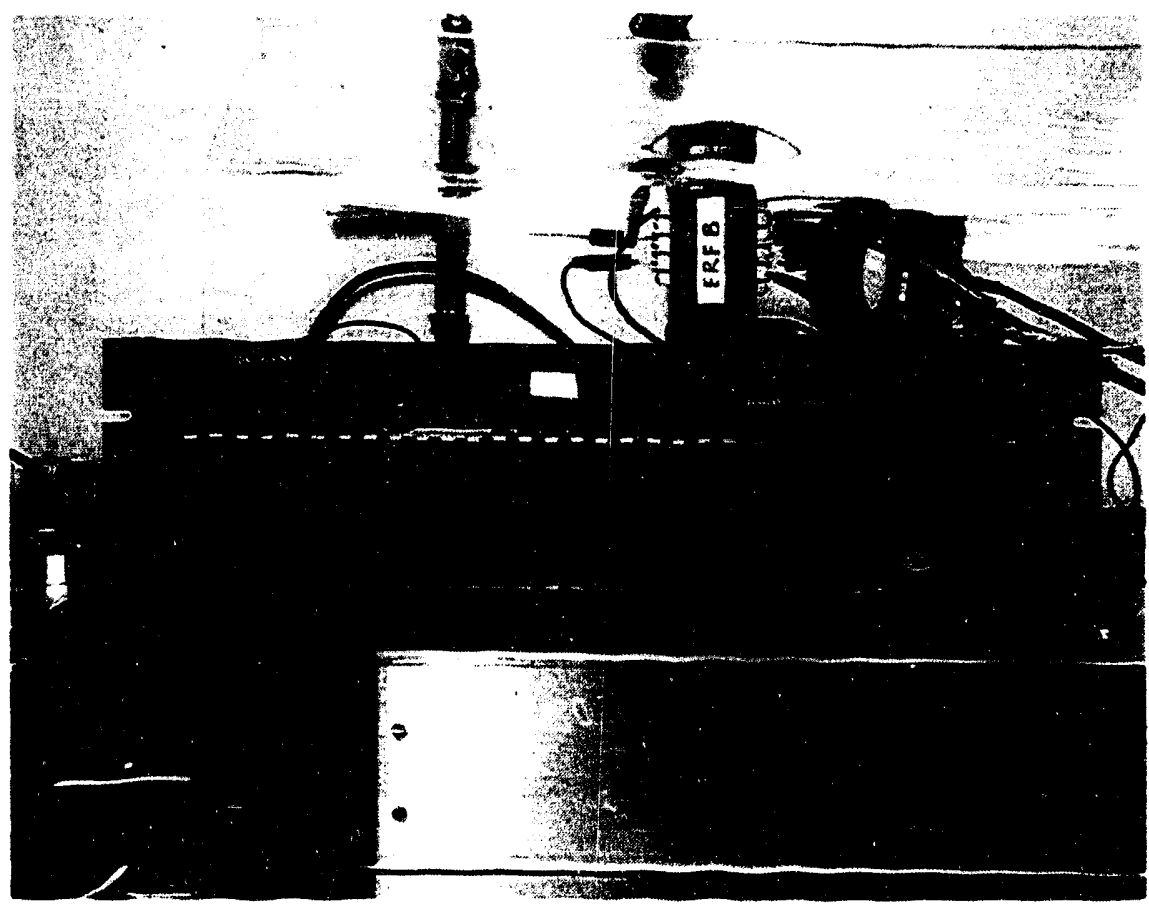

Figure 2.10 Validyne isolator and support equipment shown undergoing fault testing in the BNL isolator test bed 


\subsubsection{Optically Coupled Isolators}

The optically coupled isolators which were tested included three digital isolators: two from the Technology for Energy Corp. and one Halliburton NUS unit. These isolation devices are described briefly in this section.

The Technology for Energy isolation device tested is an encapsulated, single channel digital isolator as shown in Figure 2.11. The sealed case is flanged to allow surface mounting, and the input signal connections and the output signal and power connections are made to terminal strips on opposite sides of the unit. The digital voltage signal is coupled through an optical isolator to assure positive isolation with the unit powered or unpowered (Ref. 25).
The other two optically coupled isolators are both multiple channel digital isolation devices utilizing an open circuit card configuration. The devices, one from the Technology for Energy Corp. and the other from Halliburton NUS, are designed to be plugged into slots in electronic circuit card racks used in isolation systems manufactured by these companies.

The Technology for Energy optically coupled isolator, shown in Figure 2.12, is a four-channel digital isolation module which plugs into Technology for Energy's Isolation Module Bin. As shown in the figure, all input signal, output signal, power and test connections are made to the Isolation Module Bin via the 3x36-pin plug connector at the rear of the circuit board (right in the figure). Two optical couplers are used in each channel

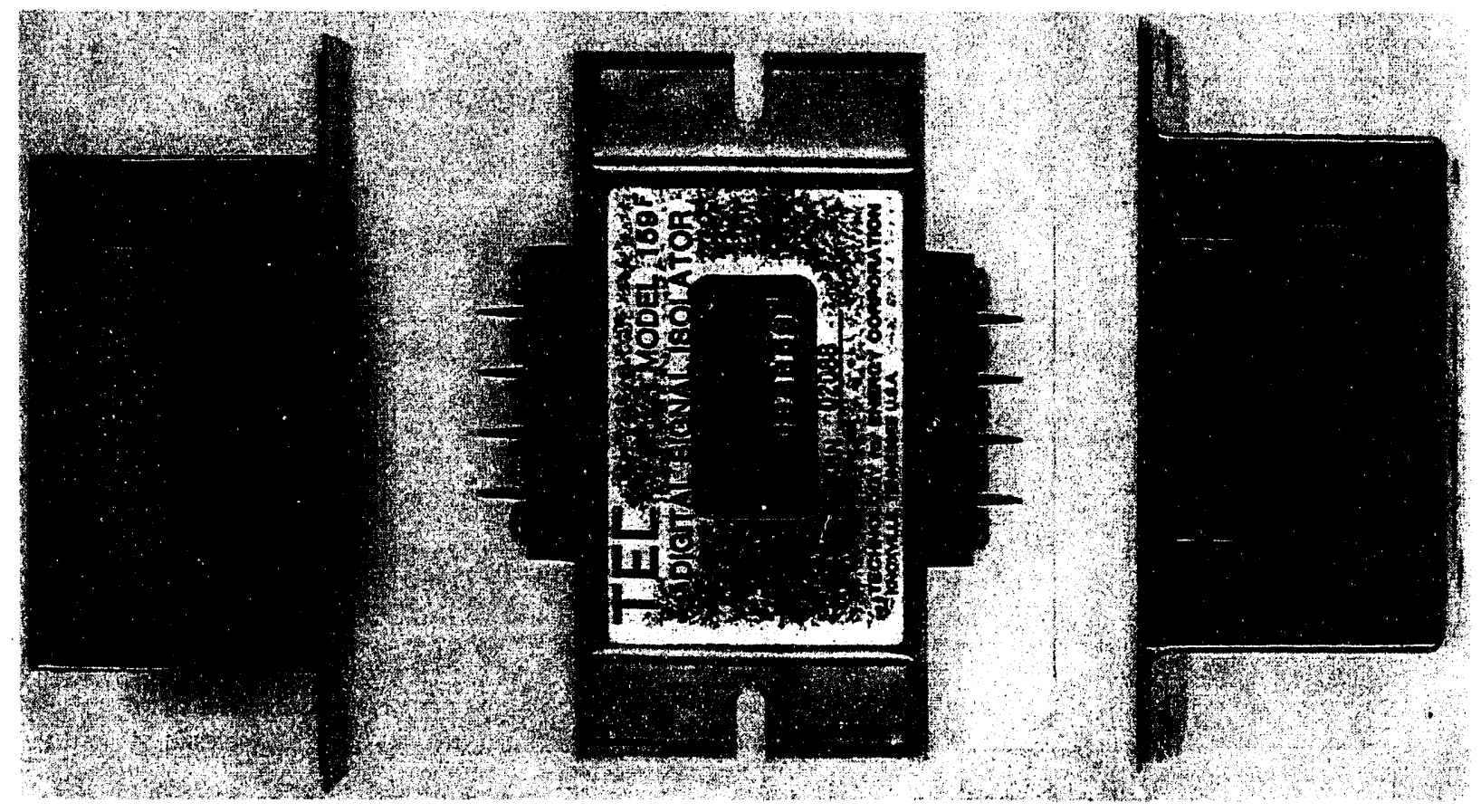

- Figure 2.11 Technology for Energy single channel encapanhted digital signal isolator 

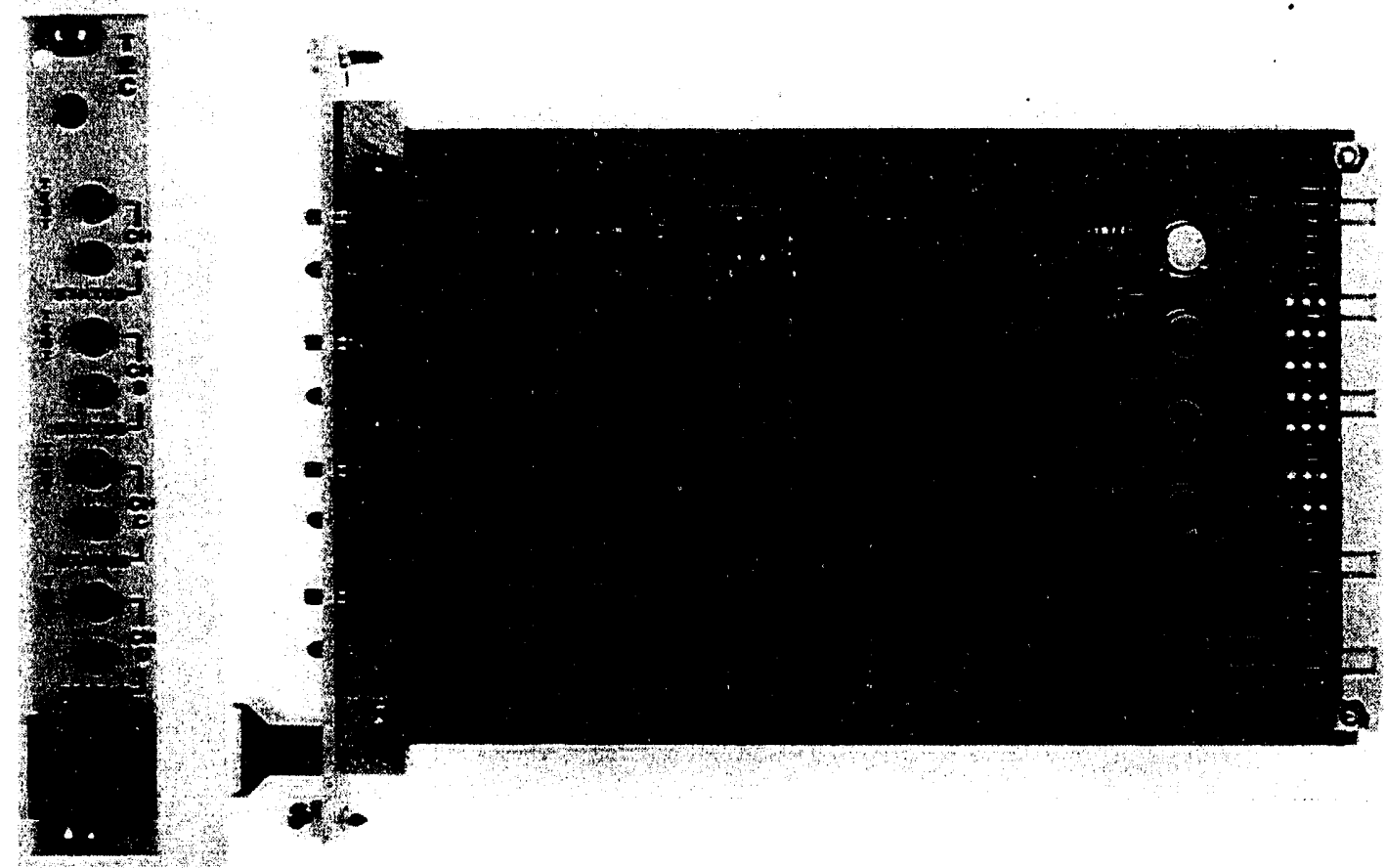

Figure 2.12 Technology for Energy four-channel digital isolation module

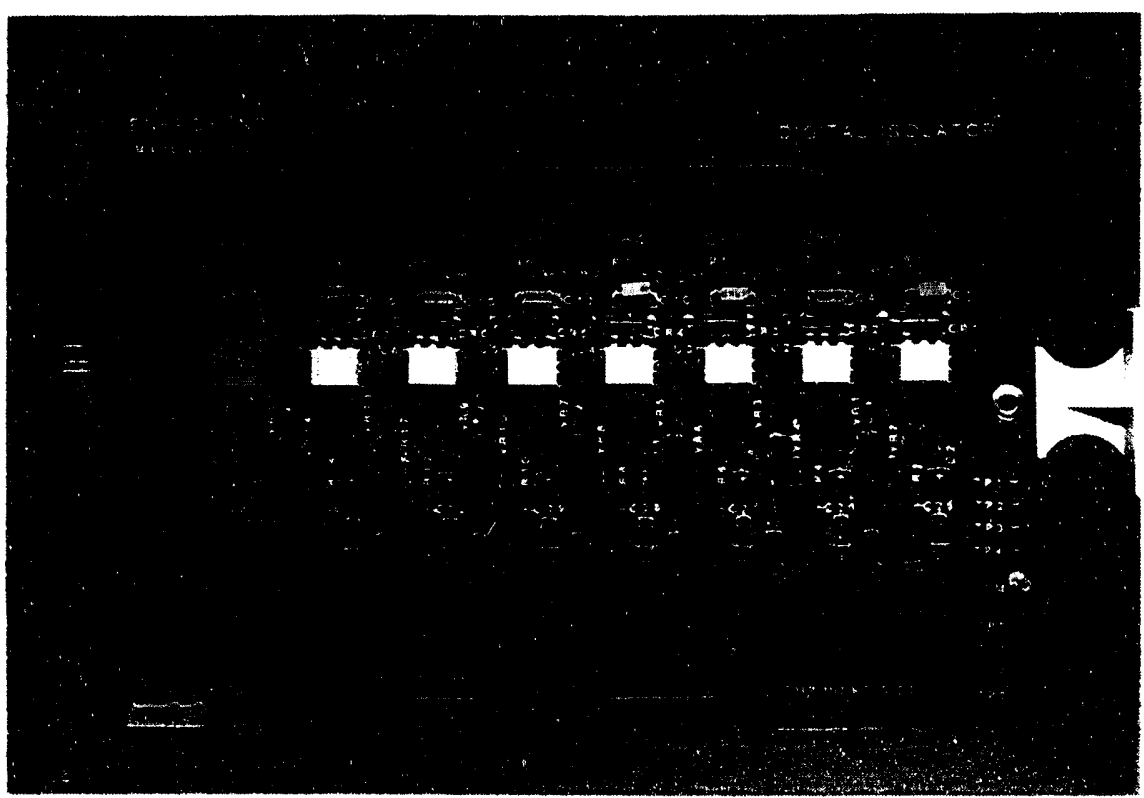

Figure 2.13 Hallibarton NUS eight-channel digital isolator card 
in this design: an AC/DC to Logic Interface Optocoupler (the four ICs vertically arranged below the serial number) and a Photovoltaic Optocoupler (vertically arranged below the "Made in USA"). The face plate of the card, shown face on and at the left in Figure 2.12, contains an LED status indicator and a pushto-test button for each of the four channels. This allows a common test signal to be applied temporarily to each channel to verify the system integrity (Ref. 26).

The Halliburton NUS optically coupled isolator, shown in Figure 2.13, is an eight-channel digital isolator card which plugs into an isolator card cage assembly znanutizetured by their company. As shown in the figure, all input signal, output signal, power, and test connections are made to the isolation card cage assembly via the 2x.22-pin plug connector at the rear of the circuit board (left in the figure). Isolation is provided by the physical separation of the inputs and outputs and a type H11G1 optoisolator in each of the of the eight channels. The output of each channel is fused and a test point is provided that is accessible from the front of the card (lower right in Figure 2.13) when it is installed in the card rack assembly (Ref. 27). 


\section{TESTING PROGRAM}

The details of the major fault testing program are described in the following sections. The objectives of the testing are given, together with descriptions of the testing equipment and the testing procedures.

\subsection{Obiectives}

The present testing program will explore isolation barrier leakage problems that might arise at fault levels up to the maximum credible potential. This was accomplished by observing and measuring the reach-through energy that passes through the isolation devices during fault conditions. A series of fault conditions, increasing in $10 \%$ incremental steps from $10 \%$ to $110 \%$ of the maximum credible fault potential, was applied to each of the tested devices. The relationship between the reach-through energy and the applied fault voltage could then be obtained. From this data, susceptibility to potential damage for various families of electronic isolators may be correlated to their potential safety significance.

The BNL isolator testing facility (ITF) was designed to provide a detailed survey of specific potential power fault conditions affecting electronic isolators. Such isolator faults might degrade or prevent input connected Class 1E equipment and systems from meeting their minimum performance requirements. In earlier testing performed under the NRC's Isolation Devices Evaluation Criteria Program, and reported by Neilsen in NUREG/CR-3453 (Ref. 4), some electronic isolation devices experienced severe damage when subjected to maximum credible $A C$ or DC voltage and current levels (e.g. 120Vac, 20A) applied to the output side of the energized device.

In addition to these maximum credible fault states, additional questions have surfaced suggesting that other, less-than-maximum voltage and current conditions might find a leakage path across the isolator allowing potentially destructive energy levels to breach the isolation barrier (see Section 2.2). The faults with less-than maximum credible potentials may contain other properties influencing damage to connected devices. Such power conditions might occur as a result of subtly induced power levels that are a function of power fault transients relating to wave shape, as well as amplitude. The maximum credible fault (MCF) for a given isolation device must thus be defined not only as that fault potential at which the maximum reach-through energy is passed across the isolation barrier, but also as a function of waveform dependent parameters.

\subsection{Test Procedures}

The general test procedure for this program is outlined below in Table 3.1. Each isolation device under test (DUT) was subjected to a series of fault conditions at the signal output terminals, increasing in $10 \%$ incremental steps from $10 \%$ to $110 \%$ of the maximum credible fault potential. For each $10 \%$ step of applied fault potential, a set of basic tests were performed: Pre-Fault Baseline and Functional Tests, a Fault Application Test, and Post-Fault Baseline and Functional Tests.

\subsubsection{Baseline Electrical Tests}

Prior to the application of fault waveforms, it is desirable to quantify the baseline electrical characteristics of the isolation barrier. Changes in the integrity of the isolation barrier due to subsequent application of fault waveforms may be reflected in corresponding changes in the electrical characteristics of the isolation barrier. This is the purpose of the baseline barrier tests listed in Table 3.1. Measurements of the isolation barrier resistance and capacitance are obtained as described in the following sections. 
Table 3.1 General Test Procedure Sequence

- PERFORM BASE-LINE BARRIER TESTS

Isolation barrier de resistance test

Isolation barrier ac capacitance test

Record, store, and print results

- PERFORM FUNCTIONAL TEST

Verify output signal consistent with applied input signal

Record, store, and print results

- APPLY FAULT FUNCTION TO OUTPUT OF ISOLATOR

Set fault waveform generator to desired amplitude

Apply fault waveform to DUT output terminals

Monitor all points

Record, store, and print results

- REPEAT BASE-LINE BARRIER TESTS

Isolation barrier dc resistance test

Isolation barrier ac capacitance test

Record, store, and print results

- REPEAT FUNCTIONAL TEST

Verify output signal consistent with applied input signal

Record, store, and print results

Isolation Barrier Resistance The configuration for this test segment is shown in Figure 3.1. Direct measurement of the isolation barrier resistance using a multimeter is impractical due to the high value encountered (generally $>1 \mathrm{GQ}$ ). In the method shown in Figure 3.1, a large sampling resistor $(10 \mathrm{M} \mathrm{Q})$ is placed is placed in series with the positive input terminal of the isolator. A known de voltage is then applied across the series combination of the sampling resistor and the isolation barrier resistance. The voltage drop $\left(V_{S R}\right)$ is measured across the known sampling resistor to find the current $\left(I_{m}\right)$ flowing through the circuit. The de resistance of the isolation barrier may then be calculated from the current $\left(I_{m B}\right)$ and voltage drop $\left(V_{\mathbb{B}}\right)$ across the isolator.

Isolation Capacitance The capacitive coupling across the isolation device is the primary means by which energy may be transferred across the isolation barrier. This isolation capacitance may be measured by the test configuration shown in Figure 3.2. The function generator is set to apply a low voltage ( $\left.<5 \mathrm{~V}_{\mathrm{RMs}}\right)$, sinusoidal waveform of known frequency across the positive terminals of the isolation device. The current $\left(I_{m B}\right)$ flowing across the isolation barrier is measured on the digital multi-meter (DMM). Isolation capacitance $\left(C_{B B}\right)$ may then be calculated as: 


$$
C_{\mathrm{IB}}=\frac{I_{\mathrm{IB}}}{2 \pi \mathrm{f} V_{\mathrm{BB}}}
$$

\subsubsection{Isolation Device Functional Test}

Prior to the application of fault waveforms, the functional performance of the isolation device must be verified. This is achieved by applying signals to the input of the energized isolation device and measuring the corresponding output signal transmitted throughout the device.

The basic functional test configuration for analog or digital voltage-to-voltage isolators is shown in Figure 3.3. With the isolator powered, analog input signals may be applied at three levels (zero, midpoint, full span) or five levels (zero, $25 \%, 50 \%, 75 \%$, and full span) of the specified device input range, and the corresponding outputs measured on a DMM as shown in the figure. For digital devices, the technique is the same except only two levels need be checked: the digital low and digital high.

In the case of current-to-current isolators, the functional test arrangement is as shown in Figure 3.4. An adjustable de power supply is used to supply known currents at three or five levels, from zero (typically $4 \mathrm{ma}$ ) to full span (20 ma), to the input terminals of the powered isolation device. The input current may be measured directly with a DMM or as shown in the figure using a series 1KO sampling resistor at the input and measuring the voltage drop across the resistor with a DMM. The output of the device is connected across a load resistor $R_{L}$ of the magnitude specified by the manufacturer. Output current is measured on the DMM by the voltage drop through the load resistor $R_{L}$.

\subsubsection{Fault Application to DUT}

For each electronic isolation device tested the AC fault voltage will be applied to the output terminals of the energized isolation device, as shown in Figure 3.5, in the form of a single, half-cycle, cosine waveform (see Figure 3.7 and associated discussion in Section 3.3) and in amplitude steps of $10 \%$ of maximum (120V rms) ranging from 0 to $110 \%$ with the input terminated in a resistance, $R x$. The applied AC voltage starts at zero and slews rapidly to the maximum, continues for a half cycle and then slews rapidly from a negative maximum to zero. For maximum stress, the transition time should be as short as possible. For the fault pulse generator developed for this test program (described in Section 3.3), the typical transition time is no more than $50 \mathrm{nS}$ for a $10 \%$ to $90 \%$ rise on the leading edge and $10 \mu \mathrm{S}$ from $90 \%$ to $10 \%$ on the trailing edge. The AC voltage is applied in this form since it is expected that the isolation devices to be tested employ solid-state devices. This implies that whatever is to be measured will occur with a time-scale of microseconds, or perhaps milliseconds.

The applied fault voltage and current (at the DUT output terminals) were monitored and recorded at each incremental step, as was the output (if any) across the $1000 \mathrm{ohm}$ input resistor, $R x$. From this, reach-through energy was calculated (the integral of $\left.[V x(t)]^{\star}[V x(t) / R x]^{*} d t\right)$ at each amplitude step of applied fault potential.

The series of incremental fault steps was applied in an increasing sequence of $10 \%$ steps up to $110 \%$ of the maximum credible fault (MCF) potential selected for this testing. As mentioned above, electrical characteristics and functional tests were performed between each $10 \%$ step. The devices were visually monitored throughout the testing for physical signs of damage. When a device was found to no longer pass the functional test, no attempt was made to repair the problem or restore the 


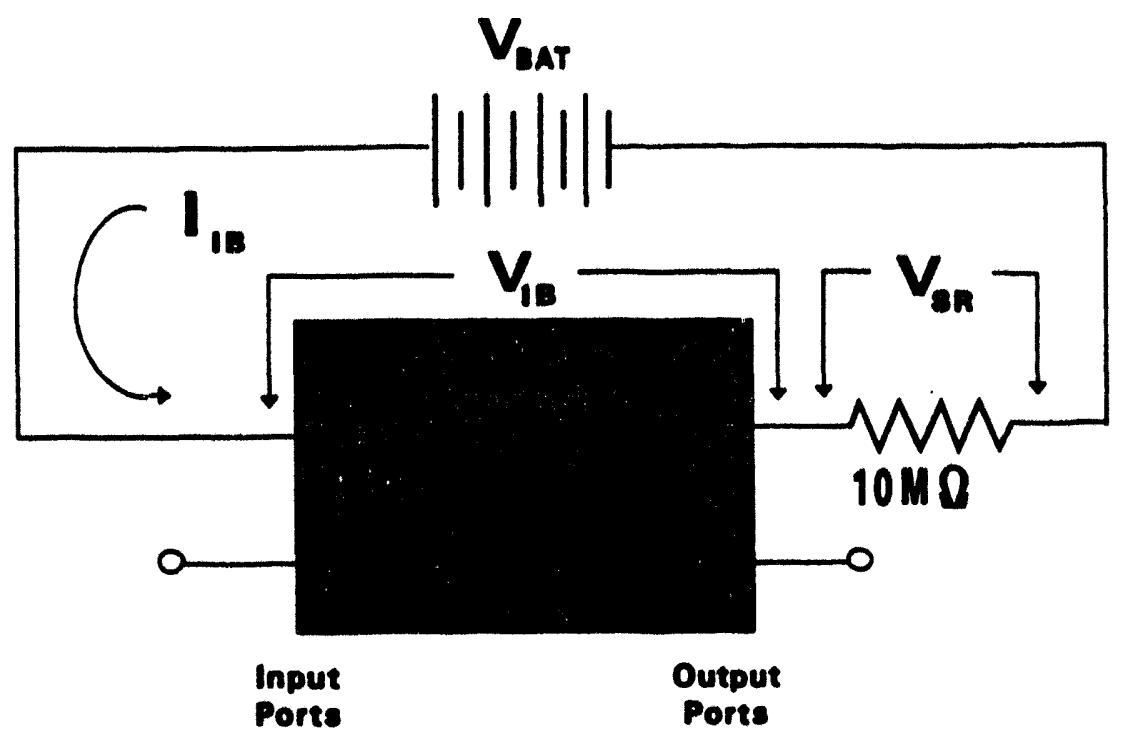

Figure 3.1 Isolation barrier resistance measurement

\section{FUNCTION GENERATOR}

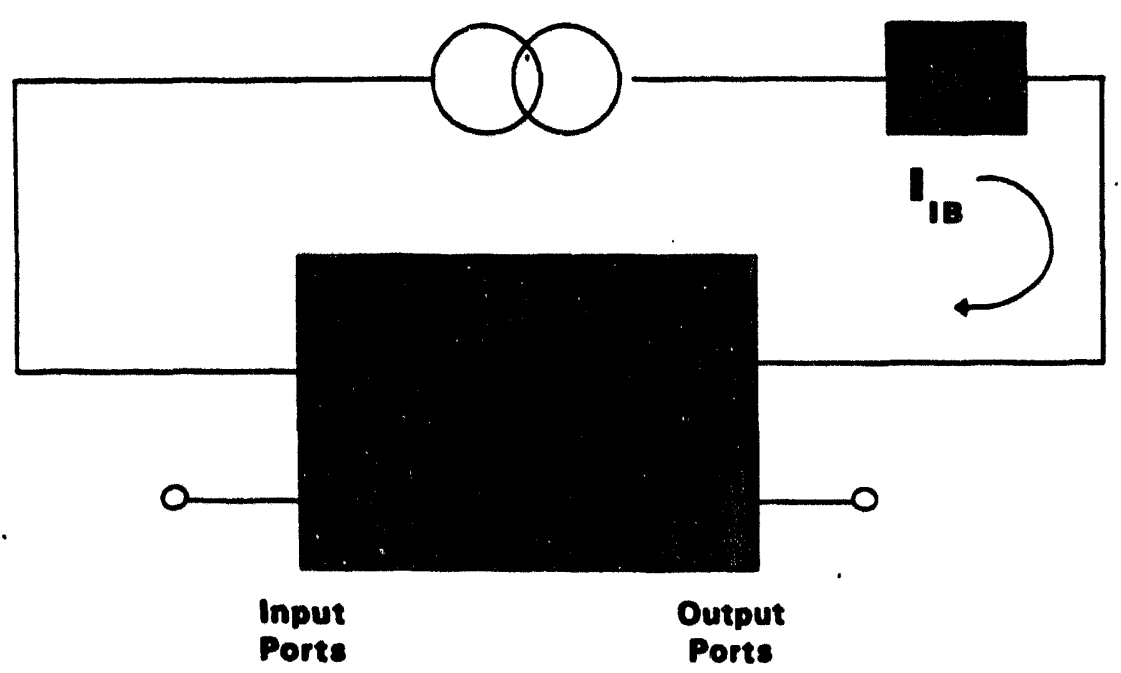

Figure 3.2 Isolation capacitance measurement 


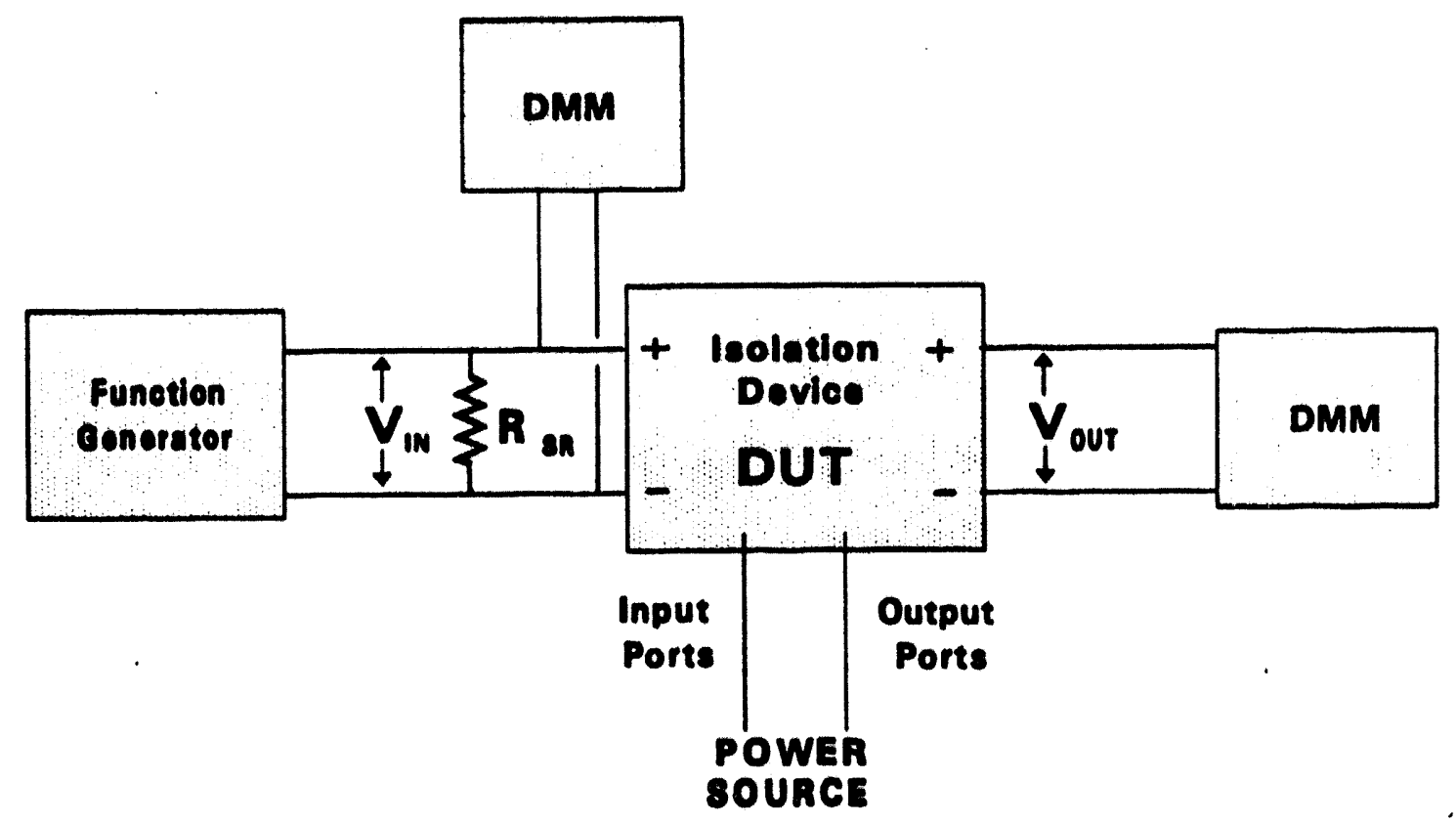

Figure 3.3 Voltage-to-voltage icolator functional test

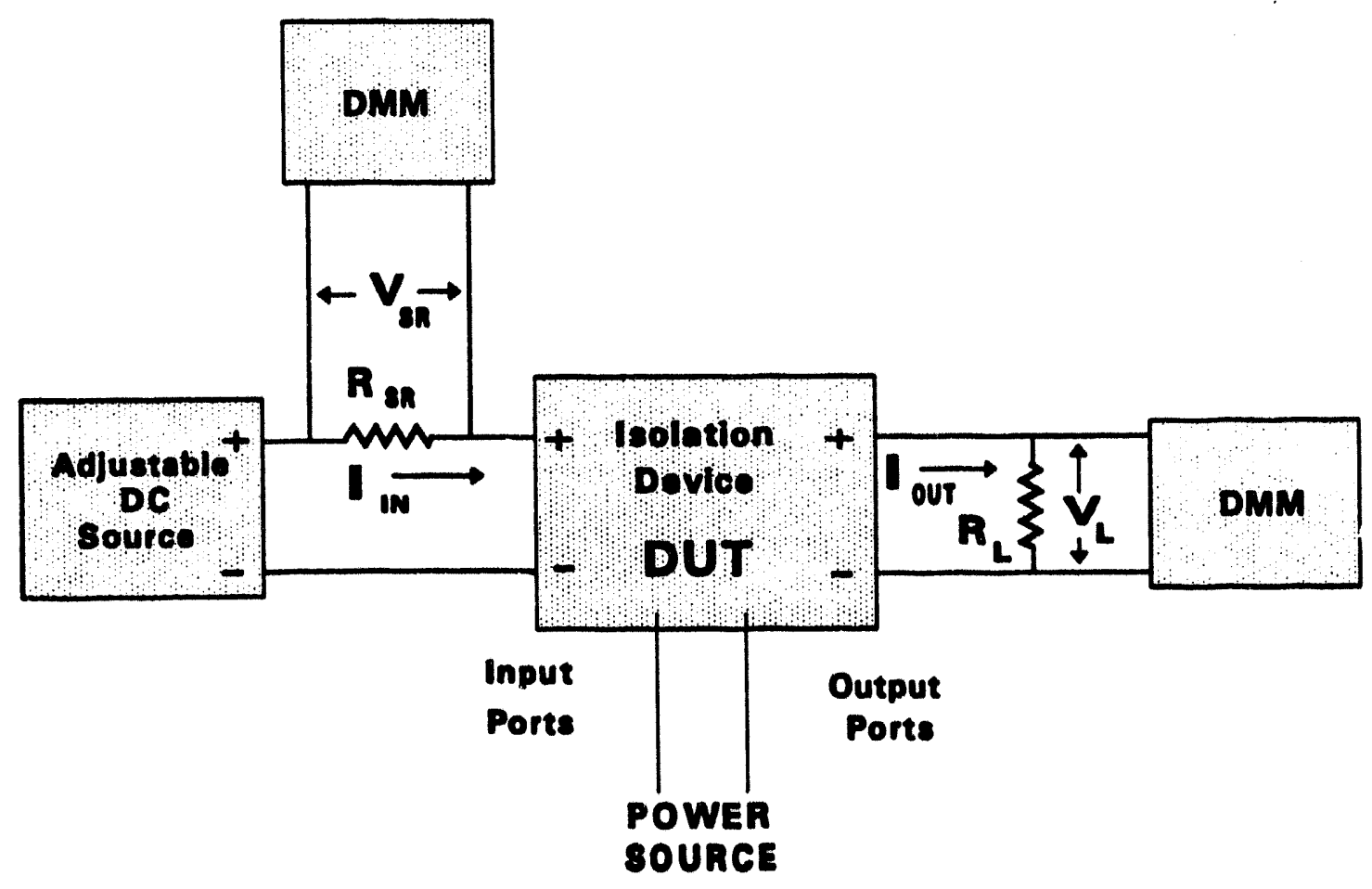

Figure 3.4 Current-to-eurrent isolator functional test 


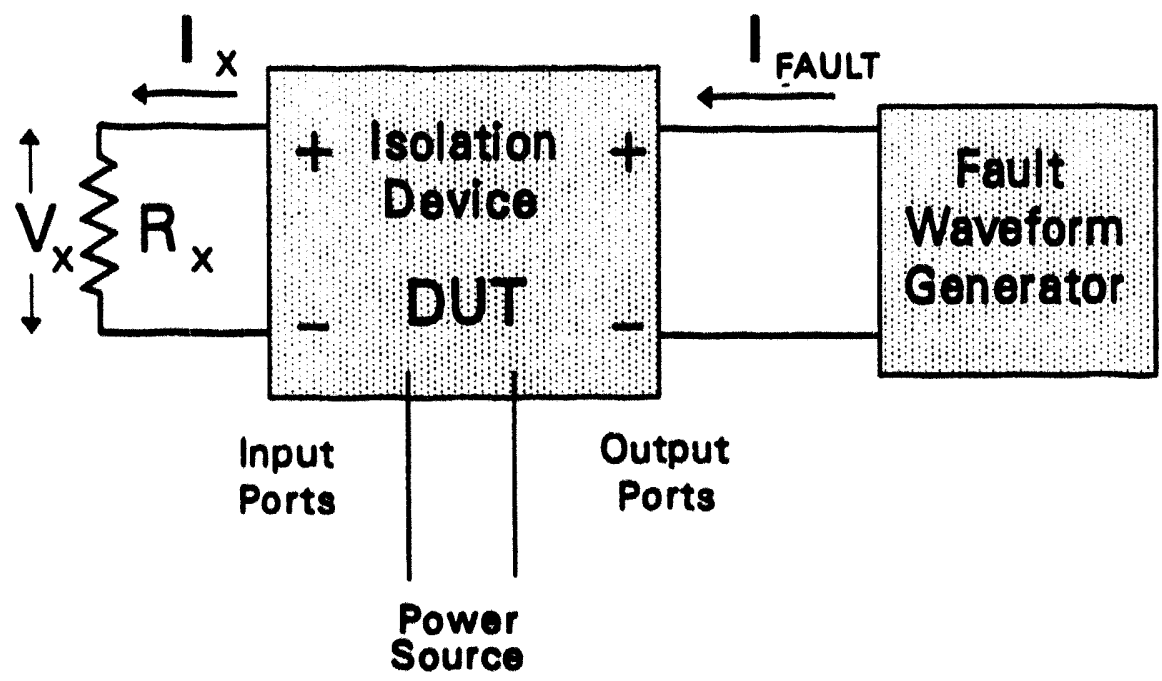

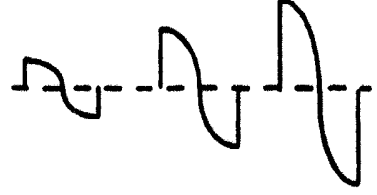

Incremental Steps of

1/2 Cycle Cosine

Fault Waveforms

\section{Figure 3.5 Isolator incremental fault application test}

device to functional status. The fault step at which the functional failure occurred was noted and the test preceded on from there up to the $110 \%$ fault level. The isolation devices were kept energized at their normal power supply requirement for the functional testing and fault testing. No signal was applied to the input at the time of fault testing since it was felt that for faults applied directly to the output terminals of an isolation device, the internal impedance of the fault generator was much lower than that of the isolator so that any signal voltage transmitted to the output would not significantly contribute to the overall fault voltage applied at the device output terminals.

\subsection{Mulliple Channel Isolators}

Among the isolation devices tested for this program were several multiple channel units. When testing these isolators, one channel (designated Channel " $A$ ") was selected for full testing as described in the previous section. In addition, all the remaining channels in the device were subjected to full clectrical characteristics measurements and functional verifications prior to the application of any faults. If the primary channel under test, Channel $A$, was found to have stopped functioning at some fault level, then all the remaining channels were again subjected to electrical characteristics measurements and functional verification before continuing to the next higher fault step. Finally, after the final $110 \%$ fault had been applied and the final post-fault electrical measurements and functional tests were performed on Channel $A_{1}$ then the remainder of the channels, would also undergo a final set of post-test electrical measurements and functional tests (if they were still functional at the end of the test).

\subsection{Tert Bapipment Setup}

The isolator test facility (ITF) was designed to accurately and automatically monitor the vital connections to the isolation device under test while systematically applying predetermined fault profiles to the output terminals of the DUT. To ensure maximum detection capability, electronic measuring 


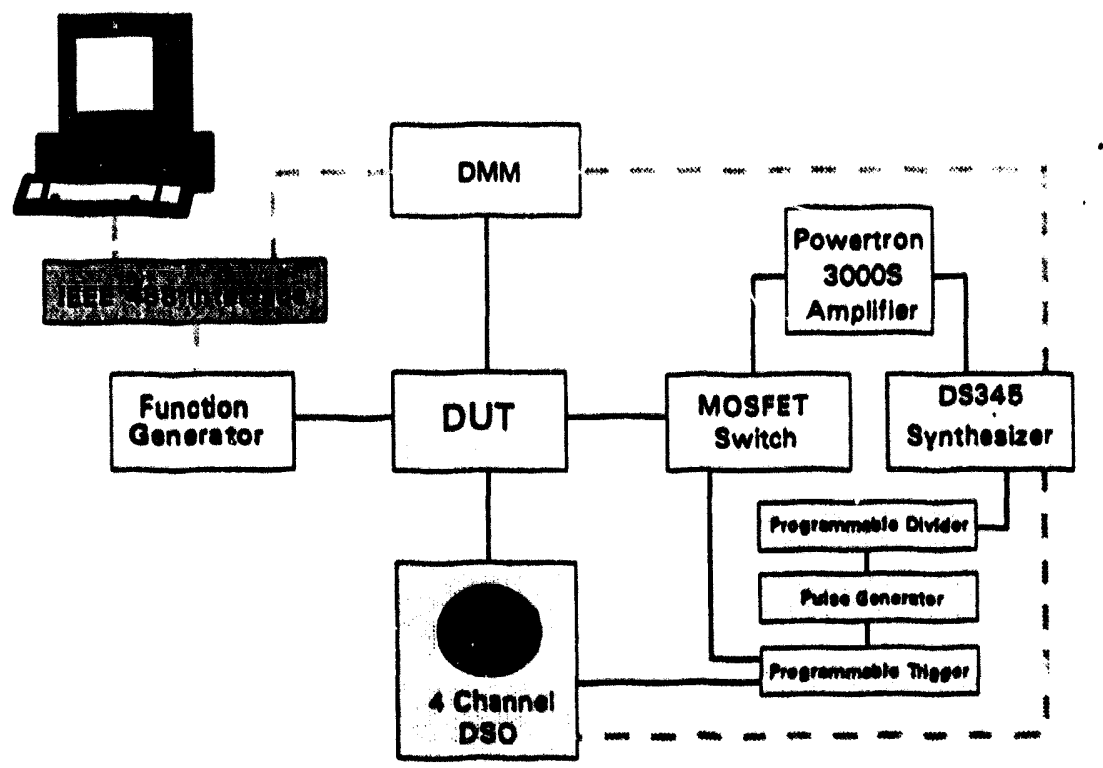

Figme 3.6 Baske teat equipment setup

instruments were chosen that are capable of the highest sensittitity and resolution relative to the measurement objectives. These sensitive instruments permit minute currents to be detected, both statically and dynamically, so transient through-put phenomena can be observed and quantified.

The basic teat set-up is shown in Figure 3.6. Program control is provided by National Instruments NI-488.2 software and Microsoft Quick BASIC sottware running on an IBM PS/2 Model 55X PC. An IEEE-488 Standard Bus digital interface provides for control of the LeCroy Model 9314M Digital Storage Oscilloscope (DSO), Keithley Model 2001 Digital Muli-meter (DMM), Stanford Research Systems (SRS) DS345 Synthesized Function Generator, and Hewlett Packard Model HP3325A Synthesizer/Function Generator. A list of the major equipment and sottware is provided in Table 3.2. Some technical details and specifications of the test equipment and software are found in Appendices A and B.

The fault waveform generator consisted of the SRS DS345 Synthesized Function Generator, the ITECo Powertion
Model 3000 s AC Amplifier, and the custom designed ITECo high-speed MOSFET switch/controller (see Appendix B). The DS345 served as both the waveform source (wave shape and amplitude) for the Powertron amplifier, and as the synchronizing clock to gate the MOSFET switch/controller and to triger the LeCroy DSO via the BNL designed programmable trigger (see Appendix B). The Powertron operated as a continuous waveform (CW) amplifier. When the gate from the programmable trigger unit triagered the high-speed MOSFET switch/controller, it unblocked the CW output of the Powertron amplifier and directed the selected portions of the waveform to the DUT at electronic speeds.

The number of fault pulses to be applied to the DUT can be selected from the programmable trigger to be one and only one per event, up to 99 fault pulses per event. The programmable divider is used to select the delay between pulses (the duty cycle) in multiple fault pulse events (e.g., by setting the programmable divider to 5 and selecting 3 fault pulses on the programmable trigger, three cosine fault pulses will be applied to the DUT at an interval of one fault pulse every 
Table 3.2 Equipmont Let for BNL Isolator Teat Facillty

Tex Eouipment

Powertron, 3 KVA source, single $\phi$

MOSFET Power Switch/Controller

IEEE-488 Interface Board w/connecting cables

Synthesized Function Generator

Pulse Generator

High Performance Digital Multi Meter

IBM PCIAT or better

S-Decade Programmable Divider

Programmable Pulse Trigger

4-Channel Digital Storage Oscilloscope

\section{Regulated DC Power Supply}

MicroSott Quick BASIC Sotware Verion 4.5

IEEE 488 Bus Language Interfice and Device Drivers for MS-DOS

Current Transformer Syntheaizer/Function Generator

fith cycle). The standard Powertron includes a provision to switch the unit automatically at a predetermined load current from the constant voltage mode into a constant current mode (20A max).

As mentioned in Section 3.2.3, the fault generator designed for this teating is capable of producing a cosine waveform with a leading edge rising transition time from $10 \%$ to $90 \%$ of no more than $50 \mathrm{nS}$, and no more than $10 \mu \mathrm{S}$ from $90 \%$ to $10 \%$ on the trailing edge. Figure 3.7 is an oscilloscope trace of the cosine fault waveform produced by the
Mf. \& Model No. (where avelbble)

Model 3000S, Industrial Test

Equipment Co., Inc.

Custom Design, Industrial Test

Equipment Co., Inc.

National Instruments MC-GPIB

Stanford Research Systems Model DS345

Interstate Electronics Corp. Model P12

Keithley Model 2001 DMM w/10-channel scanner card

IBM PS/2 Model 55X

Custom Design, BNL

Custom Design, BNL

LeCroy Model 9314 M-MCO1/04

w/Optons WP01/02 and Trigger Out Provision

Power Designs Model 5015-S

MicroSoft Corp.

National Instruments NI-488.2 for MS. DOS Software

Peareon Electronics Inc. Model 110A

Hewlett-Packard Model 3325A

fault generator. In Figure 3.8, the time base was expanded to show details of the leading edge (left) and the trailing edge (right) of the waveform in Figure 3.7.

Since the rapidity of the leading edge of a cosine wave can be expected to add significantly to the isolation barrier reach-through current through the outputinput capacitance $\left(I=C \frac{\mathrm{V}}{\mathrm{a}}\right)$, the cosine wave produces more testing stress in the DUT (as compared to a sine wave for the same peak amplitude), and the results thus obtained represent the upper bound of the 


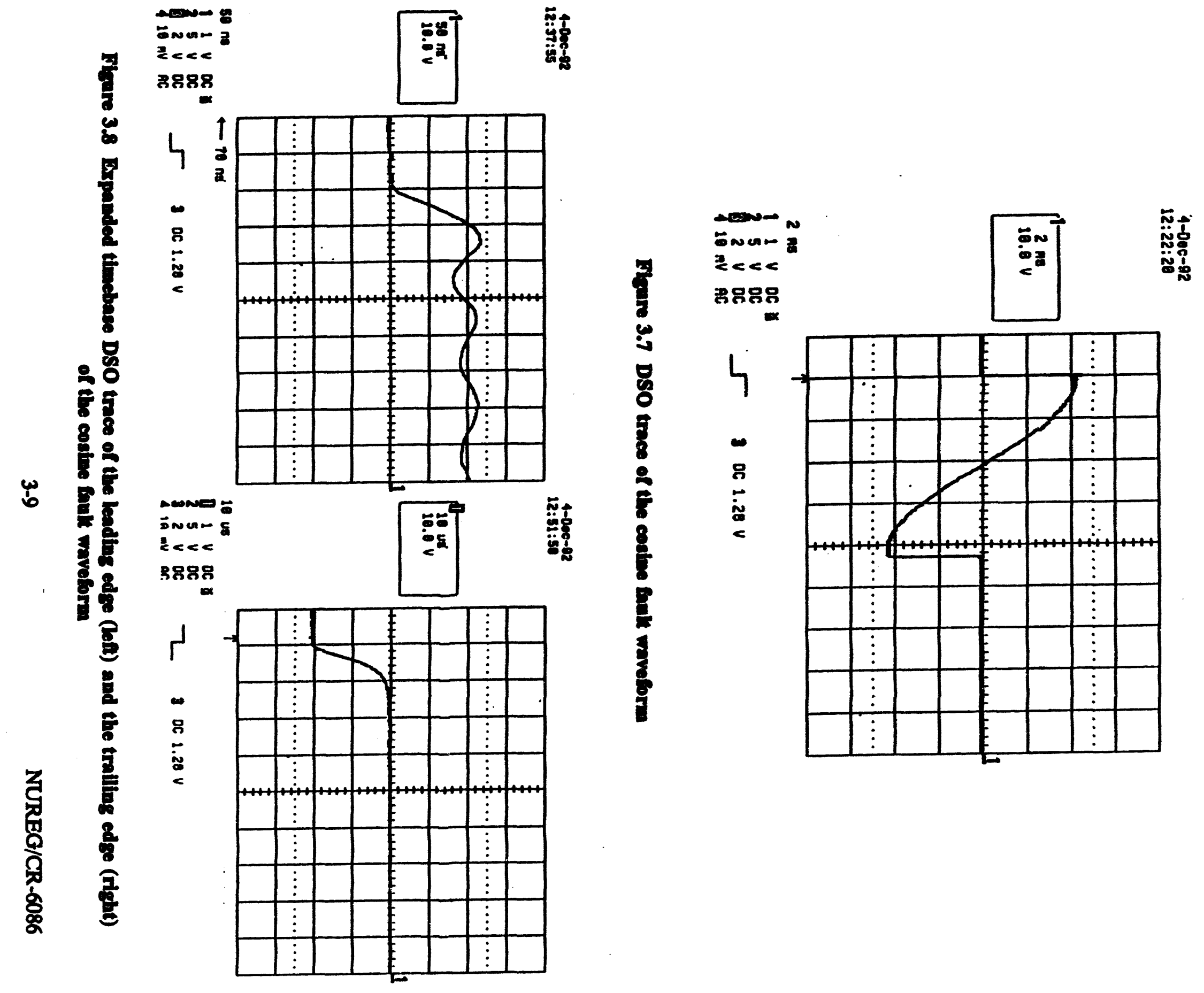


worst case fault conditions that will be experienced at each level. Consequently, the fault testing was conducted by applying one and only one cosine waveform of the proper magnitude to the output terminals of the DUT at each testing level.

Test measurements were made using either the Keithley DMM or the LeCroy DSO. Prior to the testing, a calibration check of the instruments was performed and documented by the manufacturers (see Appendix C). The DMM was used primarily in the performance of the baseline electrical testing of the DUT isolation barrier and for DUT functional testing. The LeCroy was used to capture the data associated with the fault application testing.

The LeCroy digital storage oscilloscope has the capability to record fast transient events such as those that occurred during the fault application testing of the isolation devices. These are time dependent voltages that are not possible to detect with a digital voltmeter or similar device. Such voltages are significant because they can be of sufficient amplitude to cause induced faults without being detected under normal operating conditions. With this instrument it is possible to record any potential transient effects and assess their potential to compromise critical protection systems.

The LeCroy oscilloscope used in the test is capable of recording four transient events simultaneously. Four input channels are used to monitor both input and output voltages to the DUT. It is also used to monitor input and output currents of the DUT through sensitive, fast-response current transformers connected at those respective locations. The resulting data acquisition from the digital recording oscilloscope is both controlled by, and transferred to, the computer through an IEEE-488 Standard Bus digital interface for display, storage, and analysis. 


\section{TEST RESULTS}

This section offers a summary of the results obtained during this testing program. Twelve isolation devices, listed in Table 2.2, were subjected to the incremental series of fault application tests described in section 3.2.3. In accordance with the program objectives, it was demonstrated that all the isolators maintained the integrity of their isolation barriers throughout the testing, while passing only minute quantities of reachthrough energy. The highlights of the testing are detailed below in Section 4.1. Additional observations that were made during the test program are discussed in Sections 4.2 and 4.3.

As a result of the faults applied during their testing runs, all but two of the units ceased to function electronically as instrument signal transmitters, i.e. they could no longer transmit signals accurately from input to output.

\subsection{Reach-Thourh Prerey}

The primary objective of the testing was to study the reach-through energy characteristics of isolation devices when subjected to a series of applied faults ranging in magnitude from $10 \%$ to $110 \%$ of the maximum credible fault (MCF) potential selected for these tests $(120 \mathrm{~V} \mathrm{~mm})$. The results of the testing are summarized in Table 4.1. The tested isolators are grouped into three categories: magnetically coupled voltage-to-voltage isolators, magnetically coupled current-to-current isolators, and optically coupled isolators.

The integrity of the isolation barriers in all of the units tested was maintained satisfactorily throughout their testing run. No attempt to repair damage or replace blown fuses was made before proceeding to the next higher step of fault potential. Units were physically inspected for signs of damage at the end of the test series (after the application of the $110 \%$ fault and completion of post-fault electrical and functional tests).

For each of the isolation devices tested, the reach-through energy was measured at each incremental step of applied fault potential in the testing progression. As described in Section 3.2.3, the applied fault was a single, 1/2 cycle cosine waveform injected at the output terminals of the isolator. The quantity of energy measured at the isolator input terminals is thus the corresponding $1 / 2$ cycle reach-through energy resulting from that applied fault waveform. These reach-through energy data are plotted in Appendix $D$ as a function of the applied fault potential (expressed as a fraction of the maximum credible fault (MCF) potential) for the twelve isolation devices tested.

The second column in Table 4.1 summarizes the trends observed in these graphs. For example, the graph for the first isolator DA-3-1 (Figure 4.1), displayed an increasing trend in reach through energy as the applied fault potential was increased from $10 \%$ up to $100 \%$ of the maximum; there was also a large peak of reach-through energy observed during the application of the $50 \%$ fault potential. In contrast, the graph for the second isolator in Table 4.1, isolator FA-3-1A (Figure 4.2), shows that this unit passed no significant reach-through energy for faults up to $90 \%$ of maximum; measurable reachthrough energy was first observed at the $100 \%$ fault level and then increased again at the $110 \%$ level.

As can be seen from the summary table, the quantity of $1 / 2$ cycle reach-through energy measured at the input terminals of the magnetically coupled isolators generally either increased steadily as the applied fault potential was increased, or remained relatively constant up to some point (where internal damage may have occurred), and then increased throughout the remainder of the series. The quantity of $1 / 2$ cycle reach- 


\section{VI-8-va dopसcm}

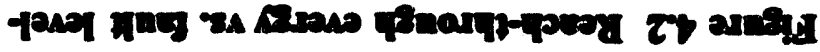

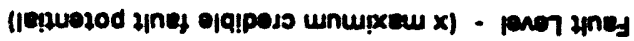

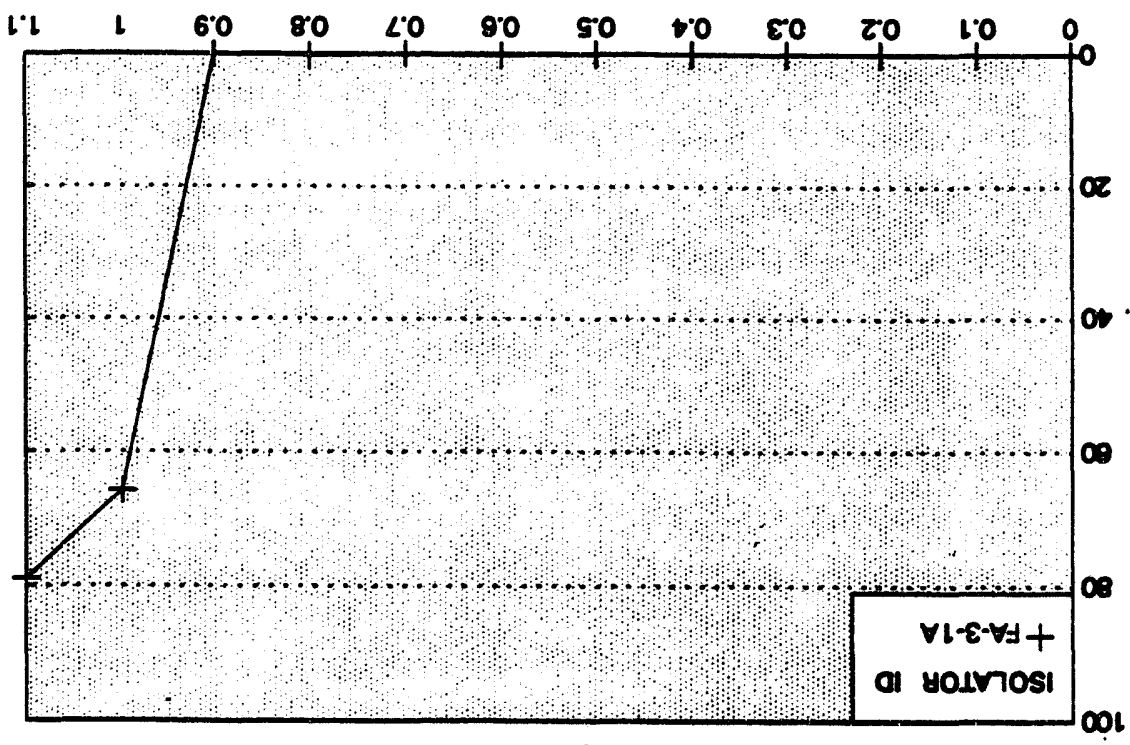

(soinofosopu 90-3 X) ABsaug 4Bnos4 L-4950y

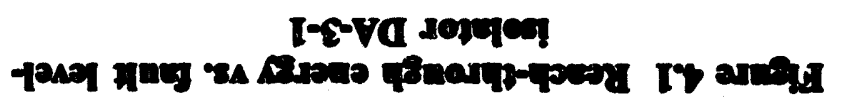

(lepuosod uncs olq!pess unupxeu x) - prov uned

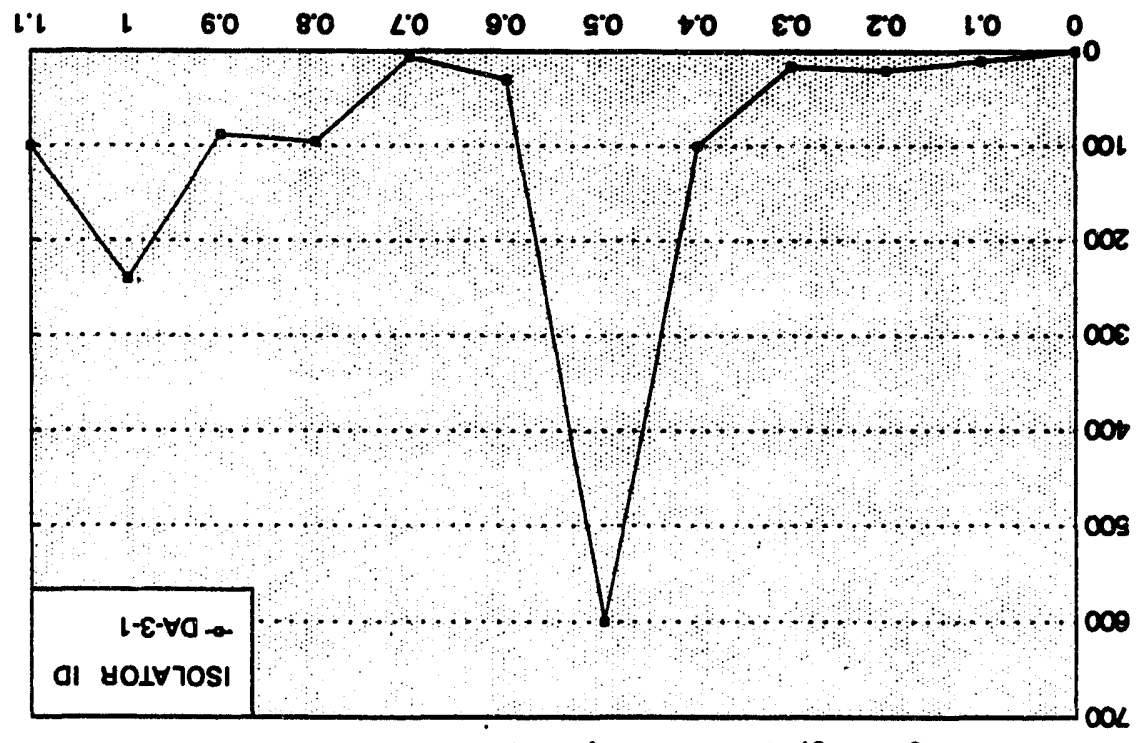

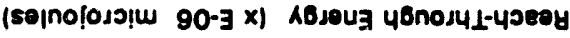




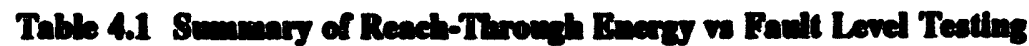

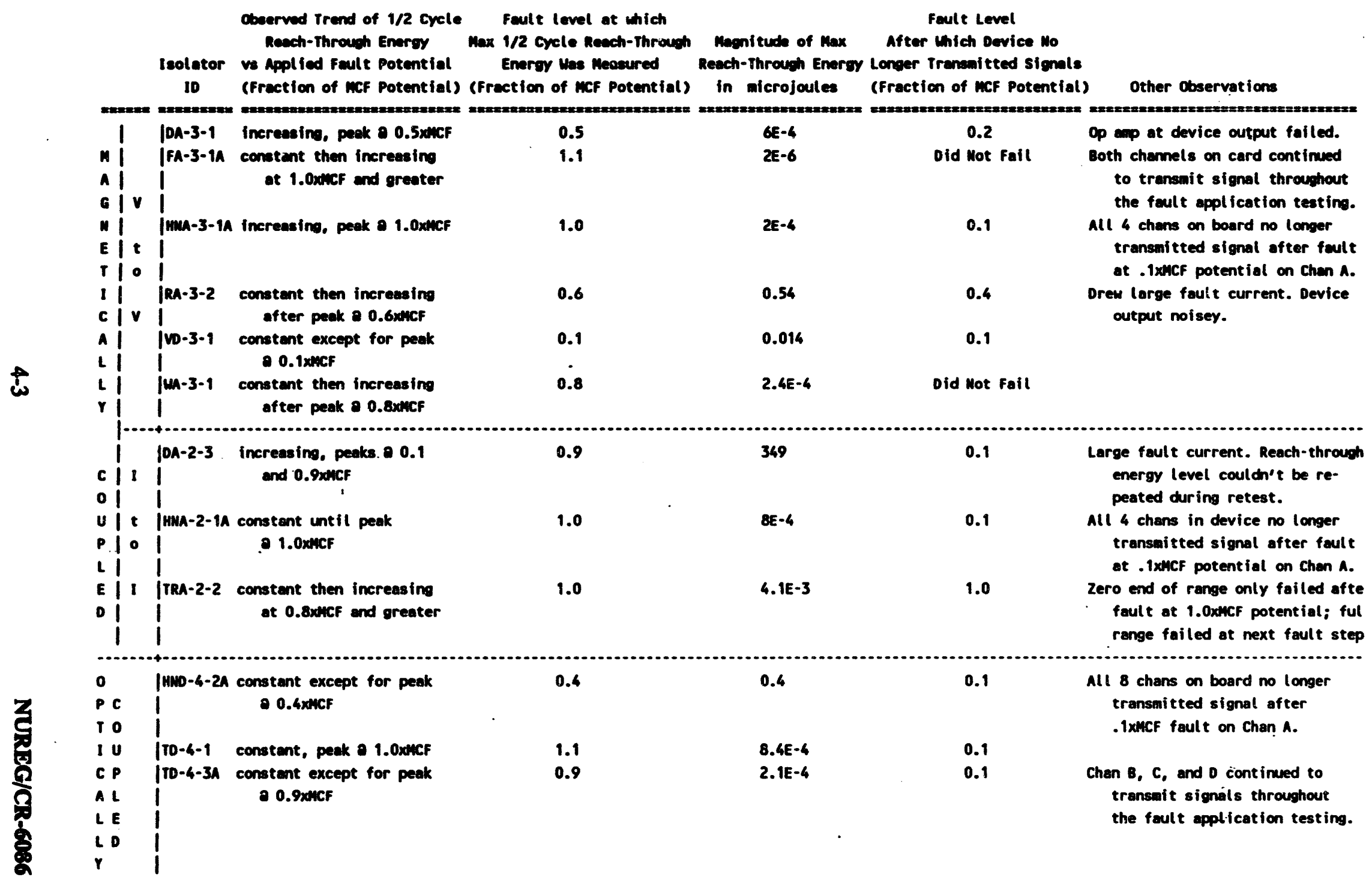


through energy measured at the input terminals of the optically coupled isolators tended to remain relatively constant throughout the series of tests, but typically exhibited one or more peaks of higher reachthrough energy.

Table 4.1 also indicates the fault level, as a fraction of the MCF potential, at which the maximum reach-through energy was measured for each of the isolators tested. The basis for the qualification testing of electronic isolators at a fault equal to the maximum credible potential is that this condition would simulate the worst case fault in regard to the measured reach-through energy. This was not always the case as observed in the present test program. For example, Figure 4.3 shows the plot of $1 / 2$ cycle reach-through energy verses applied fault potential for one of the voltageto-voltage magnetically coupled isolators, RA3-2. In this test, the reach through energy was minimal until the 0.4xMCF potential,increased slightly at 0.5 , and peak reach-through energy was measured at the $0.6 \times \mathrm{MCF}$ level. For this particular isolator then, the maximum credible fault potential in regard to reach-through energy was not the maximum credible potential of $120 \mathrm{Vac}$, but rather $0.6 \times 120 \mathrm{Vac}$ rms, or $72 \mathrm{Vac}$ rms. Figure 4.4, presents another example of a voltage-to-voltage magnetically coupled isolator, HNA-3-1A, in which the testing did find that the peak reachthrough energy occurred at the maximum credible potential. Hence for this isolator, maximum credible potential was representative of the worst case, or maximum credible, fault.

For most of the isolators tested, however, the maximum credible potential did not produce the maximum credible fault in terms of the measured reach-through energy. In the magnetically coupled isolators, the fault level at which maximum reach-through energy was measured encompassed the entire range of applied fault potentials from 0.1 to 1.1xMCF, with a mean of 0.683 for the voltage-to-voltage isolators and a mean of .967 for the current-to-current isolators. For the optically coupled isolators, the mean fraction of MCF potential at which the maximum reach-through energy was measured was 0.8 .

Table 4.1 lists the maximum magnitudes of the reach-through energies measured for each isolation device tested. These ranged from $2 \times 10^{-6}$ microjoules up to 349 microjoules, and this latter measurement could not be repeated during retesting. It should be noted that these are the energies measured at the input terminals during the application of $1 / 2$ cycle of the cosine shaped waveform described in earlier in Section 3.3 and shown in Figures 3.7 and 3.8. This waveform represents the worst case fault in terms of the isolation barrier capacitance, since the rate of change of voltage is extremely rapid. This was reinforced during the data analysis where it was found that when reach through energy was observed, the peaks usually accompanied the rapid voltage changes at the leading and trailing edges of the applied fault waveform. Therefore, sustaining the fault application time for a $60 \mathrm{~Hz}$ waveform would not have changed the picture significantly in terms of reach-through energy.

Nevertheless, the magnitudes of the maximum reach-through energies were very low. A determination of whether fault energy of the order of magnitude observed in the testing is potentially damaging to components connected at the input of an electrical 


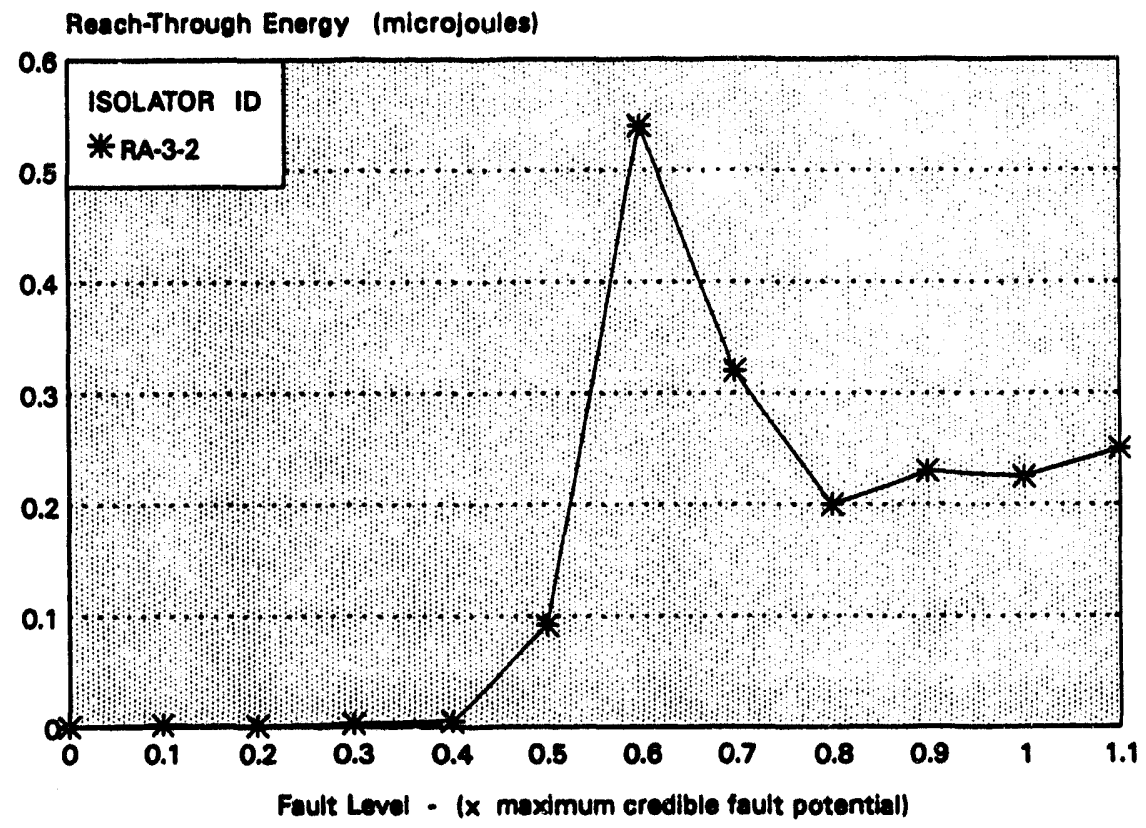

Fignre 43 Reach-through energy ve. fult levelisolator RA-3-2

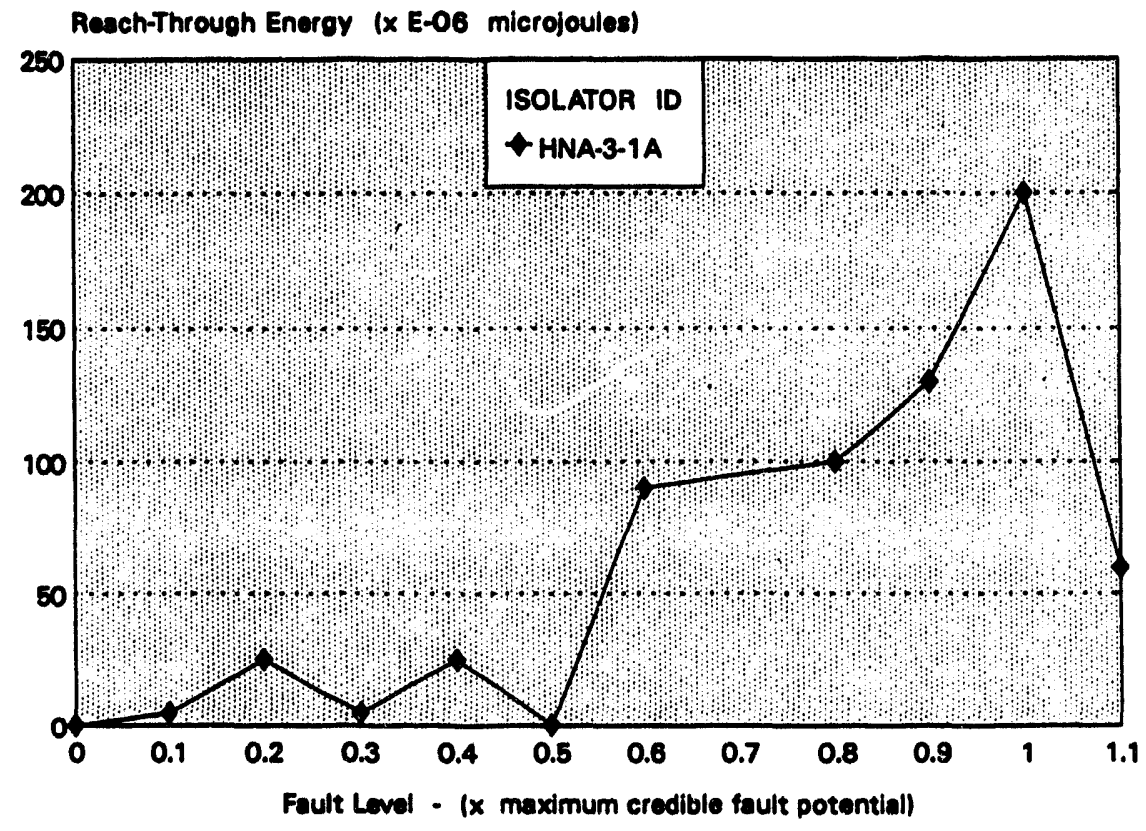

Figure 4.4 Reach-through emergy vs. fault levelisolator FNA-3-1A 
isolation device is difficult to make. First of all, it is dependent upon the types of components that may be found at the input of the isolation device. Secondly, data regarding damage threshold energies for electrical components is difficult to obtain and by its nature is not precise. However, general estimates for families of components indicate that semiconductors, CMOS circuits, and other electronic integrated circuits are the most sensitive to electrostatic discharge induced fault damage, as seen in Figure 4.5 (Ref. 28). Using the figure as a guide, the maximum reach-through energies observed for the worst case waveform (fault with rapid voltage rise time), could present a problem for semiconductors. In actual application, however, the isolation devices are not likely to be exposed to a such a severe fault waveform as in the testing, so the reach-through energies seen in the field would be much less. In addition, semiconductors and other electronics would not be located right at the isolator terminals, but rather are some distance away, further attenuating the effects of any reach through energy. The likelihood of damage to equipment on the input side of electrical isolation devices resulting from faults at the output is thus considered to be low.

\subsection{Ieolator Functional Tests}

Prior to the application of each incremental fault level, the isolation device under test (DUT) was subjected to a functional test as described in Section 3.2.2. This was done to determine whether an applied fault had affected the basic functional capability of the DUT to transmit signals from input to output. The fifth column of Table 4.1 indicates the applied fault level, as a fraction of the MCF potential, at which each isolator no longer transmitted signal from input to output.

All but two of the isolators stopped transmitting signal at some point during the series of fault tests. Both of these isolation devices were of the magnetically coupled, voltage-to-voltage type. In addition, one other unit, a magnetically coupled current-to-current unit, continued to function up to the full MCF potential at which time the zero end of the 4$20 \mathrm{ma}$ output range failed. After application of the next higher fault level (110\%), the entire output range of that device then ceased functioning as well. As shown in the table, most of the units lost the capability of transmitting signals; after the $10 \%$ fault was applied. It should be noted that most isolation devices are not designed to continue operating after withstanding this type of fault; the primary function of the isolation device in such a circumstance is to maintain electrical isolation even though its signal transmitting capability may have been lost.

Another noteworthy finding arising during the functional tests involved the integrity of isolation channels on multiple channel isolation devices. As described in Section 3.2.4, when testing multiple channel isolators, the series of fault tests was only applied to one channel (Channel $A$ ) on the device. However, functional tests were performed on all channels prior to the first fault application, after functional failure of the channel under test, and following the completion of the fault testing series. Among the five multiple channel units that were fault tested, in three of them, when the channel under test stopped functioning, all of the other channels in the device were found to have stopped functioning as well. The most likely reason for this is that a common power supply was shared by all the channels on the isolator on the Non-Class $1 E$ output side of the device. Thus, when the fault applied to the output side of the channel under test caused the failure of the common power supply, all channels on the board were affected. System designers should therefore be aware of, and consider, this aspect in the selection and grouping of signals to be processed through multiple channel isolators. 


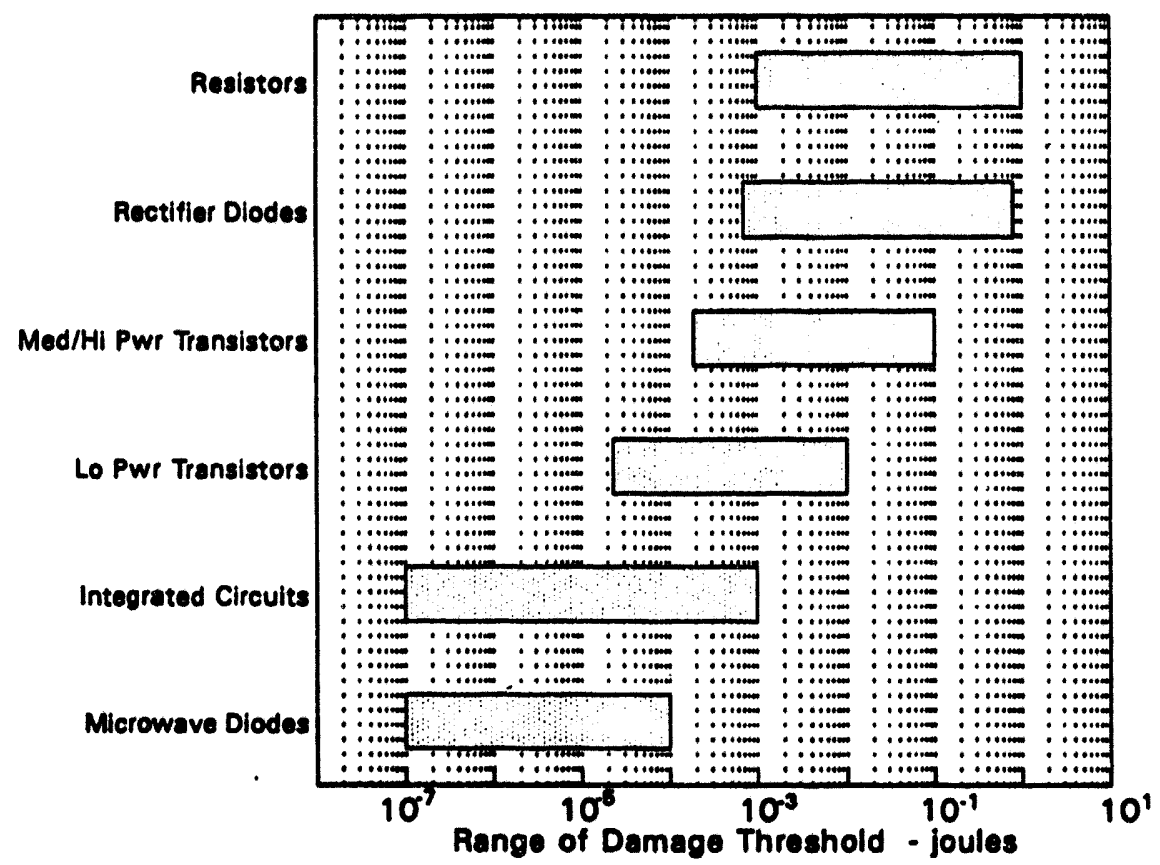

Figure 46 Extimation of the vabermbility of various components to ESD-induced damage (Rer 28).

\section{Bamiar Fhotrical Chancteritice.}

The baseline electrical characteristics of the isolation barrier were measured throughout the fault testing of the isolators as described in Section 3.2.1. The purpose of this is twofold: to identify if and when an isolation barrier has been compromised, and to determine whether progressive deterioration of the integrity of the isolation barrier might be accompanied by measurable changes in electrical characteristics.

On the first point, the isolation barrier integrity was not compromised in any of the devices during fault testing. It must be emphasized that the purpose of this test program was the investigation of reachthrough energy characteristics, and accordingly only single, half cycle bursts of fault energy were applied to the isolators. The thermal and electrical effects of longer applied fault times on the isolation barrier integrity, therefore should not be implied from this test program.

In pursuit of the second point, barrier resistance and capacitance measurements taken during the fault testing runs were plotted as function of applied fault level. These may be seen in Appendix $D$. The measurement of the isolation barrier resistance using the technique described in Section 3.2.1 proved to be a difficult task. The difficulties of this sensitive measurement are reflected in the fair amount of data scatter that was observed (see graphs in Appendix D). In those cases where it was difficult to obtain a reliable reading of this characteristic, a direct measurement was made using the DMM, to establish a lower limit on the actual value (i.e., greater than 1.05 Gigaohms, the 
upper limit of the ohmmeter range of the DMM). This still allowed the verification of the integrity of the isolation barrier, as shown by the high value of barrier resistance.

Linear regression of the barrier resistance data for those cases where measurements could be obtained indicated that barrier resistance showed a slight tendency to decrease as the applied fault level was increased. However, this trend is not conclusive due to the amount of scatter observed in these data measurements. Graphs of the isolation capacitance measured at $50 \mathrm{kHz}$ as a function of applied fault level generally remained constant throughout the series of tests, however fluctuations coincided with those applied faults that caused damage to internal components. There may therefore also be some relationship between the electrical characteristics, and hence the reachthrough energy, and the age of the isolator. However, further testing would be required to firmly establish this relationship. 


\section{CONCLUSIONS AND RECOMMENDATIONS}

A total of twelve models of isolation devices were subjected to incremental fault testing under this program. This section lists the conclusions resulting from the testing, and identifies potential problem areas requiring further research and investigation.

\subsection{Conclusione and Obrencritione}

From the test data obtained during testing of the twelve models of isolation devices the following conclusions and major observations are made:

- All of the devices tested demonstrated their ability to withstand and isolate a series of incremental faults, in increasing increments of $10 \%$ of the maximum credible fault (MCF) potential from $10 \%$ up to $110 \%$ of MCF potential, applied directly to the signal output terminals, without transferring significant quantities of energy across the isolation barrier to the input side. This was the main objective of the testing program.

Peak 1/2 cycle reach-through energy measured at the input terminals of the isolation devices during fault application testing did not always occur at the level defined as the MCF potential, particularly in the magnetically coupled voltage-tovoltage isolators. However, the magnitudes of the reach-through energies measured even at their peak were very small (less than 350 microjoules) and are considered insignificant.
- Nine of the twelve models of isolators tested failed electronically, i.e. functionally lost the capability to transmit signals from input to output, during the incremental fault testing process. Two magnetically coupled, voltage-to-voltage isolators continued to function throughout their test series up to the $110 \%$ applied fault level. One magnetically coupled, current-tocurrent isolator continued to transmit signals until it experienced a partial output fallure at the $100 \%$ level, and a complete loss of signal transmission capability at the $110 \%$ level. This result is not unexpected, since most isolators are not designed to continue transmitting after being subjected to such fault conditions, even though they do continue to maintain electrical isolation.

- Three of the five multiple channel isolators tested failed electronically in all of their channels even though only one of the channels was subjected to the incremental applied fault testing process. The cause attributed to these failures was the loss of a common power supply on the output side used to power all of the isolator channels on a device. System designers should consider this aspect in the selection and grouping of signals to be processed through multi-channel isolators.

- From the data gathered, it appeared that there may be a relationship between the reach-through energy and the age of an isolation device. Reachthrough energy is a function of the isolation barrier impedance, and this 
characteristic will change with time, as reflected by the changes in the barrier resistance and capacitance data during the incremental fault application testing sequences. Additional testing with aged isolation devices would be needed to verify this observation.

\subsection{Recommandhtion}

The following recommendations are made regarding the application and qualification of electronic isolation devices for use in nuclear power plants:

- Qualification of electronic isolation devices by testing only at the maximum credible potential fault level to meet the requirements of $10 \mathrm{CFR}$ 50, Section $50.55 \mathrm{a}$, paragraph (h) for protection systems is not considered adequate if the intention is to assure that the isolators are qualified for worst case, credible fault conditions. In the future, the major fault qualification test should be expanded to test at several levels up to and including the maximum credible potential to ensure that a worst case condition is not missed.

- It should be noted that the reachthrough energies measured during this testing program were considered insignificant, even in the worst case faults. Further, previous qualification tests for the twelve isolator models in this test program were adequate to demonstrate their acceptability as isolators even though all mechanisms were not explored. Consequently, expanded quallfication testing for isolators already installed in nuclear plants is not considered necessary.

- It was observed in three of the five multiple channel isolators that were fault tested, that when the channel under test stopped functioning, all of the other channels in the device were found to have stopped functioning as well, most likely due to the failure of a common power supply. Further investigation is recommended to verify that this was the underlying common cause of these fallures, the potential safety implications of this problem, and the prevalence of this type of design among multiple channel isolation devices used in nuclear power plants.

- Two isolators were found to continue to transmit signals normally from input to output throughout the entire sequence of incremental fault application testing. A review of the design features which contributed to the rupgedness of these devices should be undertaken, to identify the strong points of these designs.

- Environmental stresses and aging can affect isolator subcomponents, such as capacitors, and result in degradation of the electrical characteristics. This could lead to degraded isolator performance, potential loss of isolator function, or degradation of the isolating barrier. An aging study of isolation devices and subcomponents could identify these factors and quantify their effects. 
1. IEEE Std 384-1981, IEEE Standard Criteria for Independence of Class $1 E$ Equipment and Circuits, IEEE, 1981.

2. U.S. Code of Federal Regulations 10CFR50, Section 50.55a, Paragraph (h), Protection Systems. 1992.

3. ANSI/IEEE Std 279-1971, Criteria for Protection Systems for Nudear Power Generating Stations, IERE, 1971.

4. Neilsen, J.R, "Electronic Isolators Used in Safety Systems of U.S. Nuclear Power Plants," NUREG/CR3453, EGG-2444, EG\&G Idaho, Inc., March 1986.

5. Crammond, W.R, et. al., "Risk Assesement of Isolation Devices in Safety Systems," NUREG/CR-5683, Sandia National Laboratories. January 1993.

6. NUREG-0660 WRC Action Plan Developed as a Result of the TMI-2 Accident," Item I.D.2, U.S. NRC. May 1980.

7. NUREG-0737 "Clarification of TMI Action Plan Requirements," Item I.D.2, U.S. NRC. November 1980.

8. Correspondence, J.G.Haynes, Arizona Nuclear Power Project, to G.W.Knighton, U.S. NRC, Response to NRC Safety Parameter Display System (SPDS) Questions, December $19,1986$.

9. Correspondence, E.A.Licitra, U.S. NRC, to E.E. Van Brunt, Jr., Arizona Nuclear Power Project, Evaluation of Safety Parameter Display System for Palo Verde Units 1, 2, and 3, May 5, 1987.
10. NUREG-0933 "A Prioritization of Generic Safety Issues," Generic Issue 142, "Leakage Through Electrical Isolators in Instrumentation Circuits," U.S. NRC. July 1991.

11. "Instructions for Transmation 200, 300, 500,600 , and 900 Series Transmitters, Option \#03: Isolation Input/Output/Power, "I.S. 100603-901, Transmation, Inc., Rochester, New York. August 1981.

12. "Instruction Manual for Model 530T Signal Converter," Addendum 123, Transmation, Inc., Rochester, New York. March 1985.

13. "Operations and Maintenance Manual for Series 300 Encapaulated Analog Isolation Amplifier," EIP-M-300, Revision 4, Halliburton NUS Environmental Corp., Idaho Falls, Idaho. April 1991.

14. Tnstruction Manual for Type 18-119 High Level Isolated Transmitter," No. 990559C, Devar, Inc., Bridgeport, Connecticut. Undated.

15. Tnstruction Manual for SC-1302 Isolated Transmitter," Publication \#1067-598, Rochester Instrument Systems, Rochester, New York. June 1989.

16. 7300 Series Control Systems," Technical Data 21-830, Westinghouse Electric Corp., Pittsburgh, Pennsylvania. September 1976.

17. 7300 Series Isolator and Loop Power Supply (NLP) Card, "NLP-1, Westinghouse Electric Corp., Pittsburgh, Pennsylvania. March 1982. 
18. "SPEC 200 Selsmic Racka and RackMounted Equipment," Product Specifications PSS 9-7A1 A The Foxboro Company, Foxboro, Maseachusetts. 1987.

19. 2AO-VAI Series Voltage-to-Current Converter, 4 to $20 \mathrm{~mA}$ Isolated, Adjurtable," Instruction Manual MI 2AO-130, The Foxtoro Company, Fosboro, Maseachusetts. May 1978.

20. "Custom N-2AO-VAI Voltage-to-

Current Converter Modified to Function as a Voltage-to-Voltage Converter with 0 to 10 Volt Outputs (N-ECEP-9206)," Instruction Manual SI 1-01762, The Fouboro Company, Foxboro, Maseachusetts. April 1981.

21. "Operation, Installation, and Maintenance Manual for the Analog Isolator Card," EIP-M-002, Revision 0, BI Systems, Idaho Falle, Idaho. March 1987.

22. "Remote Carrier Module," Instruction Manual CM249-Q2, Validyne Engineering Corp., Northridge, Callfornia. Auguat 1981.

23. THigh Gain Carrier Demodulator Plug-In Module," CD173-Q2, Validyne Engineering Corp., Northridge, Callfomia. April 1981.
24. Remote Multiplezer Module/Case for Use in the HD310 High Speed Data Acquisition System," Instruction Manual MC170AD-Q2, Validyne Engineering Corp., Northridge, Califomia. July 1981.

25. TEC Model 981-1 Series Digital Signal Isolator," Operation and Maintenance Manual 981-OM-O2, Reviaion 0, Technoloy for Energy Corp., Knoxville, Tennessec. September 1984.

26. TEC Model 159 Digital Simnal Isolator," Operation and Maintenance Manual 159-OM-01, Reviaion 0, Technology for Energy Corp., Knoxville, Tennesece. April 1983.

27. "Operation, Installation, and Maintenance Manual for the Digital Isolator Cards, EIP-M-WO3, Revision O, EI Systems, Idaho Falls, Idaho. March 1987.

28. Whitaker, Jerry C, Maintaining Electronic Systems," Multiscience Press, Inc. (CRC Press, Inc.). Boca Raton, Florida. 1991. 


\section{GLOSSARY}

Coalne Whreform - Waveform used to represent a worst case applied fault in this testing program. It is a basic $60 \mathrm{~Hz}$ sinusoidal that has been chopped electronically such that it is characterized by a rapid leading edge rising transition time from $10 \%$ to $90 \%$ of no more than $50 \mathrm{nS}$ at the $90^{\circ}$ point and no more than $10 \mu \mathrm{S}$ from $90 \%$ down to $10 \%$ on the trailing edge at the $270^{\circ}$ point. The resulting fault waveform looks like the first half cycle of a cosine function (see discussion in Section 3.3 and oscilloscope trace in Figure 3.7).

Device Undar Tent (DUT) - Refers to the electrical isolation device under test in the testing apparatus.

Difita L Multh-Moter (DMMD - Digital test instrument that provides high precision, DC and AC voltage and current measurements and resistance measurements over a wide dynamic range.

Didtul Storre Onellloscope (DSO) - Digital oscilloscope that has the capability to measure, store, record, display, and process fast transient events.

Flectrical I rolntion Device (leolntor) - "A device in a circuit which prevents malfunction in one section of a circuit from causing unacceptable influences in other sections of the circuit or other circuits," (Ref. 1). "A device is considered an electrical isolation device for instrumentation and control circuits if it is applied so that (a) the maximum credible voltage or current transient applied to the device's non-Class 1E side will not degrade the operation of the circuit connected to the device Class IE or associated side below an acceptable level; and (b) shorts, grounds, or open circuits occurring in the nonclass $1 E$ side will not degrade the circuit connected to the device Class 1E or associated side below an acceptable level," (Ref. 1).
Bulf-Cycle Reach-Throush Fneryy - The quantity of reach-through energy measured at the input terminals of an isolation device during the application of a half cycle of sinusoidal fault potential at its output terminals.

Isolntion Bamier - That part of an isolation device which provides the actual electrical isolation between the input and output terminals of the device.

Irolntion Barrier Capacitance - The electrical capacitance of the isolation barrier in an electrical isolation device.

Irolntion Barrier Reintunes - The electrical resistance of the isolation barrier in an electrical isolation device.

Mnmetically Coupled Isolntor - Electrical isolation device that uses a transformer to provide electrical isolation.

Mnior Fonlt Teat - Qualification test to verify that the application of the maximum credible ac or dc potential at the output of the isolation device shall not prevent the associated protection system channel from meeting the minimum performance requirements specified in the design bases (Refs. 2,3).

Morimum Credible Fanlt (MCD) - In this test program, the fault potential, and waveform, applied in the transverse mode to the output terminals of an isolation device at which the maximum reach-through energy is passed across the isolation barrier to the input terminals of the isolation device. In the industry, the MCF is considered application specific, and is the maximum fault potential expected at the output terminals of the isolation device. 


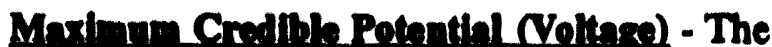
highest credible electrical potential or voltage that an isolation device could be exposed to under fault conditions during its service life. Current methods for qualification testing of isolation devices are based upon the assumption that the maximum credible potential would result in the maximum credible fault; 1.e., maximum credible potential is the same as the MCF potential.

MOSYy -Metal-Oxide-Semiconductor FieldEffect Transistor, an insulated gate field-efiect transistor characterized by its gate electrode which is insulated from the conductive semiconductor channel by a thin layer of an insulating metal oxide. The resulting device typically has an extremely high input impedance, low leakage, and low driving power requirements.

Onterlly Complat Inhter - Electrical isolation device that uses a photo semiconductor, or a photo transmitter and receiver connected by a optical link to provide electrical isolation.

Reach-Jungh Iinery - The energy passed across the isolation barrier of an isolation device, expressed by $\int V(t)^{*} I(t) d t$, and appearing at its input terminals during a fault applied to its output terminals.

Trencere Mode Fnmt: - In this test program, a fault applied in the transverse mode means that it is applied to the output terminals of the icolation device. The input terminals are simultaneously monitored to determine whether any portion of the fault has propagated back through the isolation device to appear at the input terminals. During its normal mode of operation, the isolation device recetves signals at its input terminals and transmits an equivalent signal from its output terminals. 
APPENDIX A

TEST PLAN

$$
\text { A-1 }
$$


BNL Technical Report No. L2158 - 3/93

Revision 1

\title{
A TEST PLAN FOR FAULT TESTING OF
} NUCLEAR POWER PLANT ELECTRONIC ISOLATION DEVICES

\author{
Kurt Hillman and Michael Villaran \\ Engineering and Testing Group \\ Engineering Technology Division \\ Department of Nuclear Energy \\ Brookhaven National Laboratory \\ Upton, New York 11973
}

\section{March 3, 1993}

Prepared for:

U.S. Nuclear Regulatory commission Office of Nuclear Regulatory Commission

Office of Nuclear Regulatory Research

Washington, DC 20555

FIN L-2158

$$
A-3
$$




\begin{abstract}
Described in this report is a proposed test plan for fault testing of electronic isolation devices commoniy used in nuclear power plants. Since 1984, over 700 events involving failures of isolation devices in nuclear power plant service have been reported to the Nuclear Plant Reliability Data System (NPRDS). As plants incorporate more electronic and computerized instrumentation and controls systems, the use of isolation devices is increasing. Proposed control systems for the next generation of advanced reactors will depend heavily upon the use of isolation devices. Earlier testing programs (Reference 2) have indicated some isolation device problems when subjected to a maximum credible fault (MCF). The present test program will investigate whether problems can arise at fault levels up to the MCF, by measuring the fault energy passed through an isolation device, and determining the fault energy levels that can result in damage, degraded performance, or loss of function.
\end{abstract}




\section{CONTENTS}

Page

ABSTRACT $\quad \ldots \ldots \ldots \ldots \ldots \ldots \ldots \ldots \ldots \ldots \ldots \ldots \ldots \ldots \ldots \ldots \ldots$

1. INTRODUCTION ............................ A-9

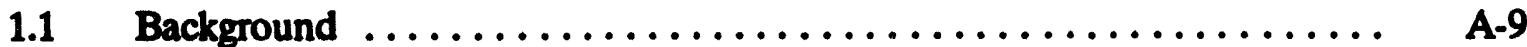

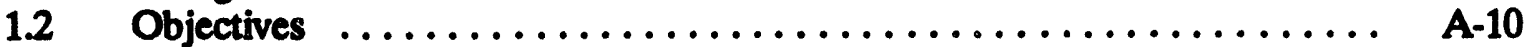

1.3 Isolation Devices to be Tested $\ldots \ldots \ldots \ldots \ldots \ldots \ldots \ldots \ldots \ldots \ldots \ldots$ A-12

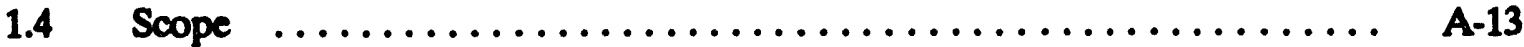

2. TEST SET-UP $\ldots \ldots \ldots \ldots \ldots \ldots \ldots \ldots \ldots \ldots \ldots \ldots \ldots \ldots \ldots \ldots \ldots \ldots$

2.1 Test Equipment List $\ldots \ldots \ldots \ldots \ldots \ldots \ldots \ldots \ldots \ldots \ldots \ldots \ldots \ldots \ldots$

3. TEST PROCEDURE $\ldots \ldots \ldots \ldots \ldots \ldots \ldots \ldots \ldots \ldots \ldots \ldots \ldots \ldots \ldots \ldots$

3.1 Isolation Impedance Measurement . . . . . . . . . . . . . . . A-15

3.1.1 Isolation Barrier Resistance .................... A-16

3.12 Isolation Capacitance $\ldots \ldots \ldots \ldots \ldots \ldots \ldots \ldots \ldots \ldots \ldots \ldots$ A-16

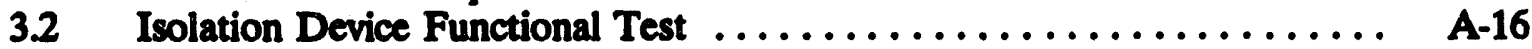

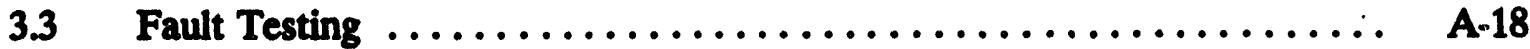

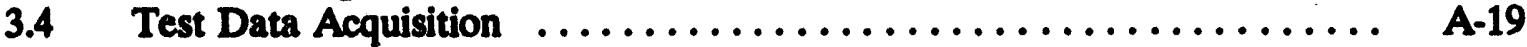

3.5 Miscellaneous .............................. A-19

4. EXPECTED RESULTS $\ldots \ldots \ldots \ldots \ldots \ldots \ldots \ldots \ldots \ldots \ldots \ldots \ldots \ldots \ldots$. . . . . . .

5. REFERENCES $\ldots \ldots \ldots \ldots \ldots \ldots \ldots \ldots \ldots \ldots \ldots \ldots \ldots \ldots \ldots \ldots \ldots$

APPENDIX A - TEST EQUTPMENT AND SOFTWARE . . . . . . . . . . A A-23

APPENDIX B - FAULT TESTING PROCEDURE . . . . . . . . . . . . . . . A-27 


\section{INTRODUCTION}

\subsection{Beckeround}

Isolation devices are used in a nuclear power plant to isolate a safety system from a non-safety or commercial system in such a way that a failure on the non-safety system does not affect operations on the safety system. In particular, the worst kind of failure is a situation where a stressed non-safety circuit causes a direct conductive path to appear between the two sets of ports. There would then be a potential for upsetting the safety system without prior waming, the normal flow of information or data not being affected by this condition.

Figure 1 portrays this situation where there would ideally exist no coupling between the input and output port. Yet the ports are coupled by resistors $R c$ which in an extreme case might be zero (short circuit). The gain "box" may be expected to override the effects of coupling resistors $R c$ so that in the normal course of plant operation involving the transmission of signals from the input to output port there would be no reason to become aware of the (unwanted) coupling. It might be noted that when a coupling path is resistive, the term leakage is sometimes employed to describe the transfer of energy between ports. In what follows below the transfer of energy. will be termed "reach-through," whatever the nature of the coupling path is.

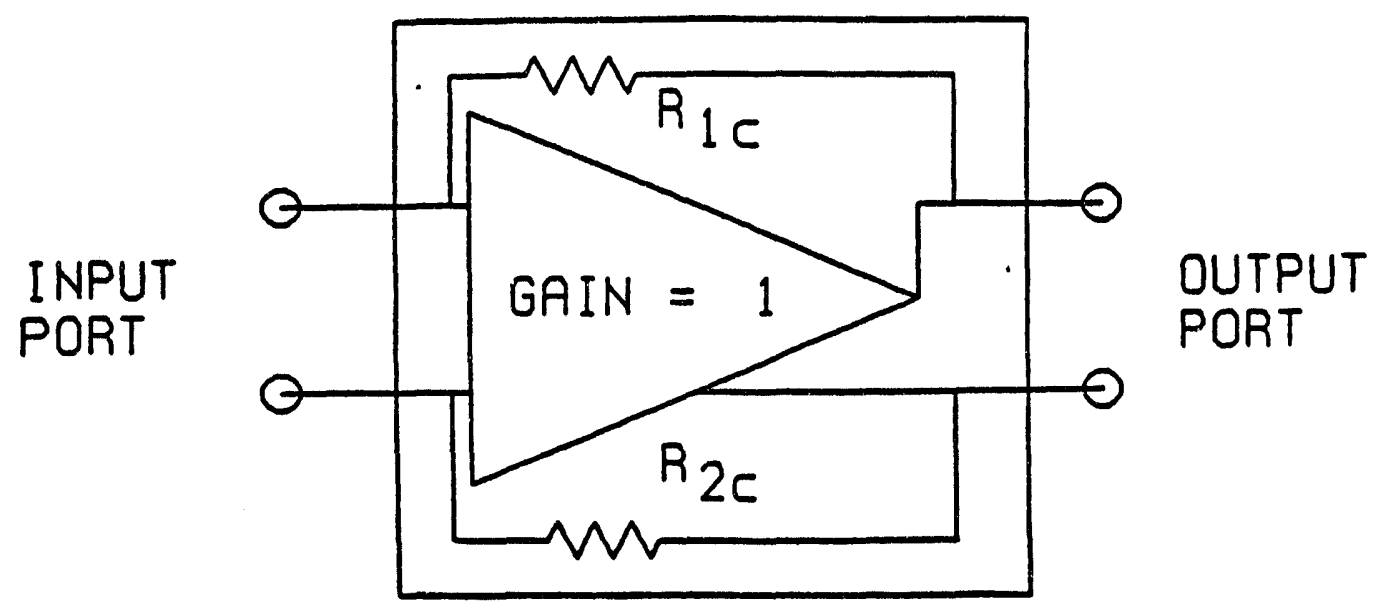

Fizure 1. Non-ideal isolator

Since 1984, more than 700 failures involving electronic isolation devices in nuclear power plant service have been reported to the Nuclear Plant Reliability Data System (NPRDS). The use of electronic isolation devices continues to increase as plants upgrade older equipment and incorporate more electronic and computer-based instrumentation and controls into their operating systems. The proposed control systems for the next generation of advanced nuclear power plants will depend heavily upon the use of isolation devices to achieve the required degree of signal isolation. 
Earlier testing programs (Ref. 1) have indicated that electronic isolation devices may experience severe damage when subjected to the maximum credible AC or DC voltage (Ref. 2) and current levels, particularly when applied to the output side of the energized device. For the testing program in Reference 1, the maximum credible AC voltage was taken to be $120 \mathrm{Vac}, \pm 10 \%, 60 \mathrm{~Hz}, 20 \mathrm{~A}$ source, and the maximum credible DC voltage was taken to be the power supply voltage of the isolator. Concerns have been.raised that similar or more severe problems might be rólized at fault voltages and currents less than maximum credible levels. The actual "reach-through" inergy" passed across the isolation device during the duration of a fault condition, even while not attaining maximum credible voltage potentials, might still be large enough to inflict damage on sensitive electronic components. The maximum credible fault (MCF) for a given isolation device is thus defined as that fault potential at which the maximum reach-through energy is passed across the isolation barrier.

\subsection{Obiectives}

The present testing program will investigate whether such problems can arise at fault levels up to the maximum credible potential, by measuring the reach-through energy passed through several different types of electronic isolation devices during a fault. An increasing, incremental series of fault conditions will be applied to each isolation device, up to the full maximum credible potential level, to determise the relationship between the reach-through energy and the applied fault voltage. The susceptibility to potential damage for various families of electronic components can then be ascertained for applications utilizing the tested isolation devices.

In the testing to be described below, a digitally controlled source of $0-120 \mathrm{Vac}(60 \mathrm{~Hz})$ will be applied to the output side, in an incremental series of steps designed to uncover "blind spots" (Ref. 3), i.e. ranges of fault voltages and currents lower than the "safe" maximum credible potential which in fact may pass through suticient energy to damage the isolation device. As discussed in Reference 3, equipment containing protective devices may perform well at maximum stress (120Vac) and yet not perform as intended at some intermediate level (<120Vac).

While driving the output side with the AC voltage, the input side will be terminated in a nominal resistance, $R x$, of 1000 . The reach-through voltage, $V x$, across the resistance will be monitored and $\int V_{x}(t)^{*} L x(t) * d t$ will be calculated to give the reach-through energy in watt-sec or joules as a function of the applied AC voltage, Vac. This will give a quantitative value to the reach-through energy which can then be related, for example, to published values of lethality in various logic component families. Since it is difficult to characterize all the variations of the "real-world" environment by a single value of input impedance, for the purposes of this testing program, a representative value of input resistance, $R x$, was chosen. The test data thus obtained will allow the plotting of the relation between reach-through energy and applied AC voltage Vac for each isolation device. If these graphs are not monotonic functions but instead show a peak (corresponding to the MCF) at values less than Vac maximum (120V AC), the testing program will be able to identify such potential problem areas.

One such possible graph is sketched in Figure 2. The reach-through energy is shown increasing linearly from zero at a threshold value of THR of 10 Vac. At a value of $\mathrm{Vac}=50 \mathrm{~V}$, the

"reach-through" energy is the integral of the voltage " current " dt at a particular voltage level.

$$
A-10
$$


reach-through energy, $\dot{\varphi}$, picks up more rapidly, reaching a maximum of $90 \mu$ joules at $\mathrm{Vac}=80 \mathrm{~V}$, after which $j$ decreases to $<40$ joules at $140 \mathrm{~V}$. It should be noted that the maximum $j$ (MCF) does not occur at the maximum credible potential of 120 Vac so that the situation portrayed is an example of a blind spot. From Figure 3, which shows the range of damage threshold (in units of energy) for various devices, it will be seen that a medium and high-power transistor suffers damage at a level somewhat $>100 \mu$ joules. In the preceding example, the reach-through eneti of $40+\mu j$ passed actoss the isolation device at the MCP fault level clearly does not indicate hoi close to the threshold of damage this device (had it been deployed) would have come (assuming a value of $R x$ $=10000$ is the appropriate value to be used). Figure 3 shows the energy range (in joules) for damage to a variety of devices. It will be seen that for medium and high-power transistors damage occurs at a level somewhat in excess of 100 mjoules. In the preceding illustrative example, at the maximum credible potential of $120 \mathrm{Vac}$, the amount of reach-through is well below this, yet the margin of safety at the peak value of 90 pjoules is very slim.

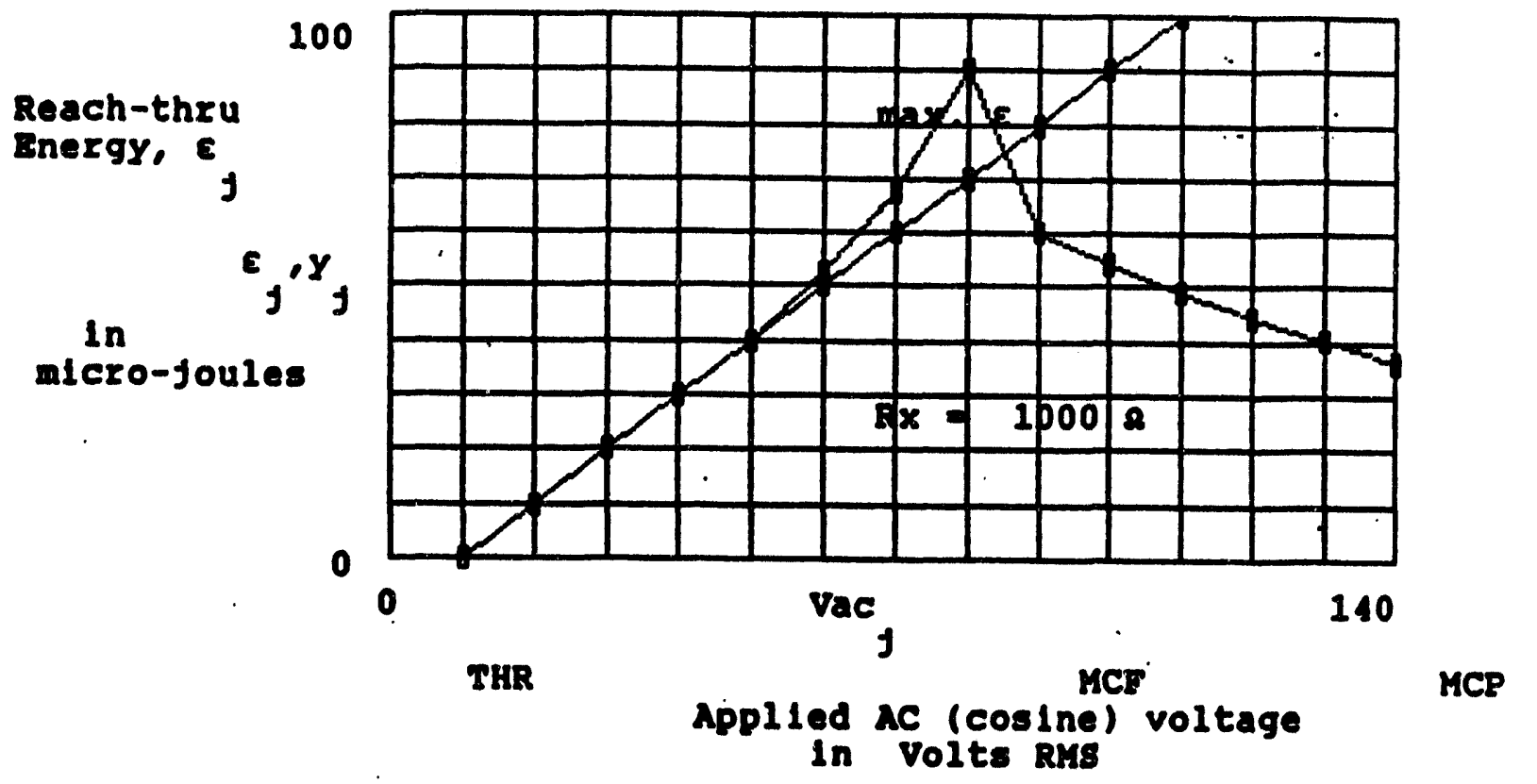

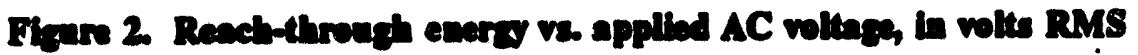

Isolators may be divided into four generic groups, as discussed in Reference 1. These are:

1. Fiber optic devices

2. Devices using transformer modulation and having voltage inputs and outputs

3. Same as 2 above, except outputs are current

4. Isolators using photo-semiconductors to achieve isolations.

One or more of the most widely used nuclear power plant electronic isolation devices from each group will be included in the test program. 


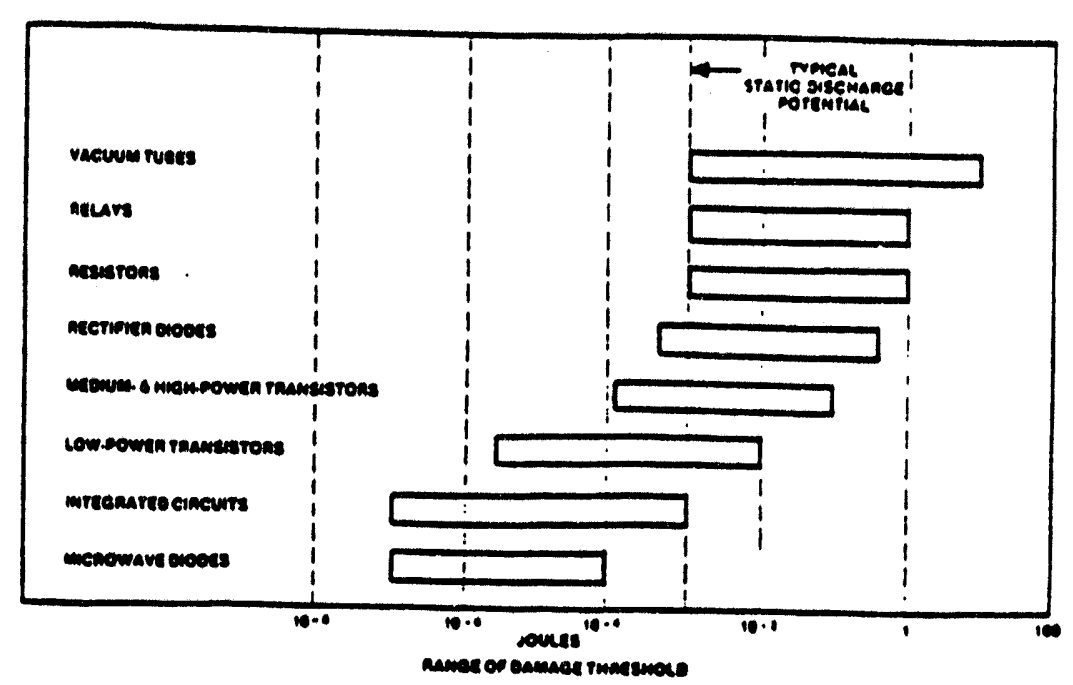

Figure 3. Range of damage threshold for electronic devices

\subsection{Isolation Devices to be Tested}

The isolation devices to be tested in this program will include a group of approximately ten different models that are representative of the equipment utilized in nuclear power stations. Surveys of the Nuclear Plant Reliability Data System (NPRDS) were conducted to gather the necessary background information such as manufacturers, model numbers, and operating and application data. Over 700 reports of isolation device failures were identified, categorized, and reviewed to aid in the selection process. The isolation devices tested previously in the NUREG/CR-3453 (Ref. 1) testing program were aiso taken into consideration.

The present fault testing program for isolation devices will include equipment from the following manufacturers:

Devar Inc.

Foxboro

NUS Corporation (formerly Energy, Inc.)

Rochester Instrument Systems

Technology for Energy Corp.

Transmation Inc.

Validyne Engineering Corp.

Westinghouse

The test sample of isolation devices will include at least one device from each of the four generic groups identified in Section 1.2 above and Reference 1. The equipment tested will represent the devices and model numbers most frequently identified in isolation device failures reported to the NPRDS data base from 1974 through mid-1991. The final selection of the test sample will be subject to the availability of the specific models which BNL intends to procure, since some of the devices may no longer be available. 


\section{$1.4 \operatorname{Sen}$}

The object of this testing program is to investigate and understand the amount of "reach-through" energy passed through various kinds of isolation devices using AC voltage as the disturbing factor (120 V ms max, 60Hz) with proper attention to "blind spots," as defined previously in Section 1.2.

The testing will be under the control of a PC in communication with the AC source and various recording devices. The IEEE 488 Standard Bus under control of the PC using National Instruments NI-488.2 software and Microsoft Quick BASIC software will be used to operate the instrumentation and record pertinent data on floppy disk data files.

It should be noted that the maximum credible potential assumed is the (mis)application of an AC voltage to the output side at $120 \mathrm{~V}$ ms. This testing program shall determine useful information on the reliability and robustness of isolation devices at much lower levels of disturbance than the MCF (120V ms AC max, 20A max). The present testing will bulld upon the earlier results of major fault testing described in Reference 1 , and investigate areas not covered in the previous work, in order to quantify the relationship between Vac applied to the isolation device output, and reach-through energy. The information gained will enhance the knowledge about the performance of electronic isolation devices. The final report will seek to relate the test results to those of Reference 1.

It will also be noted that fault application to the isolator output is required by IEEE Sted 279-1971 (Ref. 2) Section 4.7.2. Criterion 24 of 10 CFR SO, Appendix A (Ref. 6) also requires "that failure of equipment common to protection and control (i.e. isolators) leaves intact a system satiafying all reliability ... requirements of the protection system and requires that safety not be impaired..." We shall therefore be concerned with the lethality of the reach-through enerty upon equipment on the safety side of the isolation device and whether such destructiveness occurs at Vac max or a lesser value.

Useful test results should facilitate the in-house surveillance teating of isolation devices at various nuclear plants without requiring expensive surge simulation equipment.

In case of destructive fallure, a physical inspection of the isolation device together with clues from the testing data should pinpoint the exact causes of the destruction. In fact, care will be taken prior to the testing of each specific device under test to anticipate (as far as possible) destructive levels of Vac from studies of the schematic and other vendor information and coordinate this information with test abort programming. (For example, "crowbars," "clamps," and the like will be factored into account).

\section{TEST SET-UP}

The basic test set-up is shown in Figure 4. Program control is provided by National Instruments NI-488.2 software and Microsoft Quick BASIC software running an IBM PC or 100\% compatible IBM PC clone. An IEEE-488 interface provides for control of the POWERTRON Model 3000S AC amplifier, HP3325 Synthesizer, Keithley Model 2001 DMM, SRS DS345 Synthesizer, and Lecroy Model 9314M DSO. Some technical details of the teat equipment and software are shown in Appendix A. It should be noted that the AC voltage can be either a sine or 
cosine wave (or something in-between) when it is applied to the device under test (DUT). In the latter case, the time duration of the trans int between 0 and Vpeak will be no worse than 50 nS. The number of fault pulses to be applied to the DUT can be selected from the programmable trigger to be one and only one per event up to 99 tault pulses per event. The programmable divider is used - to select the delay between pulses (the duty cycle) in multiple fault pulse events (e.g., by setting the programmable divider to 5 and selecting 3 fault pulses on the programmable triggt, three cosine fault pulses will be applied to the DUT at an interval of one fault pulse every -tifh cycle). The standard generator includes a provision to switch the unit automatically at a predetermined load current from the constant voltage mode into a constant current mode (20A max).

The rapidity of the starting edge of a cosine wave can be expected to add to the reach-through current through the otriputinput capacitance by three orders of magnitude or more, by virtue of the ratio of rate of change of voltage (for the same peak amplitude) for the cosine wave as compared to a sine wave. For this reason, the cosine wave produces more testing stress in the DUT, and the results thus obtained represent the upper bound of the worst case fault conditions that will be experienced at each level.

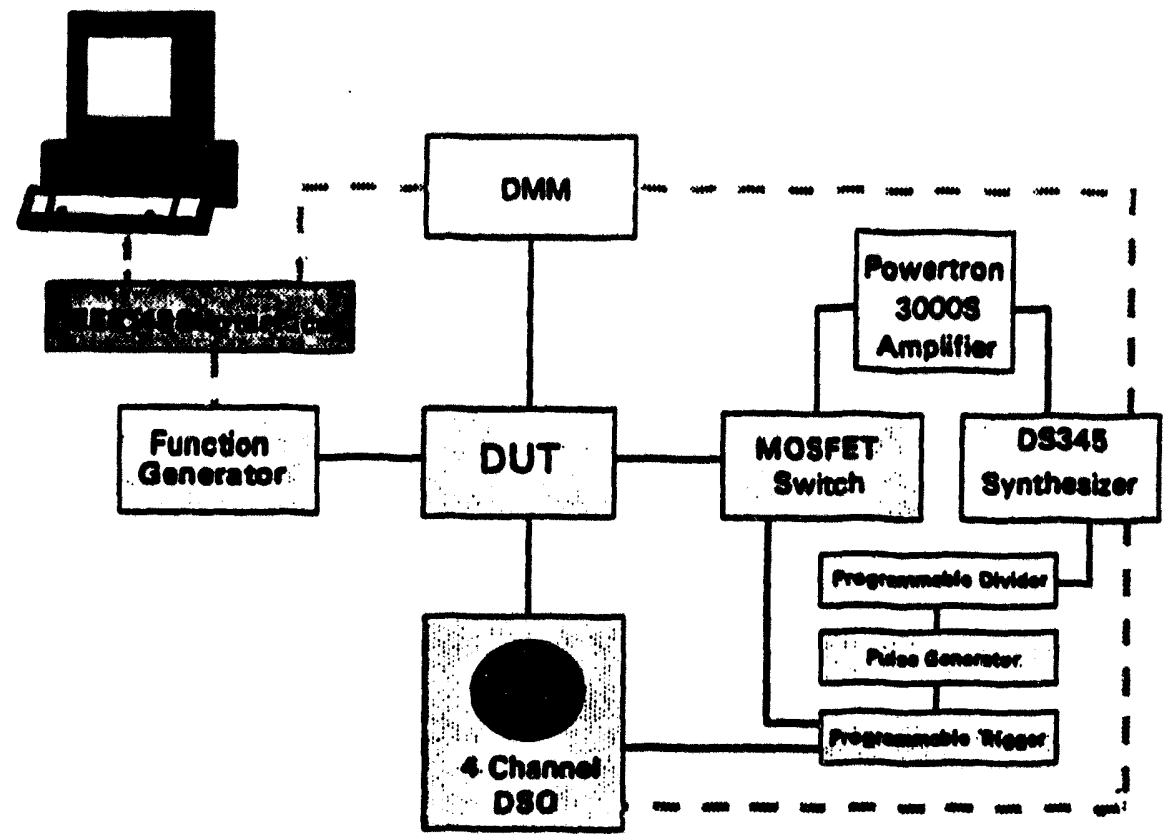

Pigure 4. Back teat selpop

As described above, the AC source can be programmed in time duration from fractional cycles to many cycles. It is proposed to run most interference teats using hall-cycles of non-contiguous cosine waves of different amplitudes to cover the requirement of blind spot teating. It may be seen that the possibility of avoiding DUT destruction exists by aborting the teat when high input currents from the AC source are starting to be sensed, or limiting applied faules to a single half cycle burst thereby minimizing the danger of destroying a DUT while still achieving the objective of measuring enera passed through the isolation barrier. 


\subsection{Ter Faniomanturs}

The test equipment to be used for this test program is listed below. Detalls and specifications of the more speclalized equipment and software are included in Appendix A.

Tent Dquipenent

Powertron, 3 KVA source, single $\phi$

MOSFET Power Switch/Controller

IEEE-488 Interface Board w/connecting cables

Synthesized Function Generator

Pulse Generator

High Performance Digital Mult Meter

IBM PC/AT or better

5-Decade Programmable Divider

Programmable Pulse Triger

4-Channel Digital Storage Oselloscope

MicroSot Quick BASTC Soltware Verion 4.5

IEEE 488 Bus Language Interfoce and Device

Drivers for MS-DOS

Current Transformer

Syntheatzer/Function Generntor
Mic. 2 Model No. (where avallible)

Model 3000S, Industrial Test

Equipment Co., Inc.

Custom Deaign, Industrial Test

Equipment Co., Inc.

National Instruments MC-GPIB

Stanford Research Systems Model DS345

Interstate Electronics Corp..Model P12

Keithley Model 2001 DMaM w/10-channel

scanner card

IBM PSR Model S5X

Custom Dedign, BNL

Custom Dedign, BNL

LeCroy Model 9314 M-MC01/04

w/Options WP01/02 and Triget Out

Provision

Merosot Corp.

National Instruments NI-488.2 for MS-

DOS Sotumare

Pearcon Electronics Inc. Model 110A

Hewiett-Packard Model 3325A

\section{TUST PROCDOURE}

In this section, each of the major sequential test segments will be discuseed.

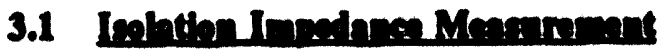

Prior to the application of tautt waveforms, it is desirable to establish the value of the baseline electrical characteristics of the icolation barrier. Changes in the integrity of the isolation barrier due to subsequent application of fault waveforms may be reflected in corresponding changes in the electrical characteristics of the isolation barrier. This is done by obtaining measurementa of the isolation barrier resistance and capacitance as described in the following sections. 


\subsubsection{Isolation Barrior Resibtance}

The configuration for this teat segment is shown in Figure S. Direct measurement of the isolation barrier realstance using a multimeter is impractical due to the high value encountered ( $>$ $1 \mathrm{GO}$ generally). In the method shown in Figure S, a large sampling resistor $(10 \mathrm{M} \mathrm{O})$ is placed in series with the positive input terminal of the isolator. A known de voltage is then applied across the series combination of the sampling reaistor and the isolation barrier resistance. The voltage drop $\left(V_{s}\right)$ is messured across the known sampling resistor to find the current $\left(I_{D}\right)$ towing through the circuit. The de resistance of the isolation barrier may then be calculated from the current $\left(I_{m}\right)$ and voltage drop $\left(V_{b}\right)$ ecroses the isolator.

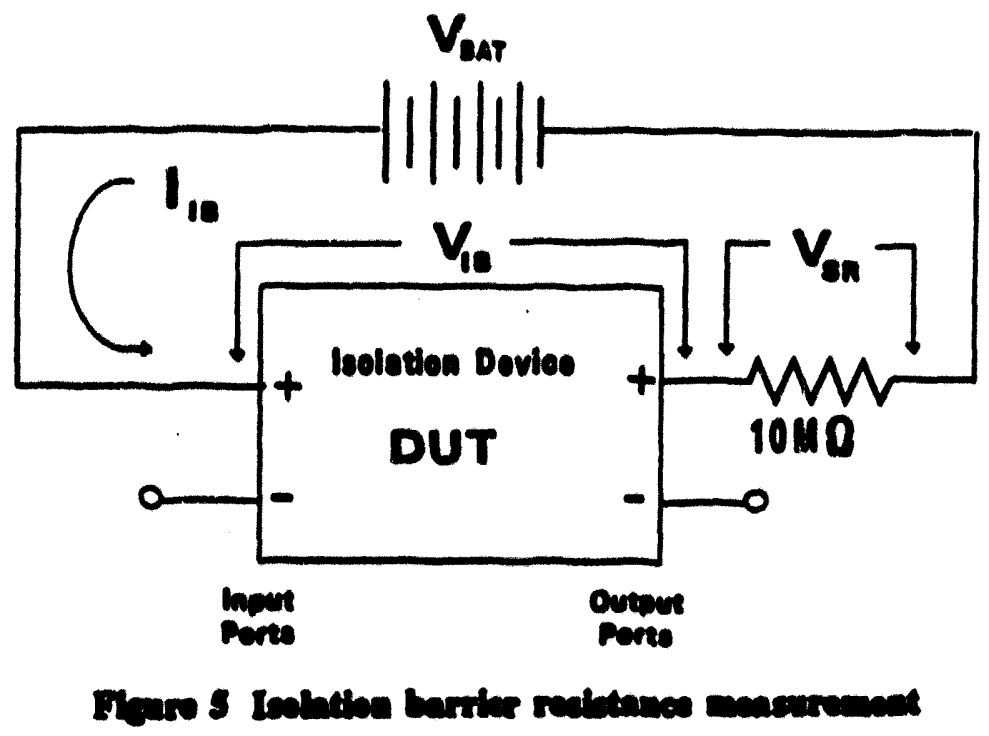

\subsection{Inolation Copactunese}

The capacitive coupling seross the isolation dovice is the primary means by which energy may be tranterred seross the iolation barrier. This isolation capadence my be measured by the test configuration shown in Fizure 6. The tunction generntor is set to apply a low voltage (< SV mas) sinusoidal, wavetorm of known trequency scross the posttwe terminals of the isolation device. The current $\left(I_{n}\right)$ towing across the isolation barrier is measured on the DMM. Isolation capacitance $\left(C_{D}\right)$ may then be calculited as:

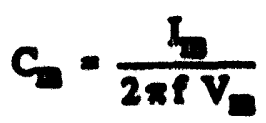

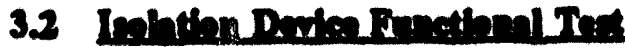

Prior to the applicution of Eult waveforms, the functional performance of the isolation device must be veritled. This is achleved by applying simals to the input of the energised isolation device and measuring the corresponding output signal transmitted throughout the device. 


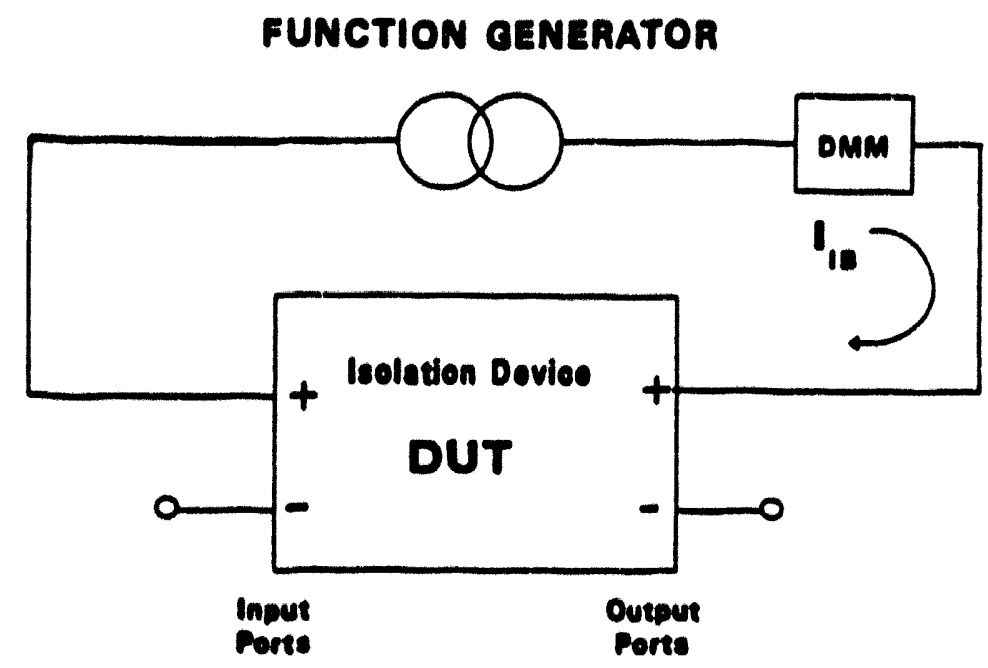

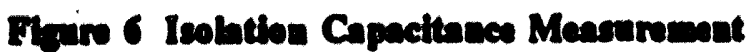

The basic functional tese contiguration for analog or digttal voltage-to-voltage isolators is shown in Figure 7. With the isolator powered, analog input signals may be applied at three levels (zero, midpoint, full span) or tive levels (zero, 25\%, 50\%, 75\%, and tull span) of the specibed device input range, and the correspondins outputs measured on a DMM as shown in the tgure. For digity devices, the technique is the sumic eweept only two levels need be checked: the didtal low and difital hich.

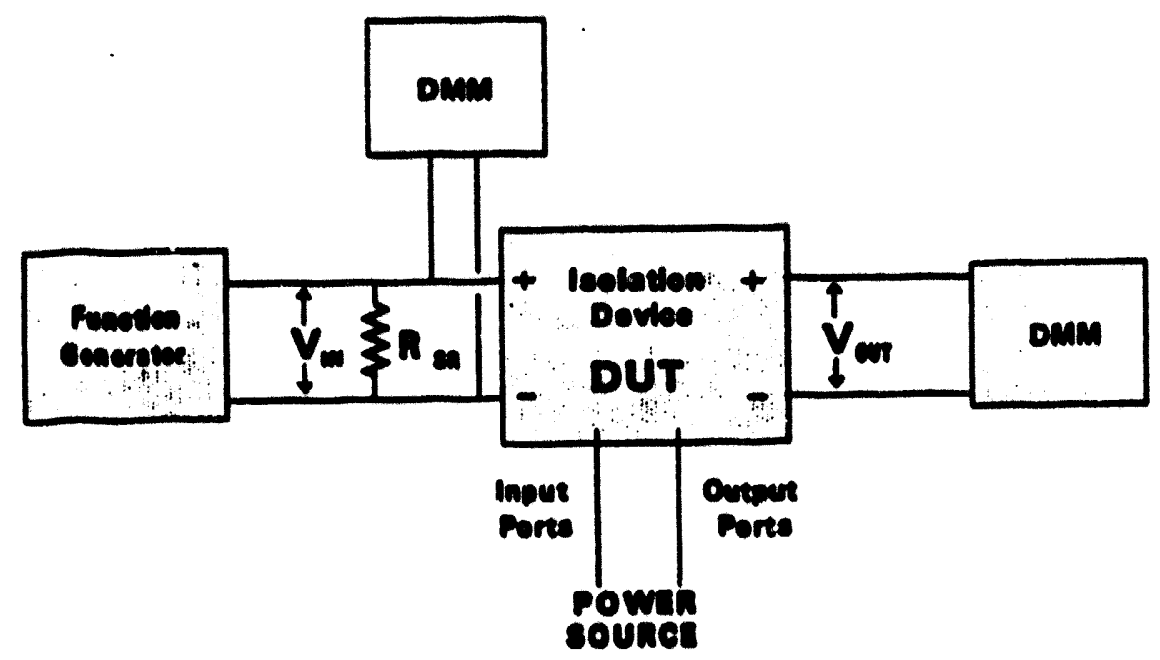

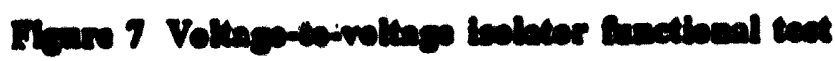

In the case of current-10-current isolatore, the tunctional test arrangement is as shown in Figure 8 . An adjustable de power supply is used to supply known currents at three or tive levelh, trom zero (typically $4 \mathrm{ma}$ ) to full span (20 ma), to the input terminals of the powered isolation device. The input current may be measured directly with a DMM or as shown in the tgure using 
a series $1 \mathrm{KO}$ simpling resistor at the input and measuring the voltage drop across the resistor with a DMM. The output of the device is connected across a load resistor $\mathbf{R}$, of the magnitude specified by the manufecturer. Output current is measured on the DMM by the voltage drop through the load resistor $\mathbf{R}_{\mathbf{L}}$.

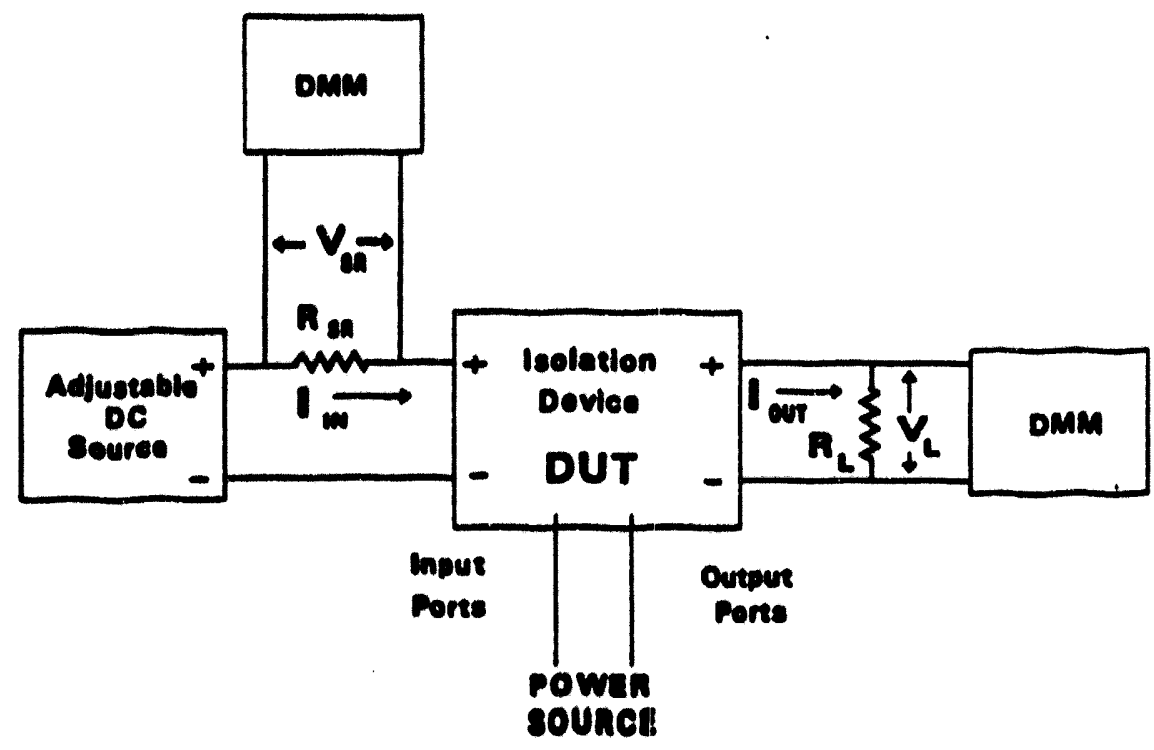

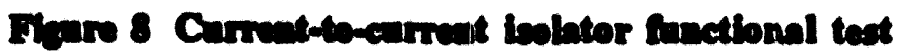

\subsection{Bulle Trethe}

In this teat segment, as shown in Figure 9, the AC fault voltage will be applied to the output terminals of the energised icolation device in the form of a single, half-cycle, cosine waveform and in amplitude steps of $10 \%$ of maximum (120V ms) ranging from 0 to $110 \%$ with the input terminated in a reaistance, Rx. The applied AC voltage starts at zero and slews rapidly to the maximum, continues for a half cycle and then slews rapidly from a negative maximum to zero. For maximum stress, the transition time should be as short as possible. For the fault pulse generator described in Section 2, the typical transition time is no more than $50 \mathrm{nS}$ for a $10 \%$ to $90 \%$ rise on the leading edge and $10 \mu \mathrm{s}$ from $90 \%$ to $10 \%$ on the trilling edge. The AC voltage is applied in this form since it is expected that the isolation devices to be tested employ solid-state devices. This implies that whatever is to be measured will occur with a time-scale of microseconds, or perhaps milliseconds.

The input current will be monitored and recorded at each incremental step as will the output (If any) acroas the input resistor, Rox. From this, reach-through energy will be calculated (the integral of $\left[V_{x}(t)\right]^{+}\left[V_{x}(t) / i x\right]^{\top} d t$ at each amplitude step).

Upon completion of each incremental test segment, the isolation impedance will be tested as described in Section 3.1. and a functional test performed as described in Section 3.2. 


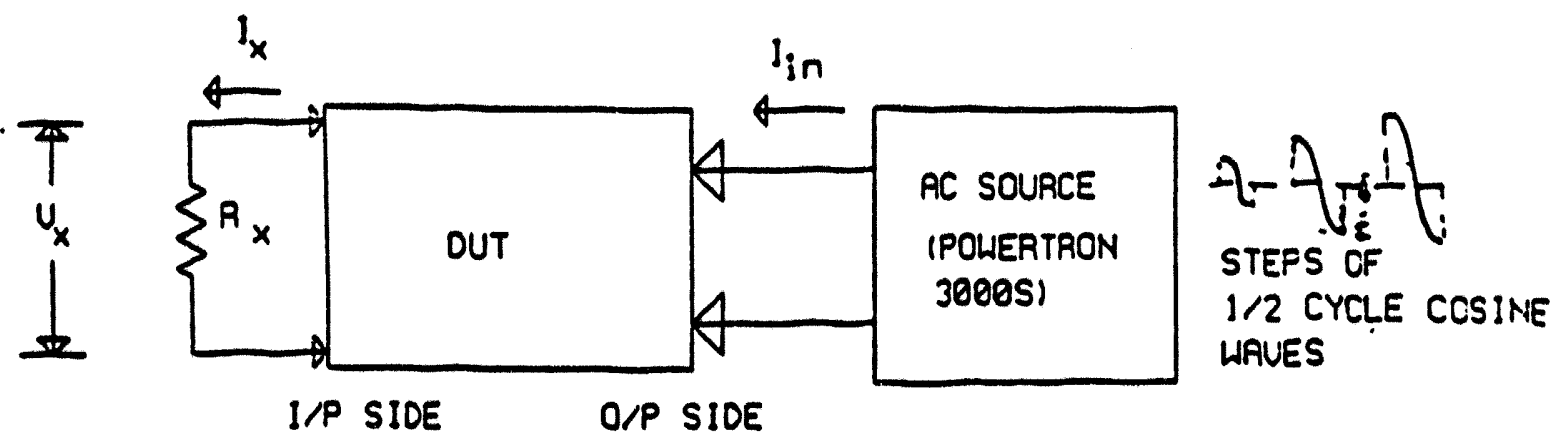

Fupres Isolator increscental taulk teating

Finally, a graph of reach-through energy vs AC voltage amplitude will be produced. A plot of input current as a function of Vac will also be made.

By comparing the responses at the front and back AC transitions at each amplitude step as well as between amplitude steps some conclusions should be possible as to linearity of response as well as sensitivity to polarity of applied AC signal. A rapid increase in input current (to the output port) with AC voltage may signal, in the absence of device protective elements such as crowbars, clamps, etc, close prosimity to the level of device destruction.

\subsection{Tert Dandentintion.}

Performance of tex segments is conducted under control of the PC. Consequently, the collection of the datn from each test level will likewise be controlled through the IEEE 488 bus by the interfecing sofware, vis the preprogrammed sequence commands. Data will be stored on foppy disles for later display and andyais.

\subsection{Misollamen}

It should be noted that moat tests, where a choice logically erists, will be performed with power on to the equipment under teat.

\section{ENPJCLDD RESULTS}

The results from this teat program will identify and characteribe the following

4.1 Physionl Inspection - At the end of the various automated test segments, physical inspection of the device under test will be made to identily any damaged components (ach as iou or burned resistors, peeling circuit boand traces, etc) and relate them to appropriate test data and test conditions to pinpoint specific problems and weaknesses. Where necessary the teating will be stopped and such parts will be replaced or repaired to return the DUT to normal conditions and then the teating will continue. 
4.2 Analysis of Test and Monitoring Data - Each device will be characterized by a maximum reach-through energy number and applied $\mathrm{AC}$ voltage (sine or cosine amplitude), and impedance level ( $R x$ required to produce it. Also furnished will be the linear response range since it is likely that from this, a judgement of how close to destruction the device came, can be made.

4.3 Recommendations for the Improvement of Plant Maintenance and Surveillance Procedures for Isolation Devices - Certain procedures and results from the test program will be examined for application to the plant as isolation device surveillance testing. An example might be the isolation impedance test described in Section 3.1.

4.4 Analysis of Circuit Design - Where possible study of the device circuitry and schematic will be made to correlate observed performance with results obtained. Also, where possible, the results will be correlated with those of Reference 1 .

\section{REFERENCES}

1. John R. Nielsen, Electronic Isolators Used in Safety Systems of U.S. Nuclear Power Plants, NUREG/CR-3453, EGG2444, EG\&G Idaho, Inc. March 1986.

2. ANSI/IEEE Std. 279-1971, IEEE Standard Criteria for Protection Systems for Nuclear Power Generating Stations, IEEE, New York, 1971.

3. ANSI/IEEE Std. C62.45-1987, IEEE Guide on Surge Testing for Equipment Connected to Low-Voltage AC Power Circuits, IEEE, New York, 1987.

4. IEEE Std. C62.36-1991, IEEE Standard Test Methods for Surge Protectors Used in LowVoltage Data, Communications, and Signaling Circuits, IEEE, New York, February 1992.

5. 10 CFR Part 50, U.S. Nuclear Regulatory Commission, Appendix A General Design Criteria for Nuclear Power Plants, U.S. Code of Federal Regulations.

6. Powertron Industrial Test Equipment Co., Inc., AC Power Catalog. Powertron Industrial Test Equipment Co., Inc. 21 Yennicock Ave., Port Washington, NY 11050. Undated.

7. LeCroy Model 9314 Portable Digital Oscilloscopes Product Bulletin. LeCroy Corp., Chestnut Ridge, NY 10977, April 1992.

8. Keithley Instruments Model 2001 DMM Product Bulletin No. 1535, 19275 KEP. Keithley Instruments, Cleveland, Ohio 44139. 1991.

9. Pearson Model 110 Current Monitor Product Bulletin. Pearson Electronics, Inc., Palo Alto, CA. 1990.

10. National Instruments MC-GPIB IEEE 488 interface for IBM PS/2 and NI-488.2 for DOS driver software, National Instruments 1993 Catalog, pp 2-25 to 2-28. National Instruments, Austin, TX 1993. 
11: Stanford Research Systems Model DS345 Instruction Manual, Rev. 1.2, Stanford Research Systems, Sunnyvale, CA. 1991.

12. Hewlett Packard Model 3325A Product Description, 1986 Hewlett Packard Catalog, Pp 452 \& 453. Hewlett-Packard Co., Palo Alto, CA 1986.

13. Whitaker, Jerry C.s "Maintaining Electronic Systems," pp 100-101. CRC Press, Boca Raton, Florida, 1991. 
TEST PIAN APRENDIX A

Test Equipment and software

A-23 
AMPLIFIERS - SERIES 1000S, 1500S, 2000S, 3000 S

\section{GENERAL SPECIFICATIONS}

Output Circuit: Single phase isolated (Ground terminal is provided for optional grounding of output.)

Load Power Factor: 0.7 Lead through $0.7 \mathrm{Lag}$ for full power. Useable to 0.2 at reduced power.

Output Voltage Range: 0-130 V RMS. (An output connector provided at the rear of the unit may readily be reconnected to provide optimum power output at other voltages. Ranges available are: $0-300 \mathrm{~V} *, 0-260 \mathrm{~V} * 0-150 \mathrm{~V}, 0-140 \mathrm{~V}$. $0.130 \mathrm{~V}, 0.76 \mathrm{~V}, 0.65 \mathrm{~V} .1$

- With internal strapping

Output Distortion: $0.5 \%$ mid band.

Load Regulation: Factory set to $\pm 0.5 \%$ mid band. (A control is provided for zero regulation adjustment over most of the frequency range)

Line Regulation: $\pm 0.1 \%$ for $=5 \%$ line change.

Transieat Respouse: 50 microseconds.

Hum Level: $70 \mathrm{db}$ approx below rated output voltage.

Short Circuit Protection: Output may be shorted indefinitely without damage to unit

Thermal Overload Protection: Output transistors - protected by thermal cutout circuit.

External Amplifier Input: An input cornector is provided on the rear of the unit when it is desired to drive the amplifier from an external source. Model XA-1 plug-in module is required for this mode of operation.

Exterinal Sync Input: An input connector is provided at the rear when it is desired to synchronize the plug-in oscillator with an external frequency
source.

Convenience Outlets: An auxiliary power outlet, controlled by the power switch, is provided at the rear of the unit. This permits single control operation of one or two additional amplifiers when $2 \phi$ or $3 \phi$ outputs are required.

Meter: A voltmeter with range of $0.150 \mathrm{~V} R M S$ is provided to monitor the output voltage. When used on higher output voltage, meter reads $1 / 2$ voltage.

Loput Power: 208 V RMS line to line. 36. $50-60 \mathrm{~Hz}$. Also available $190 \mathrm{~V}$ RMS. $225 \mathrm{~V}$ RMS, $240 \mathrm{~V}$ RMS. 380 V RMS. 450 VRMS.

Ambieat Temperature Range: $0^{\circ} \mathrm{C}$ to $50^{\circ} \mathrm{C}$

\begin{tabular}{|c|c|}
\hline $\begin{array}{l}\text { MODEL 1000S } \\
\text { Output Power: } \\
\text { IKVA } \\
\text { Freg. Ranye: } \\
45 \mathrm{~Hz} \text {. } \\
5 \mathrm{KHz} \text { (full } \\
\text { power) } \\
20 \mathrm{HZ}-10 \mathrm{KHz} \text { (reduced Power) } \\
\text { Size: } 121^{\prime \prime} \times 19^{\prime \prime} \text { rack panel } \times 22^{\prime \prime} \text { deep } \\
\text { Weight: } 210 \mathrm{lbs} \text {. }\end{array}$ & • \\
\hline $\begin{array}{l}\text { MODEL } 1500 S \\
\text { Output Power: } \\
\text { 1.5 KVA } \\
\text { Freg. Range: } \\
45 \mathrm{~Hz}- \\
5 \mathrm{KHz} \text { (full } \\
\text { power) } \\
20 \mathrm{~Hz}-10 \mathrm{KHz} \text { (reduced power) } \\
\text { Size: } 12 \mathrm{~K}_{4}^{\prime \prime} \mathrm{X} 19^{\prime \prime} \text { rack panel } \times 22^{\prime \prime} \text { deep } \\
\text { Weight: } 225 \mathrm{lbs} \text {. }\end{array}$ & \\
\hline MODEL 20005 & . \\
\hline $\begin{array}{l}\text { Output Power: } \\
2 \mathrm{KVA} \\
\text { Freg. Range: } \\
45 \mathrm{KL}_{2} \text {. } \\
5 \mathrm{KHz} \text { (full } \\
\text { power) } \\
20 \mathrm{~Hz} \text { to } 10 \mathrm{KHz} \text { (reducéd power) } \\
\text { Size: } 17 \mathrm{~K}_{2}^{\prime \prime} \times 19^{\prime \prime} \text { rack panel x } 22^{\prime \prime} \text { deep } \\
\text { Weight: } 250 \mathrm{lbs} \text {. }\end{array}$ & a \\
\hline MODEL $3000 S$ & - \\
\hline $\begin{array}{l}\text { Output Power: } \\
3 \mathrm{KVA} \\
\text { Freg. Range: } \\
45 \mathrm{~Hz}- \\
5 \mathrm{KH} \text { (full } \\
\text { power) } \\
20 \mathrm{~Hz}-10 \mathrm{KHz} \text { (reduced power) } \\
\text { Size: } 17 \mathrm{1} \mathrm{K}^{\prime \prime} \times 19^{\prime \prime} \text { rack panel } \times 22^{\prime \prime} \text { deep } \\
\text { Weight: } 260 \mathrm{lbs} \text {. }\end{array}$ & 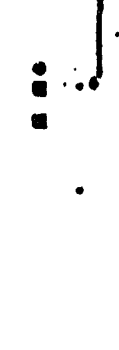 \\
\hline
\end{tabular}

Printed with permission of Industrial Test Equipment $C O$. 


\section{MODEL 5700 BCD, IEEE BUS PROGRAMMER}

- The AC Power Programmer 5700 is used in conjunction with the various $A C$ power amplifiers to provide precisely controlled frequency, amplitude. and phase angle displacement. The programmer includes the capability for 3 modes of control, by front panel $B C D$ thumbwheel switches. by remote $B C D$ signals, or by remote IEEE 488 GPIB. The modular construction of the programmer allows the user to purchase only the modules required for the application, and to expand the system as required. Thus, a single-phase application would require only a frequency module, and an amplitude module. a twophase application requires a frequency module, two amplitude modules, and a phase shift module, and a three-phase system requires the full compliment of frequency module three amplitude modules, and two phase shift modules. Remote programming is also optional and expandable in that separate modular plug-ins are available for remote $B C D$, or IEEE operation.

The digital techniques employed in the frequency and phase modules of the programmer insure pre-

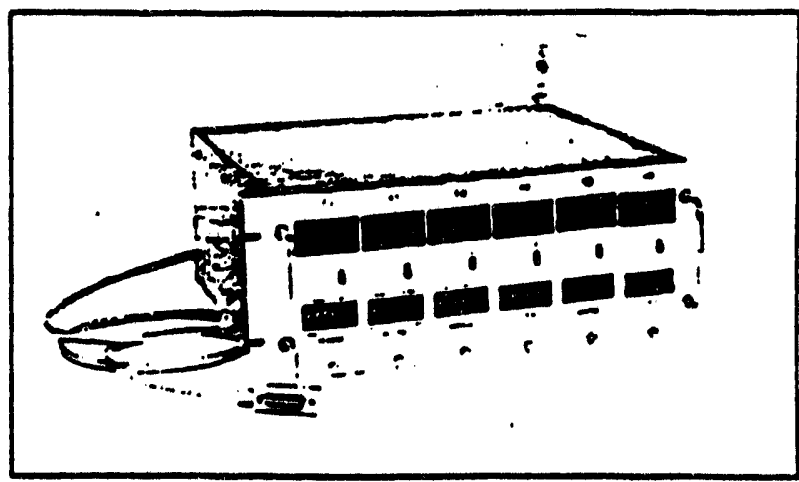

cise control of these functions: The amplitude modules provide servo loop control of the respective output amplifiers insuring precise amplitude stability and control. Local or remote programming for each function is selected by a front panel switch. Remote programming status is displayed on LED indicators of the respective control modules.

The mainframe contains the support components of this building block system: The DC power supply, the "mother board," and the cabinetry. The appropriate plug-ins can be added as needed.

In order to identify the programmer correctly, use the ordering designations shown in the example below:

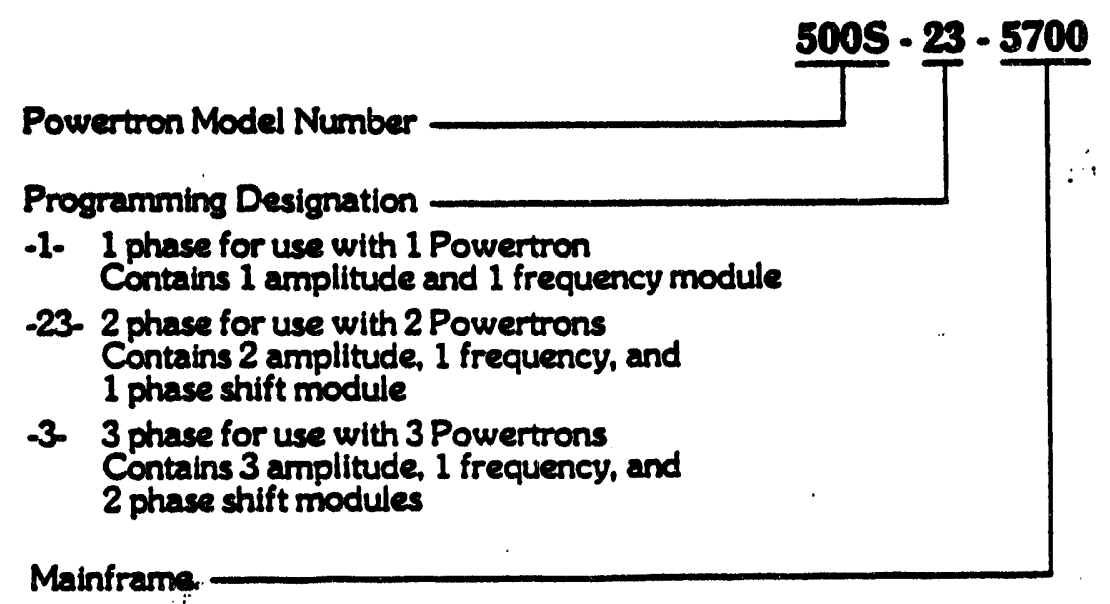

Special options to meet specific requirements are available. Please prepare a specification and consult the factory for details. 


\section{PROGRAMMABLE OSCILLATOR MODULES}

\section{SPECIFCATIONS}

\section{FREQUENCY CONTROL MODUIE}

The frequency control module provides 3 programmable ranges with provisions for locking out any range. Frequency accuracy is $\pm .005 \%$ as determined by intemal crystal reference oscillator.

Rangea: $40.00 \mathrm{~Hz}$ to $99.99 \mathrm{~Hz}$ in $.01 \mathrm{~Hz}$ steps $40.0 \mathrm{~Hz}$ to $999.9 \mathrm{~Hz}$ in. $1 \mathrm{~Hz}$ steps $40 \mathrm{~Hz}$ to $9999 \mathrm{~Hz}$ in $1 \mathrm{~Hz}$ steps

Distortion: Less than 1\%

\section{AMPLITUDE CONTROL MODULE}

The amplitude control module provides 2 ranges with provision for range programming when used with appropriately modified amplifiers. Independent or stmultaneous programming capability is provided for polyphase applications.

Ranges: 0-130 volts RMS or 0-260 volts RMS

Resolution: 0.1 volt steps

Load Requlation: $\pm .01 \%$

Line Regulation: $\pm .01 \%$

\section{PHASE SAIIFT CONTROL MODUIE}

The phace shift control module provides precies digh th phace control over the frupuiney rerios of the

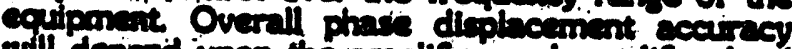
will depard upon the amplifice and aniplifier load symutury.

Rendic ov 399 degreas i: . A

Resolution: 1 degree steps

Accuracy: \pm 0.1 degrees

\section{IEEE BUS INTERFACE MODURE}

The IEEE bus module is interchangeable with the BCD interface module and is readily installed by simply plugging in at the rear of the equipment. The GPIB interface comector is included on the module. The module is microprocessor controlled with programming codes residing in PROM. This arrangement allows for modifications to meet special user requirements. Automatic diagnostics are provided to indicate incorrect character prefix, incorrect place incorrect digit, incorrect function and too low frequency. Error lights and audible alarm indicate fault.

\section{BCD INTERFACE MODULE}

The BCD interface module is interchangeable with the IEEE bus module and is readily installed by simply plugging in at the rear of the equipment.

Appropriate interface connectors are included on the modules. The input is TTL compatible.

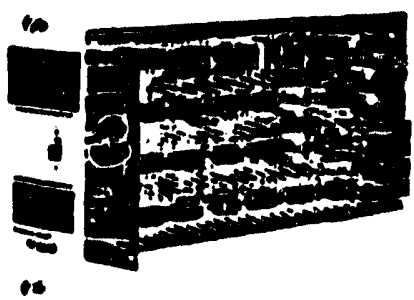

FREQUENCY CONTROL MOOURE

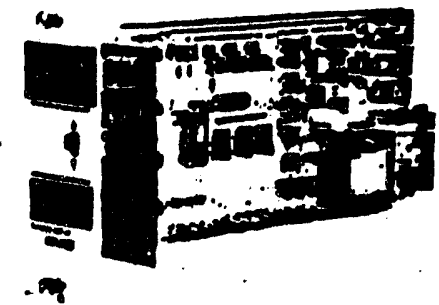

AMPUIUDE CONIROL mover

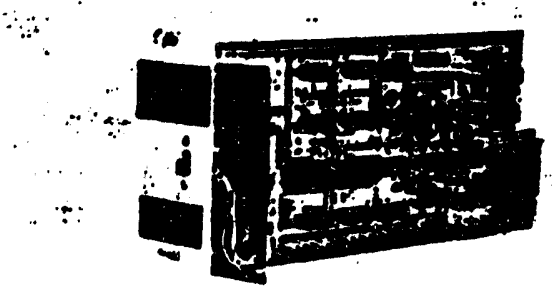

a)

PHASE SHIFT CONTROL MODULE

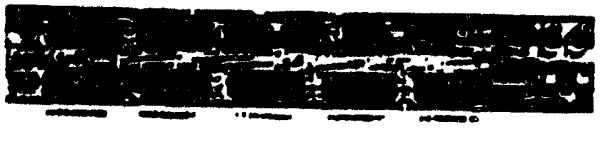

IEEE BUS INTERFACE MOOULE

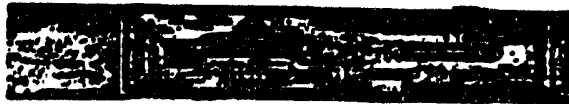


TEST PLAN APPENDIX B

rault Testing Procedure

A-27 


\section{B. FAULT TESTING PROCEDURE}

\section{B.1 Purnose}

This procedure provides a performance document for use in verifying the fault withstanding capabilities of electronic isolation devices. Tests include the application of AC voltzige across the output of the isolator in incremental steps from $.1 \times \mathrm{MCP}$ to $1.1 \times \mathrm{MCP}$, at 20 anip maximum.

\section{B.2 Test Davinment Used}

Test Equipment

1. Powertron, 3 KVA source, single $\phi$

2. MOSFET Power Switch/Controller

3. IEEE-488 Interface Board w/connecting cables

4. Synthesized Function Generator

5. Pulse Generator

6. High Performance Digital Multi Meter

7. IBM PC/AT or better

8. 5-Decade Programmable Divider

9. Programmable Pulse Trigger

10. 4-Channel Digital Storage Oscilloscope

11. MicroSoft Quick BASIC Software Version 4.5

12. IEEE 488 Bus Language Interface and Device Drivers for MS-DOS

13. Current Transformer

14. Synthesizer/Function Generator
Mfg \& Model No. (where available)

Model 3000S, Industrial Test

Equipment $\mathrm{CO}_{\text {., Inc. }}$

Custom Design, Industrial Test

Equipment $\mathrm{CO}$, Inc.

National Instruments MC-GPIB

Stanford Research Systems Model DS345

Interstate Electronics Corp. Model P12

Keithley Model 2001 DMM w/10-channel scanner card

IBM PS/2 Model 55X

Custom Design, BNL

Custom Design, BNL

LeCroy Model 9314 M-MCO1/04

w/Options WP01/02 and Trigger Out

Provision

MicroSot Corp.

National Instruments NI-488.2 for MSDOS Sotware

Pearson Electronics Inc. Model 110A

Hewlett-Packard Model 3325A 


\section{B.3 Promition}

1. All equipment is to be used in accordance with the manufacturer's instructions. Technical literature and specifications for each device are to be reviewed prior to testing to identify potential problem areas.

2. Cautions should be exercised when working on or around energized electrical components to avoid the hazard of shock.

3. Personnel should be clear of the testing area when testing is in progress to avoid injury.

\section{B.4 Setue}

1. The DUT should be inspected and calibrated in accordance with the manufacturer's specifications. Record results on Data Sheet B.1.

2. Setup the DUT and test equipment in accordance with Figure 4.

3. Driver software should be running with the testing sequence command program loaded.

4. Load the data disk, for the recording of test data. Record the disk number and test run number on Data Sheet B.1.

\section{BS Tet Performen}

1. Run Barrier Resistance measurement as described in Section 3.1 .1 and record the results on the Data Sheet B.1.

2. Run Barrier Capacitance measurement as described in Section 3.12 and record the results on the Data Sheet B.1.

3. Apply power to the DUT and perform the Isolator Functional Test measurement as described in Section 3.2 and record the results on the Data Sheet B.1.

4. Set the fault level input to the fault pulse waveform generator as described in Section 3.3.

5. Apply incremental fault waveform to DUT output terminals as described in Section 3.3.

6. Calculate $\int\left[V_{2}(t)\right]^{*}\left[V_{2}(t) / R_{2}\right]^{*} d t$ to find reach-through energy for the fault level.

7. Download fault voltage and current waveforms, and reach-through voltage, current, and energy waveforms to PC floppy disks. Record the storage disk information on the Data Sheet B.1.

8. Inspect the DUT for any damage which may have cocurred. Record any findings or observations on Data Sheet B.1.

9. Repeat steps 1 through 8 in $10 \%$ increments of fault voltage up to $110 \%$ of MCF.

$$
\text { A-29 }
$$


10. Repeat steps 1 through 3 after application of the $110 \%$ of MCF fault level.

\section{B.6 PestoTent Provening}

1. Remove power from the DUT.

2. Verify that test data has been recorded on data disk.

3. Disconnect DUT from all test connections.

$$
A-30
$$


FAULT TEST DATA SHEET B.1

Isolation Devices

MAKE:

MODEL:

DATE:

TEST RUN \#:

TIME:

SERIAL":

FAULT LEVEL:

XMCF

Pro-Teat Callbration and Inspections

OASERVATIONS:

Barribr Resiotance Measurenonatu

OBSERVATIONS:

Barribr Capacitance Measurumonte

OBgTRVATIONS:

FUNCTONAL TEST INTI OUTPUT

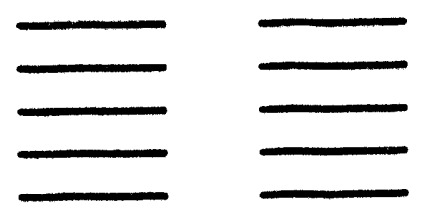

FAULT TEST:

DISE *

OBSERVATIONS:

A-31 
APPENDDX B

BNL

ISOLATOR TEST FACIITY

B-1 


\section{DESCRIPTION OF \\ BNL ISOLATOR TEST FACILITY}

The BNL Isolator Test Facility (ITF) was designed to provide a detailed survey of specific potential power fault conditions affecting electronic isolators. Such isolator faults might prevent input connected critical protection systems from meeting their minimum performance requirements. In earlier testing performed under the NRC's Isolation Devices Evaluation Criteria Program, and reported by Neilsen in NUREG/CR-3453 (Ref. B.1), some electronic isolation devices experienced severe damage when subjected to maximum credible AC or DC voltage and current levels (e.g. $120 \mathrm{vac}, 20 \mathrm{a})$ when applied to the output side of the energized device.

In addition to these maximum credible fault states, additional questions have surfaced suggesting that other, less-than-maximum voltage and current conditions might find a leakage path across the isolator allowing potentially destructive energy levels to breach the isolation barrier. The below maximum credible voltage potentials may contain other properties influencing damage to connected devices. Such power conditions might occur as a result of subtly induced power levels that are a function of power fault transients relating to wave shape, as well as amplitude. The maximum credible fault (MCF) for a given isolation device must thus be defined not only as that fault potential at which the maximum reach-through energy is passed across the isolation barrier, but also as a function waveform dependent parameters.

To satisfy the critical investigation process the ITF was developed to accurately and automatically monitor the vital connections of the isolator while systematically applying predetermined fault profiles to the output of the isolator. To ensure maximum detection capability, electronic measuring instruments were chosen that are capable of the highest sensitivity and resolution relative to the measurement objectives. These sensitive instruments permit minute currents to be detected, both statically and dynamically, so transient through-put phenomena can be observed and quantified.

\section{THE TEST INSTRUMENTS}

The complete test setup is constructed from carefully selected instruments so they can be functionally integrated through a small computer for maximum flexibility. The computer controls, monitors, and records all the critical parameters important for determining isolator barrier integrity. The major instruments that comprise the ITF and their function are listed below. 
Test Equipment

Powertron, 3 KVA source, single $\phi$

MOSFET Power Switch/Controller

IEEE-488 Interface Board w/connecting cables

Synthesized Function Generator

Pulse Generator

High Performance Digital Multi Meter

IBM PC/AT or better

5-Decade Programmable Divider

Programmable Pulse Trigger

4-Channel Digital Storage Oscilloscope

Regulated DC Power Supply

MicroSoft Quick BASIC Software Version 4.5

IEEE 488 Bus Language Interface and Device Drivers for MS-DOS

Current Transformer

Synthesizer/Function Generator
Mfg. \& Model No. (where avallable)

Model 3000S, Industrial Test

Equipment Co., Inc.

Custom Design, Industrial Test

Equipment Co., Inc.

National Instruments MC-GPIB

Stanford Research Systems Model DS345

Interstate Electronics Corp. Model P12

Keithley Model 2001 DMM w/10-channel scanner card

IBM PS/2 Model 55X

Custom Design, BNL

Custom Design, BNL

LeCroy Model 9314 M-MC01/04

w/Options WP01/02 and Trigger Out

Provision

Power Designs Model 5015-S

MicroSoft Corp.

National Instruments NI-488.2 for MSDOS Software

Pearson Electronics Inc. Model 110A

Hewlett-Packard Model 3325A

Digital Storage Osellloscope, LeCroy Model 9314M, has the capability to record fast transient events. These are time dependent voltages that are not possible to detect with a digital voltmeter or similar device. Such voltages are significant because they can be of sufficient amplitude to cause induced faults without being detected under normal operating conditions. With this instrument it is possible to record any potential transient effects and assess their potential to compromise critical protection systems.

The LeCroy oscilloscope used in the test is capable of recording four transient events simultaneoushy. Four input channels are used to monitor both input and output voltages to the DUT. It is also used to monitor input and output currents of the DUT through sensitive, fastresponse current transformers connected at those respective locations. The resulting data acquisition from the digital recording osilloscope may then be both controlled by, and transferred to, the computer through an IEEE 488 interface for display, storage, and analysis. 
Synthesizer/Function Generator, Hewlett Packard Model HP3325A, serves two purposes: first, it is used for functional testing by supplying a defined input signal to the DUT which is then compared to the signal at the output to determine functional integrity, and second, it provides an alternating current source to assess $\mathrm{AC}$ barrier integrity. It is configured to the testing apparatus for both applications via computer control (IEEE 488 Bus) and the associated switchgear.

Synthesized Function Generator (Stanford Research Systems Model DS345) provides high resolution, digitally synthesized, waveforms to $30 \mathrm{MHz}$. Outputs can be standard waveforms or complex arbitrary signals with up to 16,300 sampling points and 25 ns sampling times. Modulation capabilities include amplitude, frequency, phase, burst, along with phase continuous linear and logarithmic sweeps controlled via the IEEE 488 Standard Bus.

Precision Digital Multi-Meter (Keithley Model 2001 DMM) provides high precision, 7 1/2 digit resolution, $\mathrm{DC}$ and $\mathrm{AC}$ voltage and current measurement over a very wide dynamic range. $\mathrm{A}$ ten channel scanner allows multiplexed monitoring of up to ten inputs. The DMM can be controlled via the IEEE 488 Standard Bus.

Fault Waveform Generator consists of the SRS DS345 Synthesized Function Generator, the Industrial Test Equipment Company (ITECo) Powertron Model 3000s 3kVA AC Amplifier, and the ITECo designed MOSFET Switch/Controller. The DS345 serves as both the waveform source (wave shape and amplitude) for the Powertron amplifier, and as the synchronizing clock to gate the MOSFET Switch/Controller and to trigger the oscilloscope via the BNL designed Programmable Trigger. The Powertron operates as a continuous waveform AC amplifier. The MOSFET switch/controller allows the high speed switching of the Powertron output. The number of fault pulses generated is selected and controlled by the programmable trigger to be from one, and only one, fault pulse per event up to 99 fault pulses per event. The BNL designed Programmable Divider is used to select the delay between pulses (the duty cycle) in multiple fault pulse events.

IEEE 488 Standard Bus Digital Interface (National Instraments, MC-GPIB interface board and NI-488.2 software), also known as the General Purpose Interface Bus (GPIB), is the standard interface for the remote control of electronic instruments. The interface between the computer and the respective connected instruments is accomplished via the NI-488.2 software using standard protocols for communication. By utilizing the IEEE 488 interface, supplemented by the flexibility afforded by the control and data acquisition software, it is possible to direct a variety of adaptable options for adjusting and monitoring various testing configurations and activities.

Control and Monitoring Computer (IBM PS/2, Model 55X) is used for the instrumentation control and data acquisition and analysis. Data logging and control functions are accomplished through the installation of special purpose data acquisition and control boards (such as National Instrum nts MC-GPIB, MC-DIO-24,SC-2051, and SC-2062), running the appropriate software (such as Microsoft Quick BASIC, and National Instruments LabWindows and NI-DAQ for DOS), and the IEEE 488 Standard Bus digital interface. The block diagram of the test configuration for the fault testing of electronic isolation devices is shown in Figure 1. The Device-Under-Test (DUT) is subjected to the application of fault pulse waveforms generated at the output of the MOSFET Switch/Controller. Monitoring of various test parameters and data acquisition are accomplished with the connected test equipment via the IEEE-488 Standard Bus and computer control. 


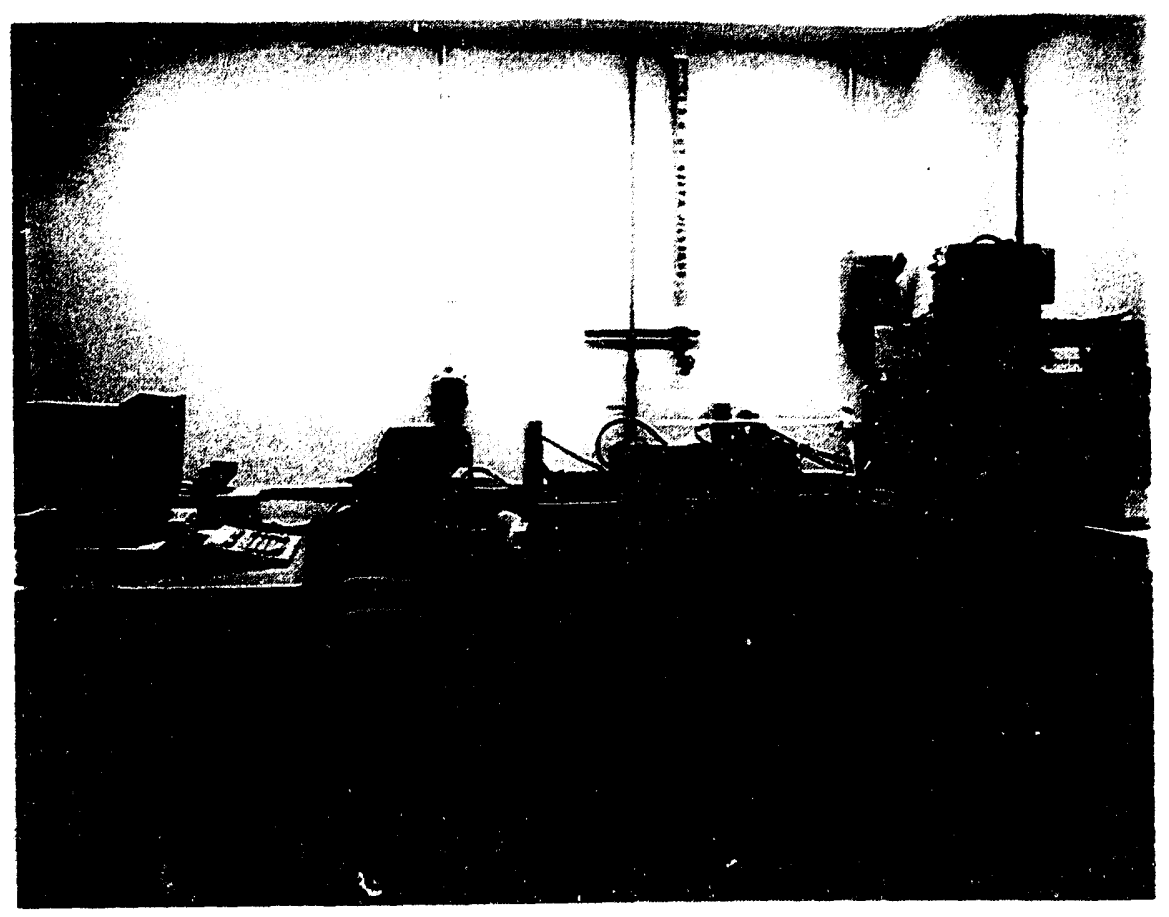

Figure B.1 BNL Isolator Test Facility (ITF)

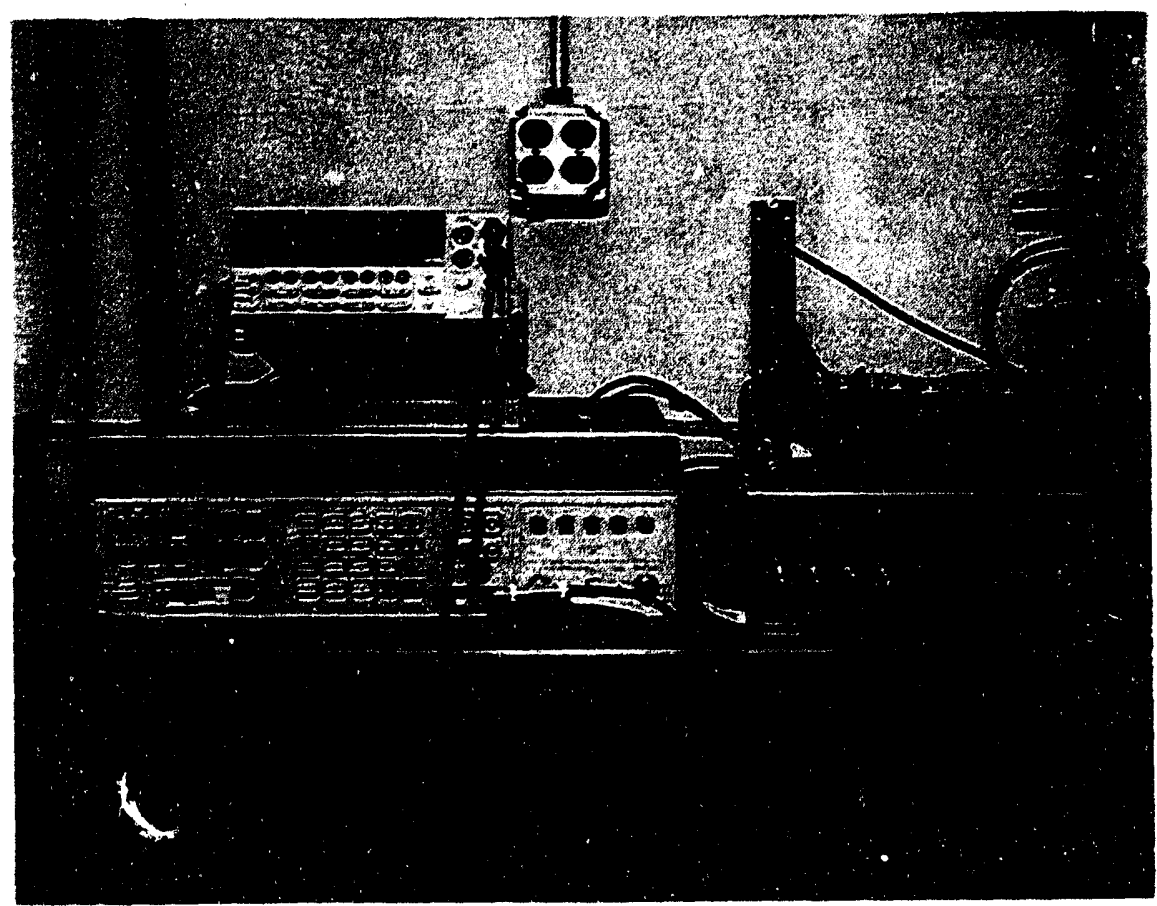

Figure B.2 Detail of ITF showing control relays, CT amplifiers, DMM, and synthesizer/ function generator 


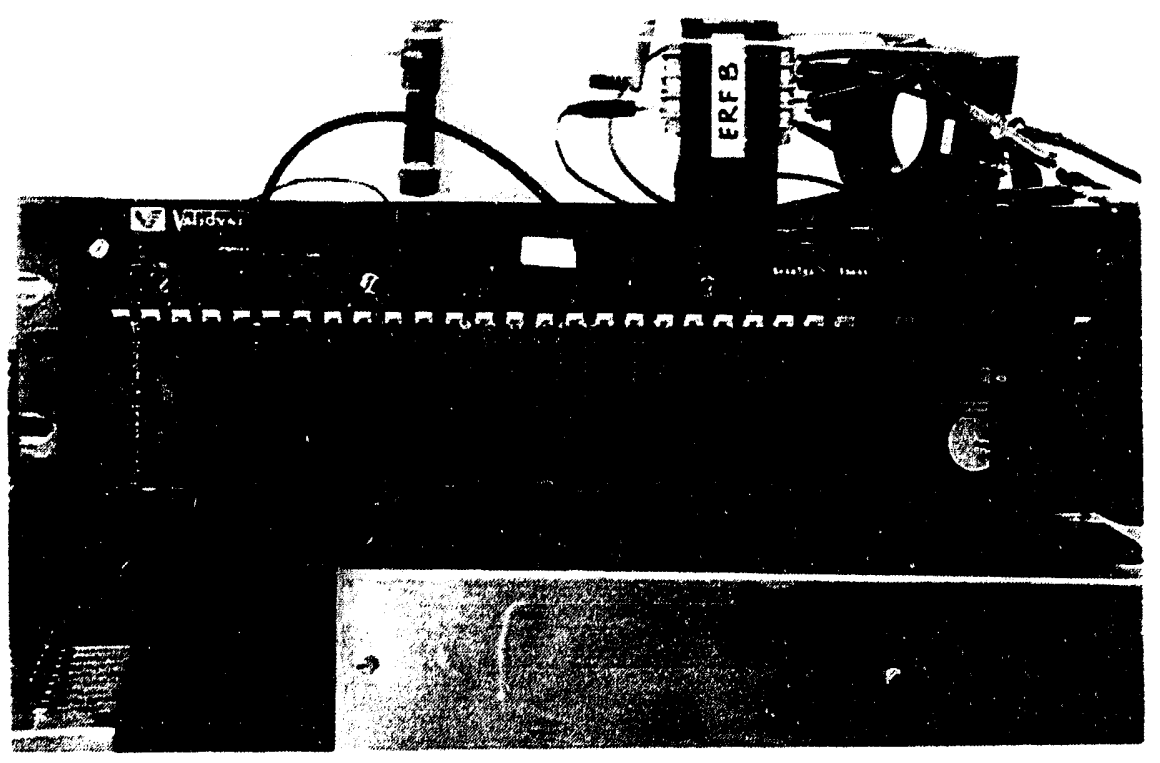

Figure B.3 Detail of ITF showing isolator test bed with a device under test (DUT)

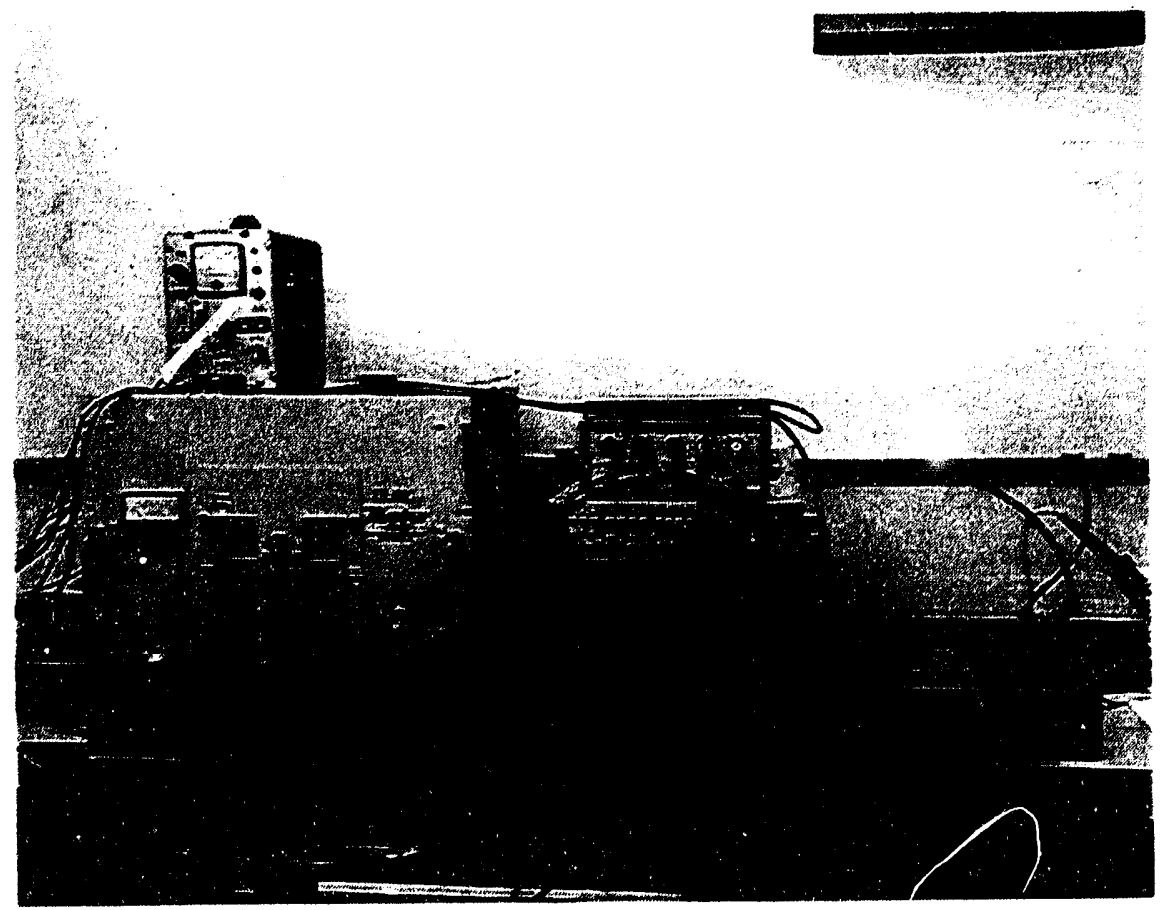

Figure B.4 Detail of ITF showing the fault waveform generating equipment and the DSO 


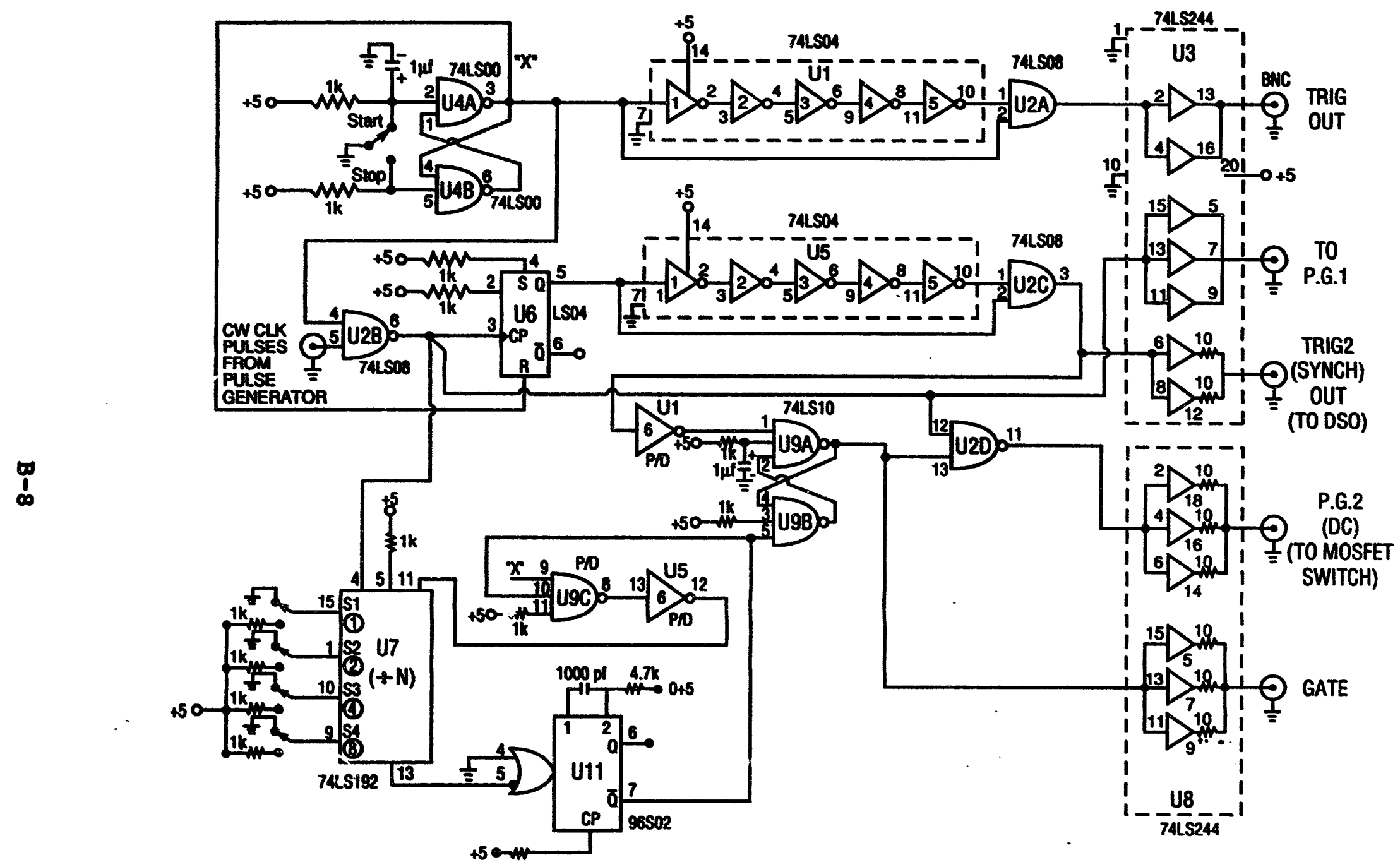

Figure B.5 Block Diagram of the programmable trigger designed by BNL for the fault waveform generator 


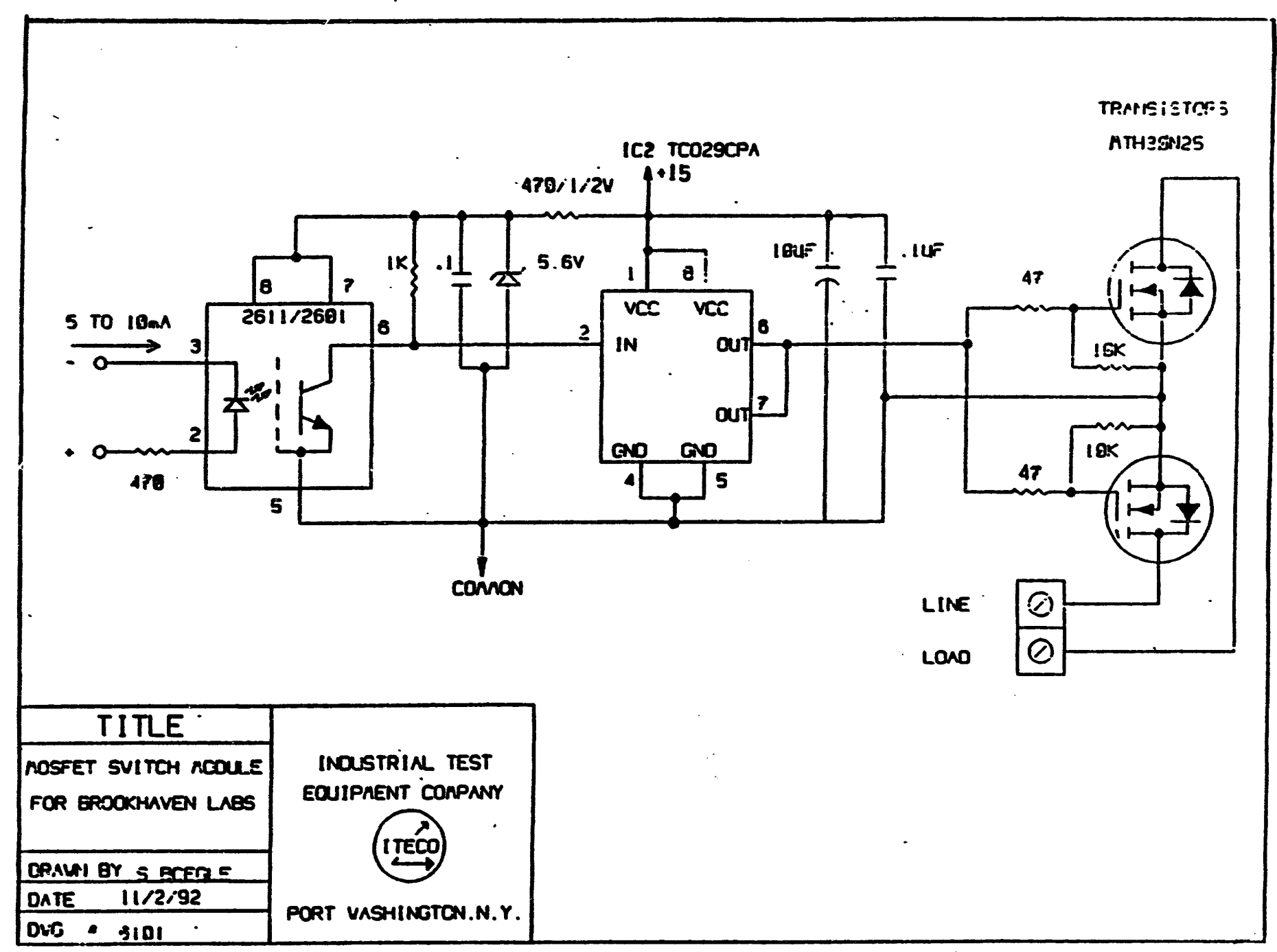

Figure B.6 Schematic of MOSFET switch module designed by Industrial Test Equipment Company (ITECo) for fault waveform generator (Ref. B.2)

(Printed with permission of Industrial Test Equipment Co.) 


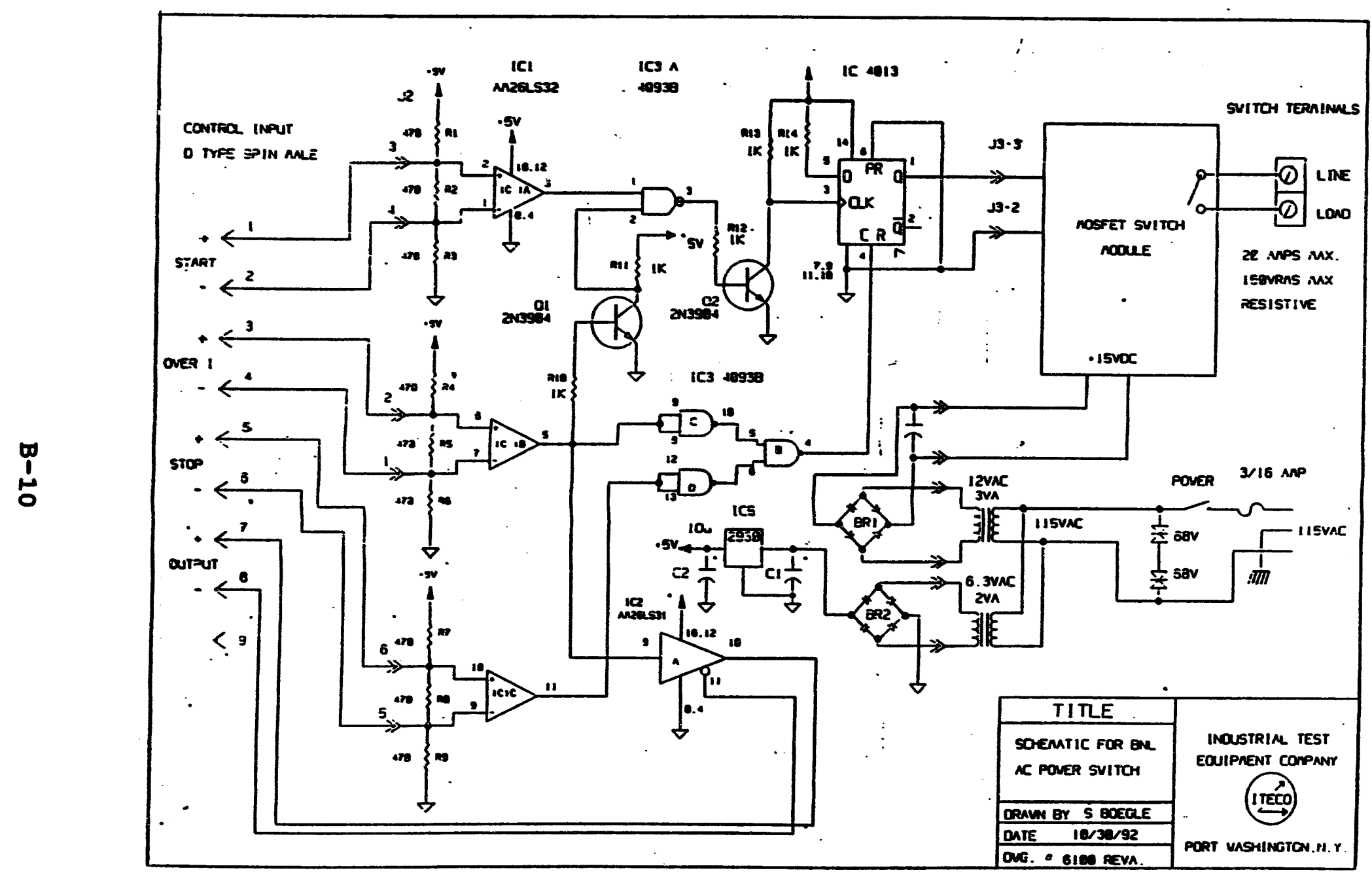

$\checkmark$

Figure B.7 Schematic for MOSFET switch/controller designed by ITECo for fault waveform generator (Ref. B.2)

(Printed with permission of Industrial Test Equipment Co.) 
References for Appendix B

B.1 Neilsen, J.R., "Electronic Isolators Used in Safety Systems of U.S. Nuclear Power Plants," NUREG/CR-3453, EGG-2444, EG\&G Idaho, Inc., March 1986.

B.2 "Instruction Manual for AC Power Switch," Industrial Test Equipment Co., Port Washington, New York. October 1992. 
APPENDIX C

TEST EQUIPMENT

CERTIFICATIONS

C-1 
Sertal * 931401897 Soltware version 02.4 .

\section{: *** CERTIFICATE DF CALIBRATION ***}

The DSD listed above, LeCroy 9314M, S/N 931401897. Software version 02.4 has been checked and caibrated against our workino standerds listed below and following the procedure oocumented in "CSO1 Calibraicion Eoftware Package for Digital 0scilloscopes" Operator's Manual. it meets or exceeds all published specifications.

LeCroy calibrations are traceable to the US National Institute of Standards and Techrology [NISTI to the extent allowed by the Oroanisation which accredits this calibration facility. This unit meets IEEE-5TD 1057 as specitied in its data sheet.

Date of cal. Sep 16, 1952 Flace of cal. LeCroy-EenEVA

Temperature:239 Humidity: G9\% Tectrnician: M.C.

Cal. due date : Sep 16, 1993 Cal. Report Nb. : FL-9314M1897

\section{Quality Assurance: H.ColhereT.} Approved: Metrology Anaiyst.

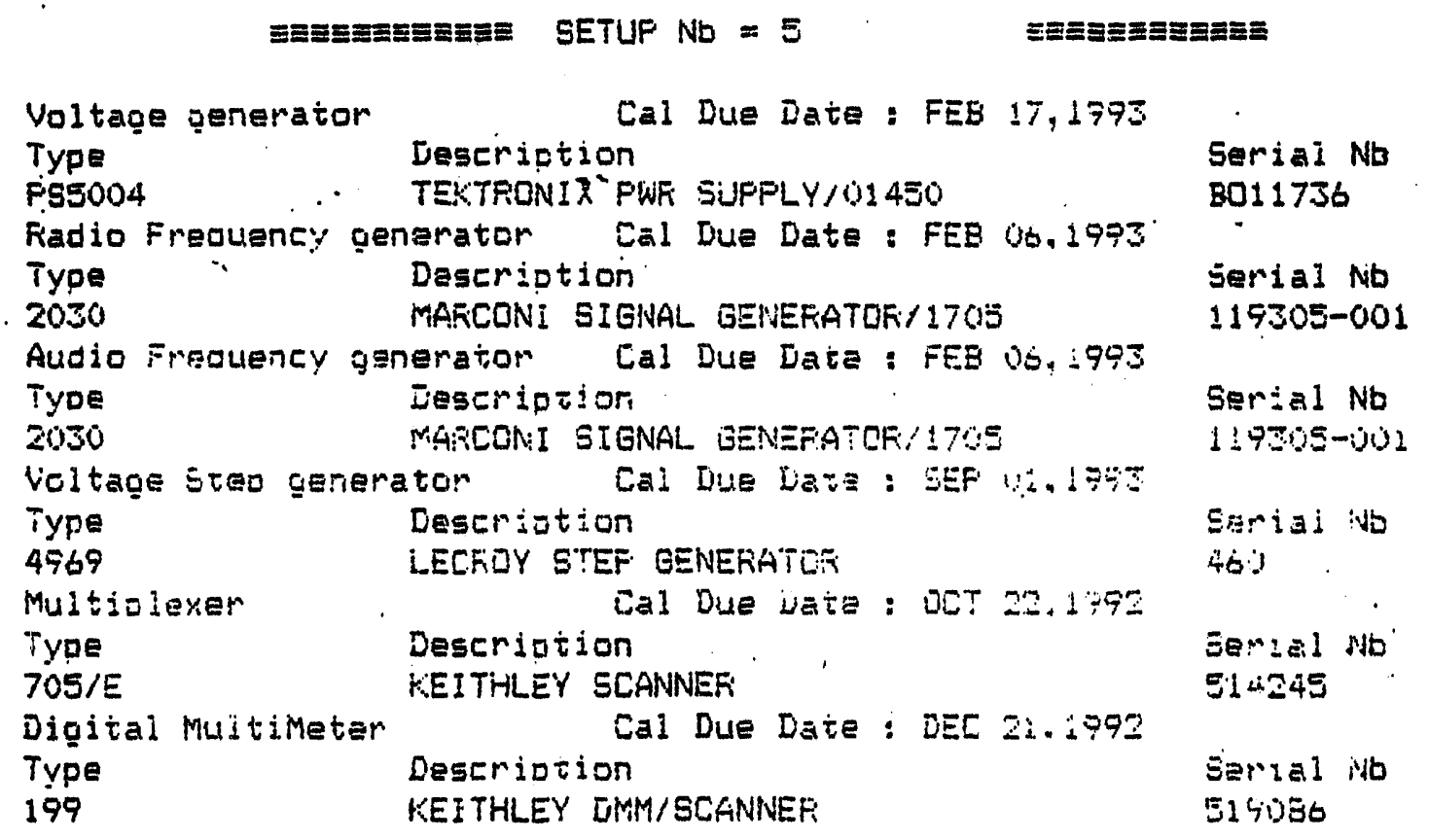




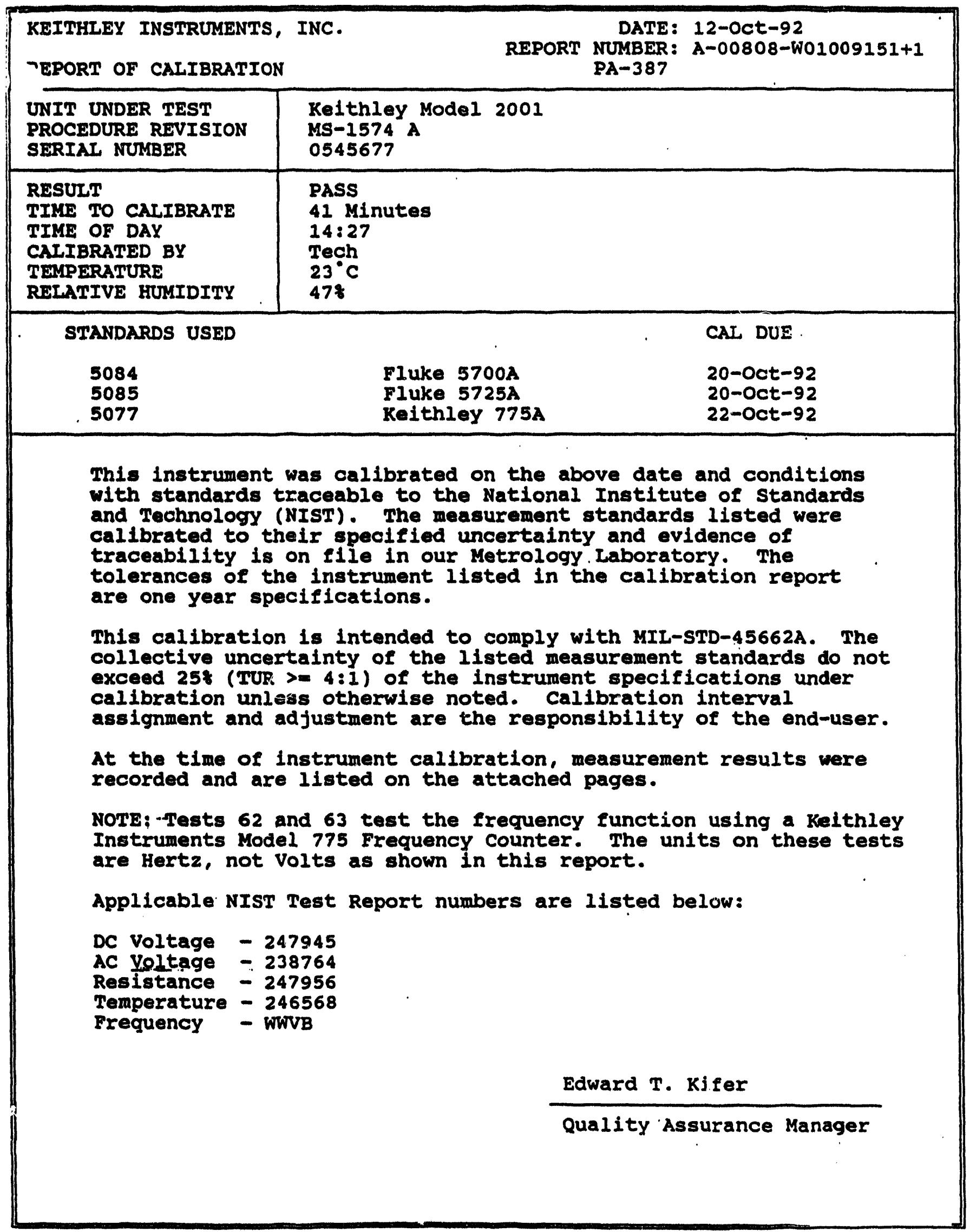


APPENDIX D

TEST DATA

D-1 
TABLE 0.1 LIST OF FIOURES IN APPENDIX D SHOWING onaphICal pRgsantation of test Data

PON EACH ISOLATON MOOLL TESTED

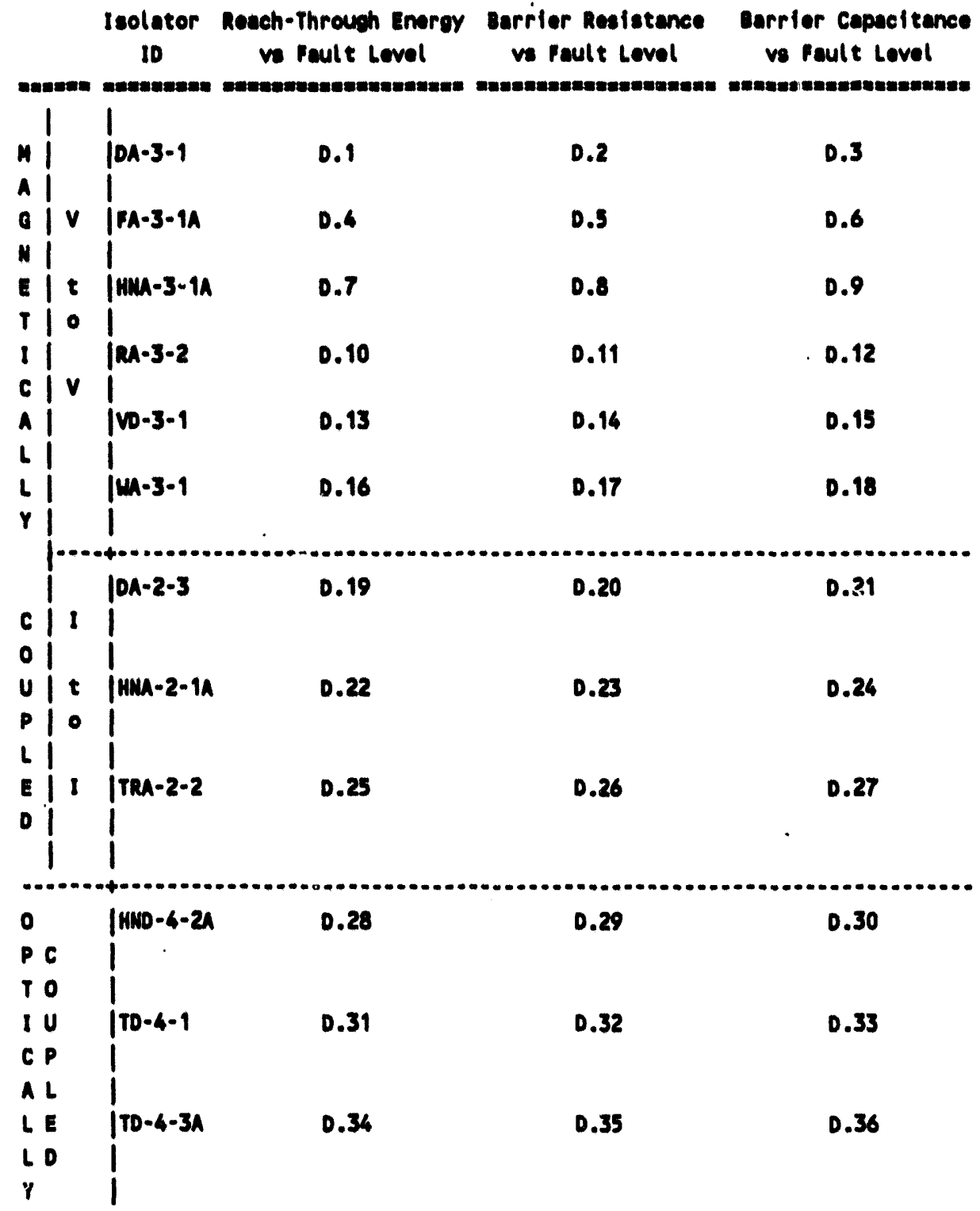




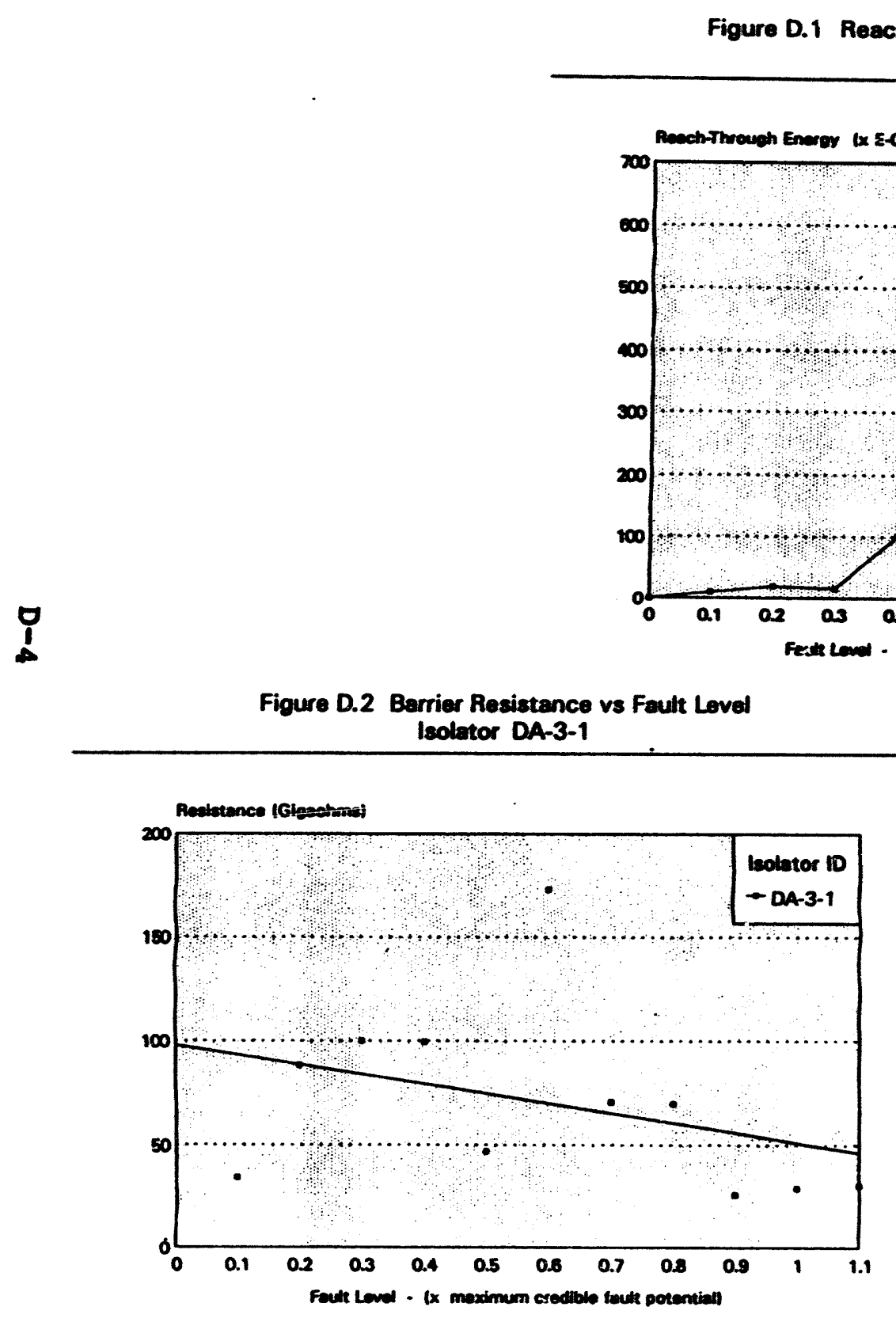

Resistance as measured after application of indicated fault bevel.

\section{lsolator DA-3-1}

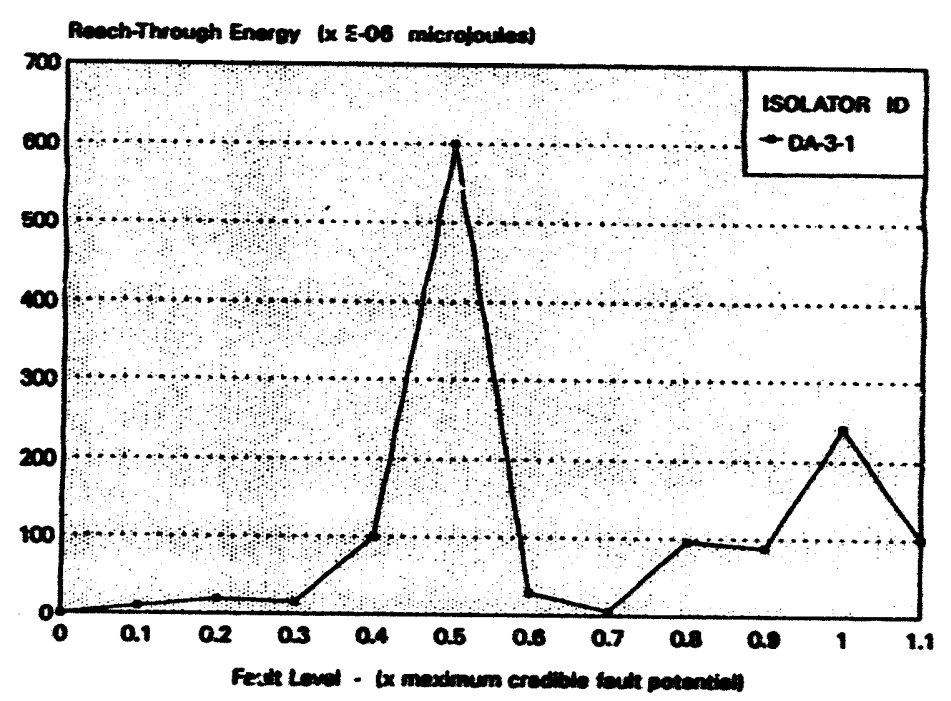

Figure D.3 Barrier Capacitance vs Fault Level lsclator DA-3-1

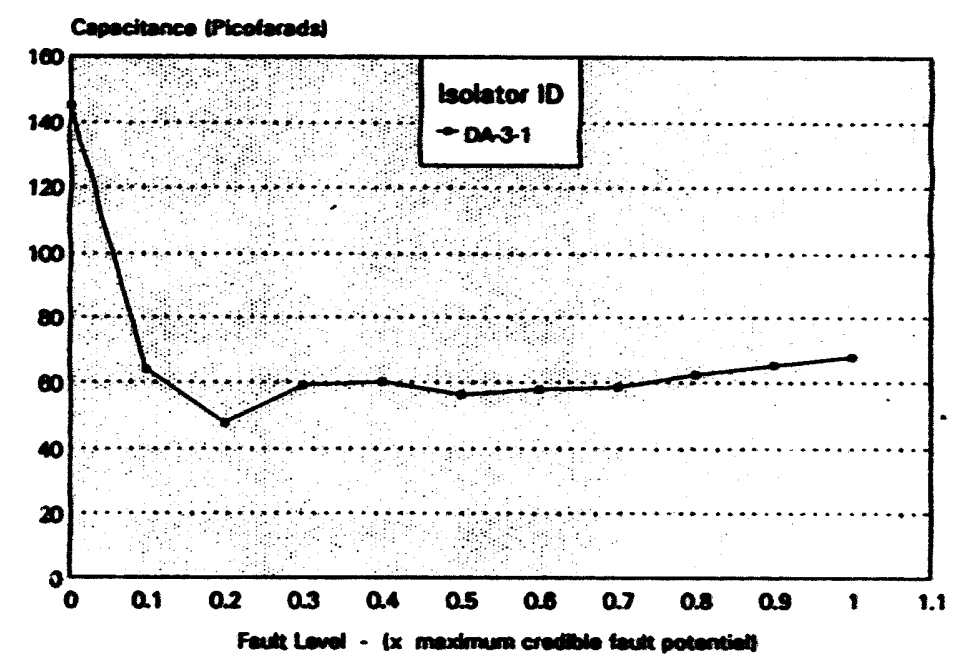

Capacitance as measured after application of indicated faut tevel. 


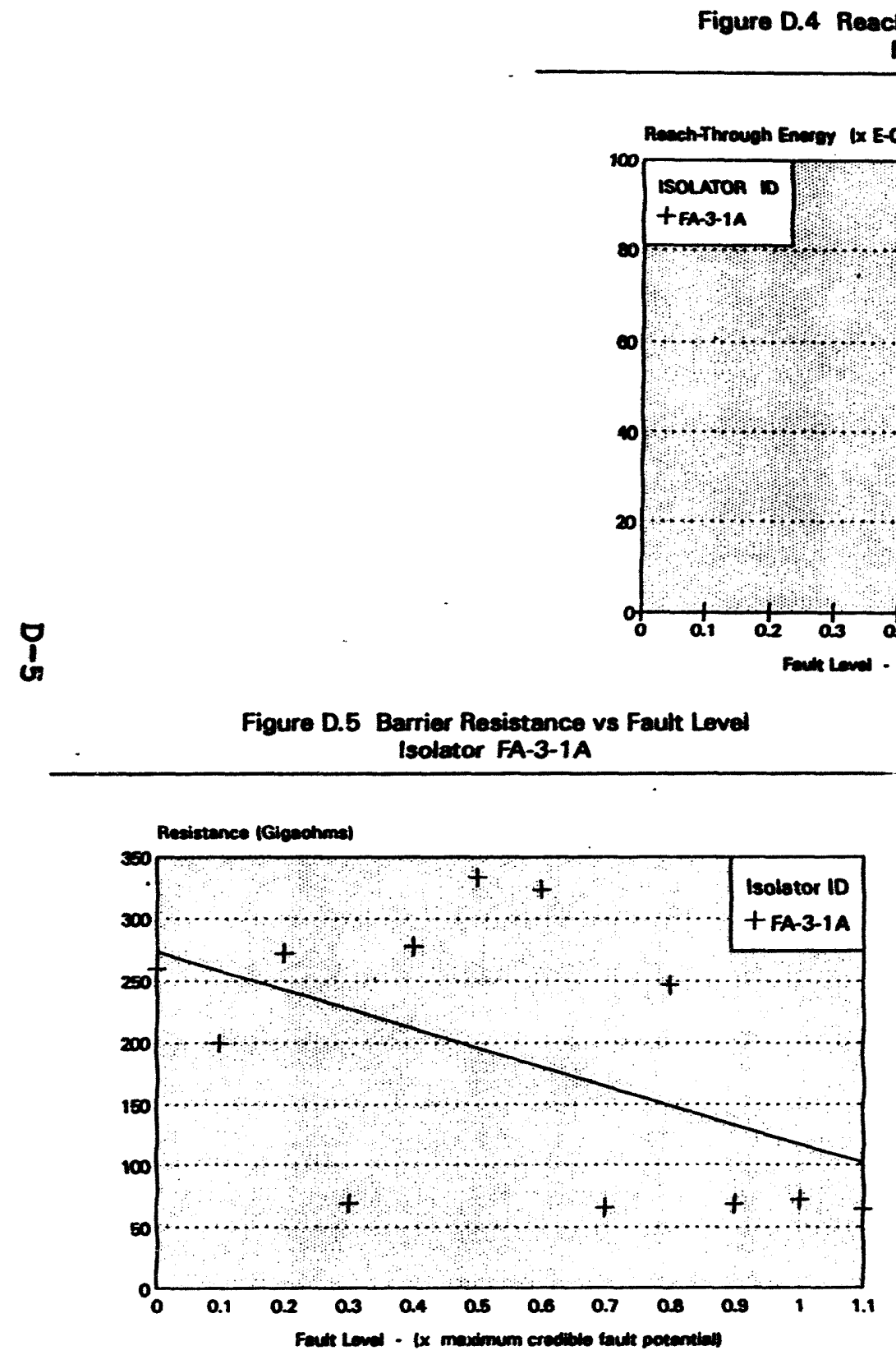

Prabatance as measured after appllication of indicatod fault lowel.
Isolator FA-3-1A

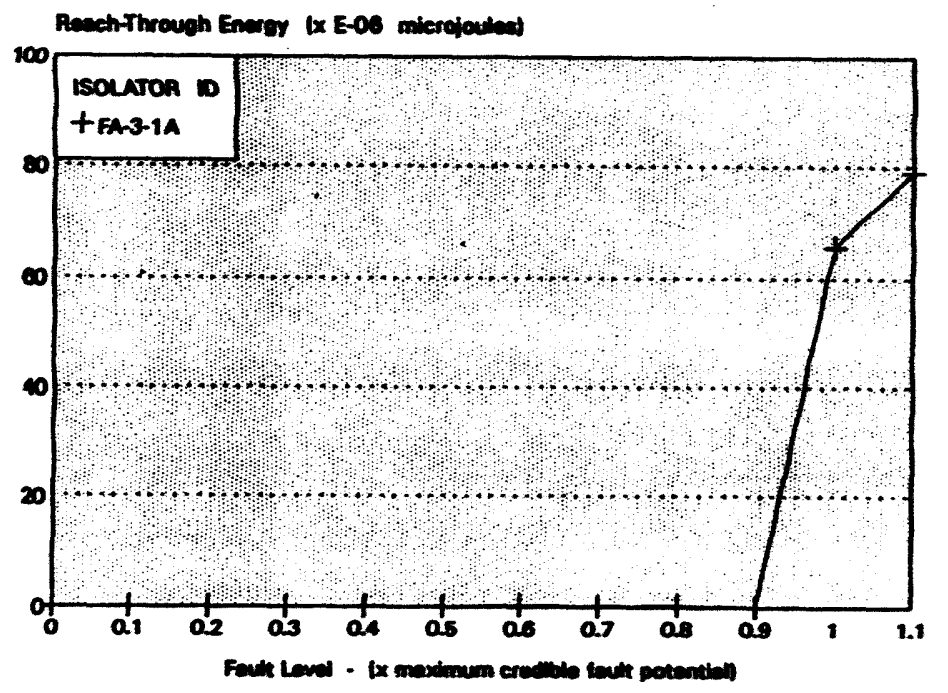

Figure D.6 Barrier Capacitance vs Faut Lovel Isclator FA-3-1A

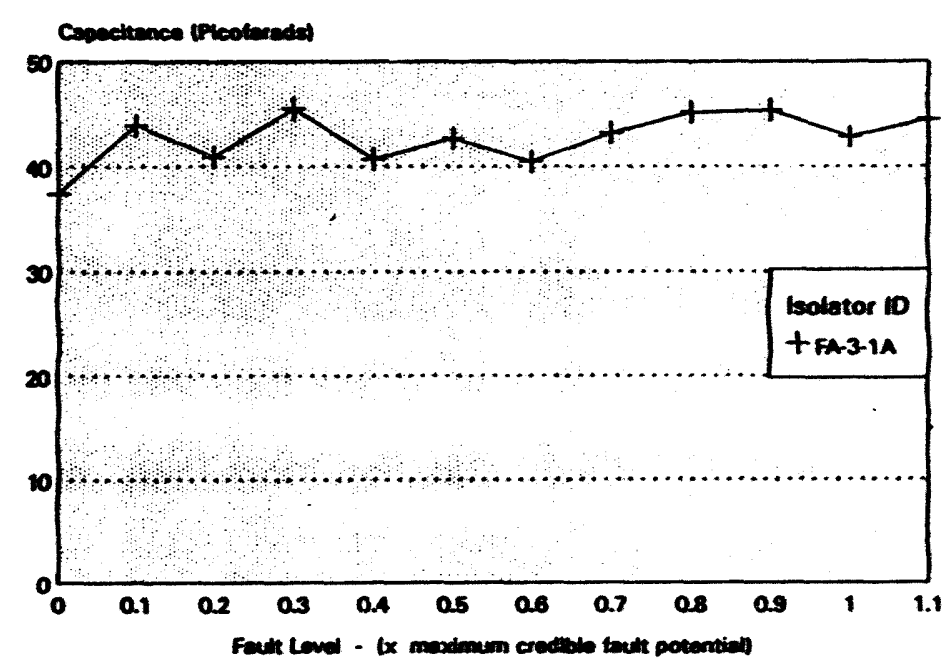

Cepactionces es measured after application of ledicated faut bevel. 

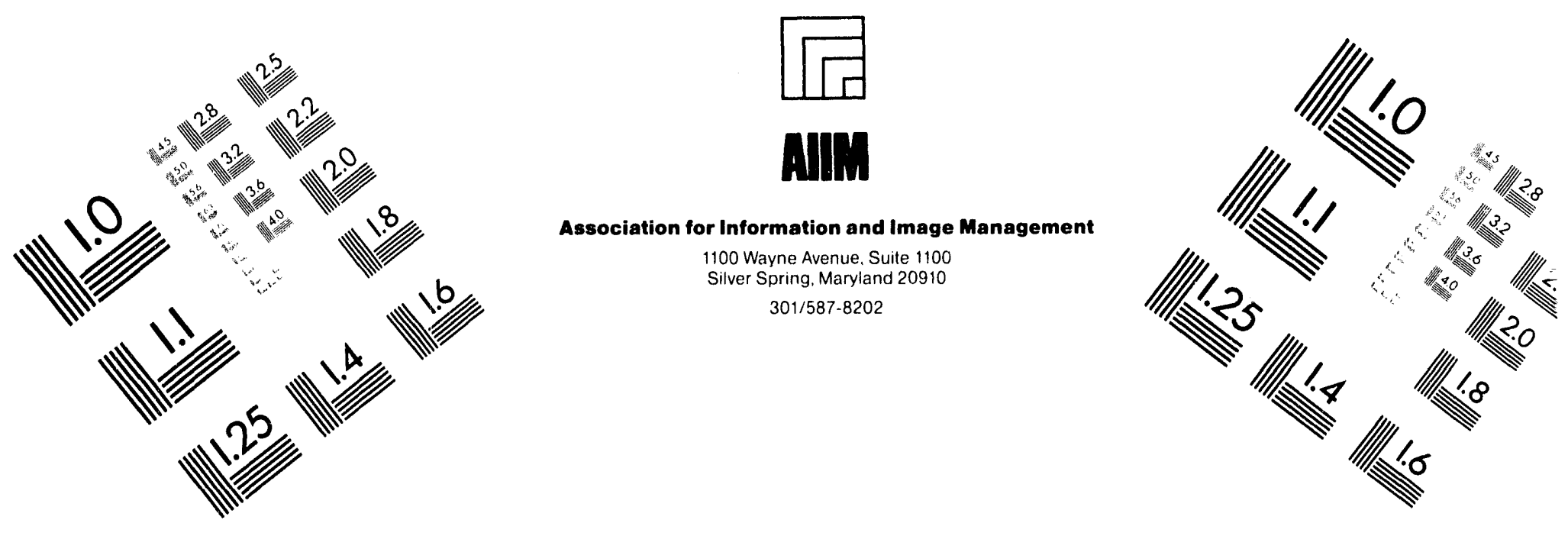

\section{Centimeter}

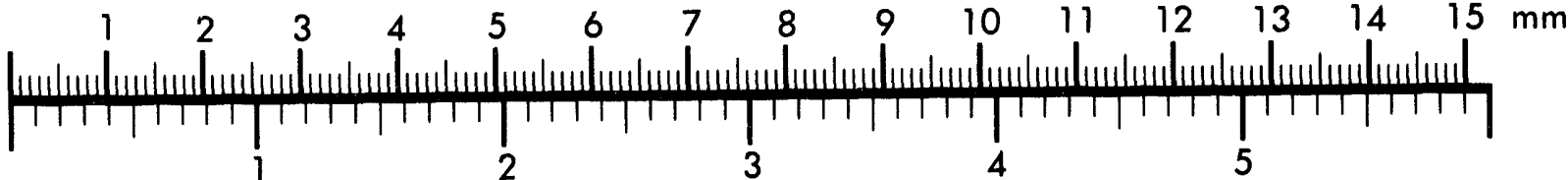

Inches
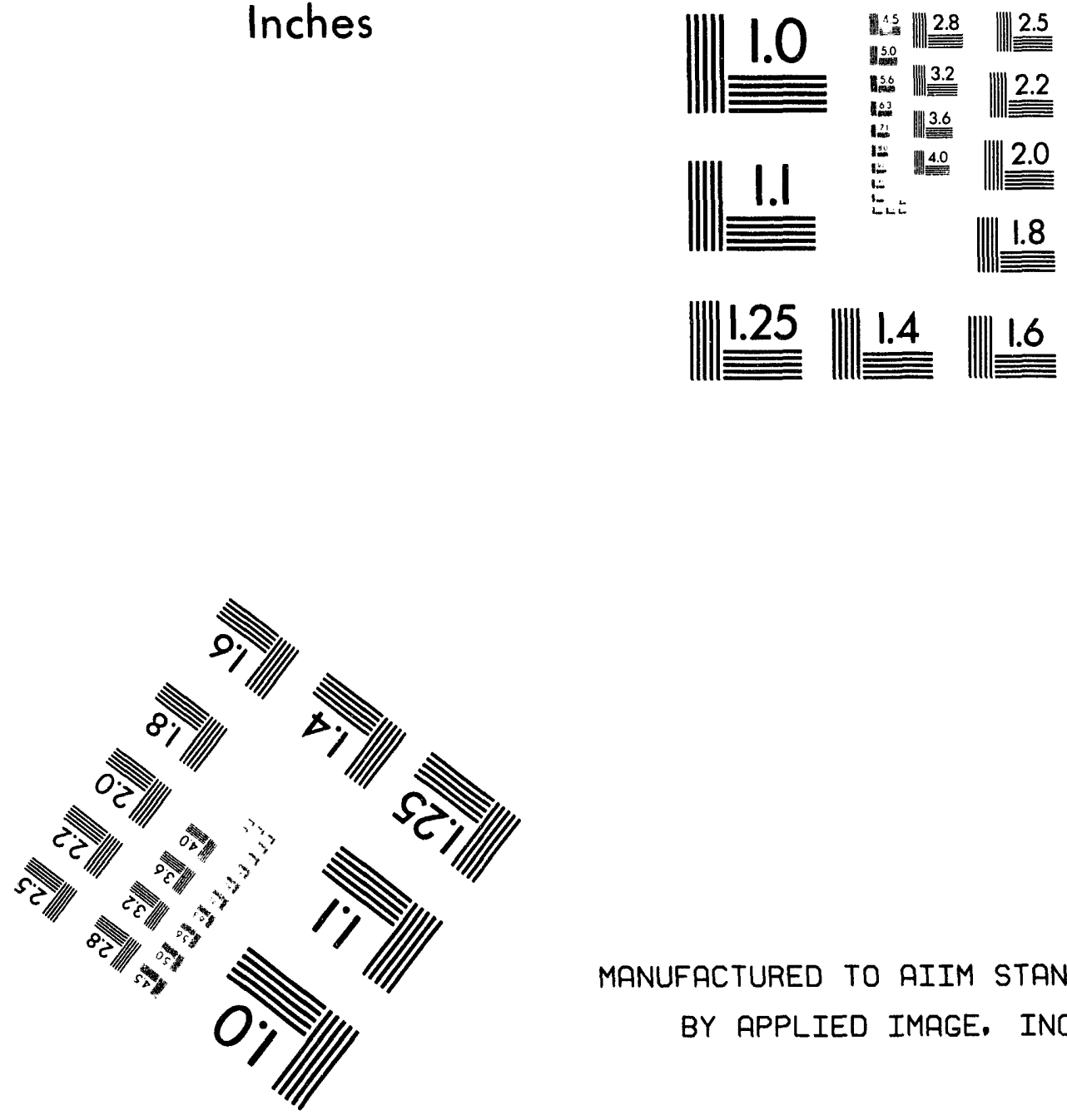

MANUFACTURED TO AIIM STANDARDS

BY APPLIED IMAGE. INC.

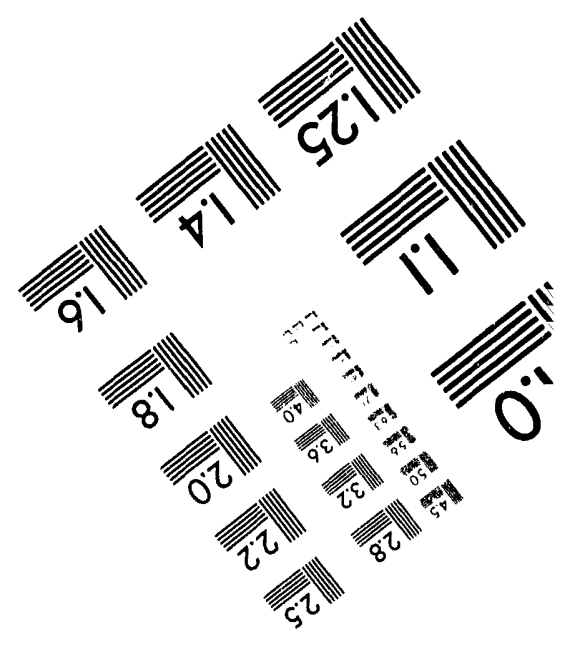



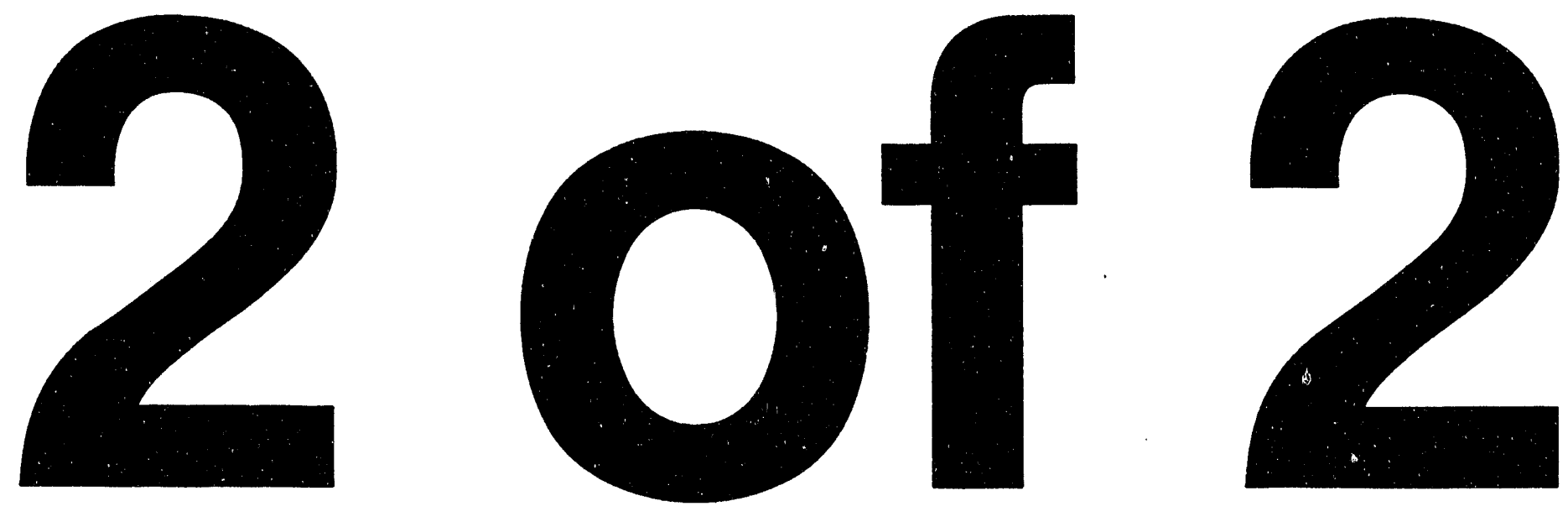


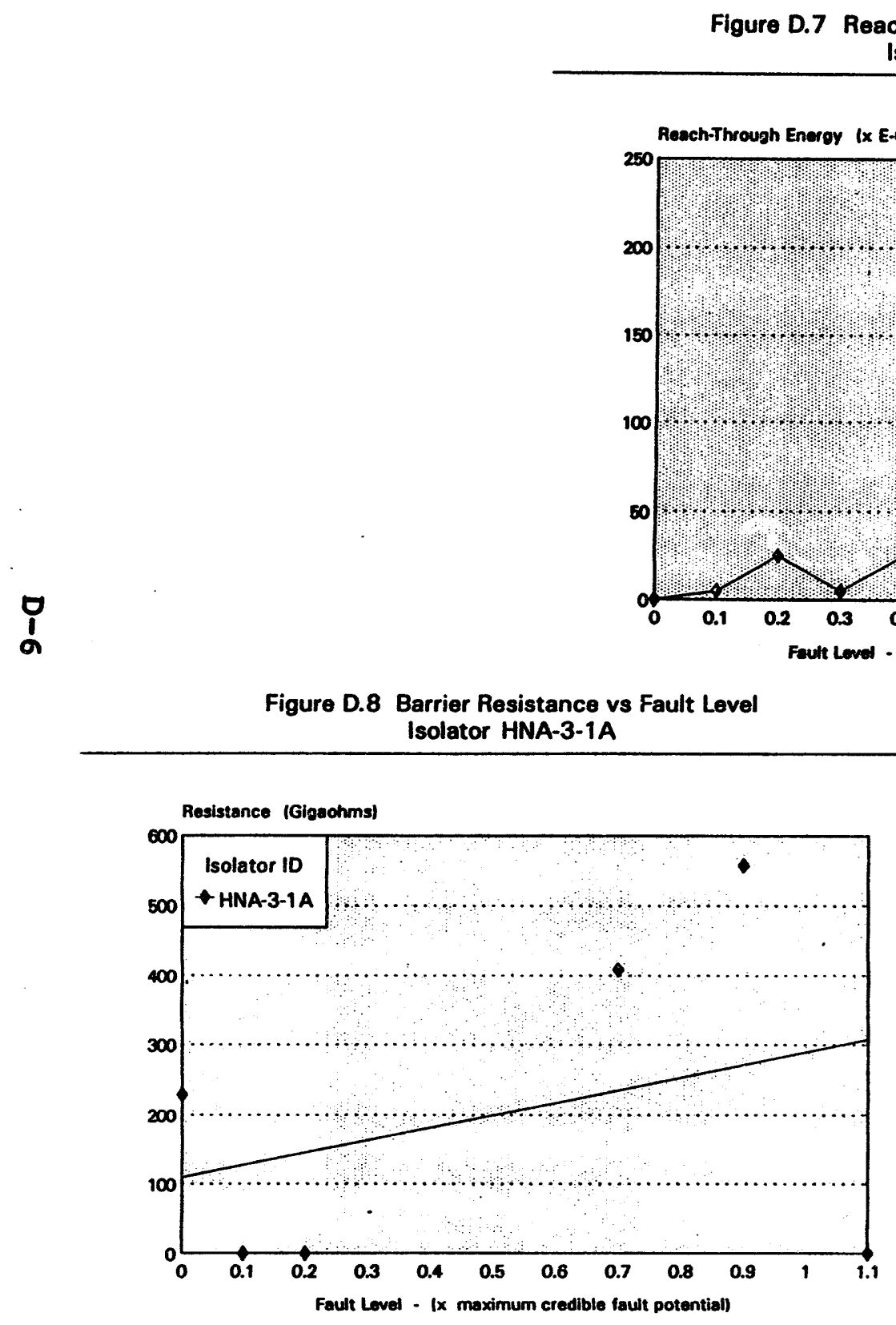

Figure D.9 Capacitance vs Fault Level Isolator HNA-3-1A

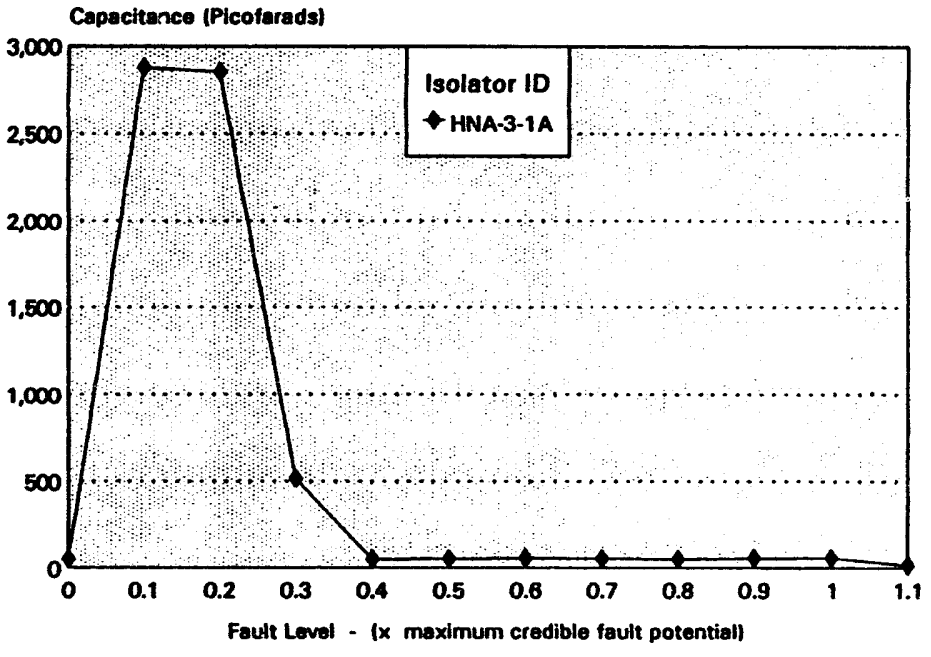

Capacitance as measured aftsr application of indicated fault level. 


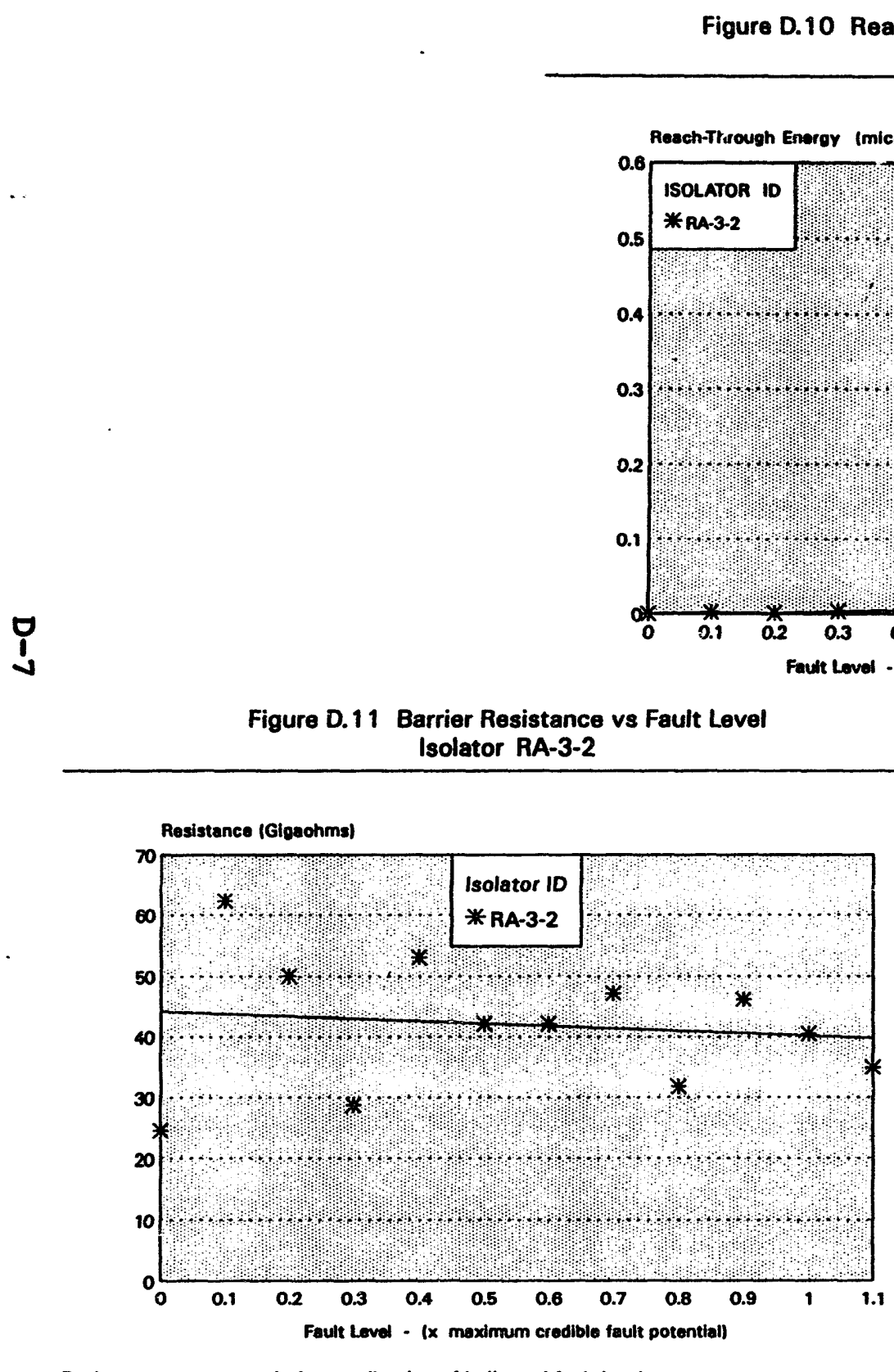

Isolator RA-3-2

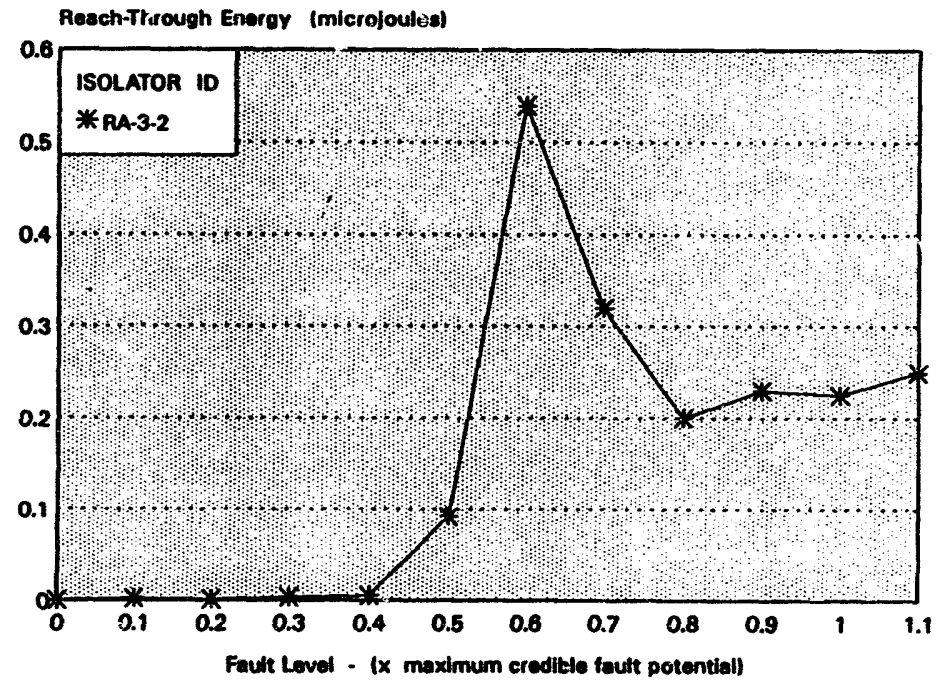

arrier Resistanc

Resistance as measured after application of indicated fautt level.
Figure D.12 Barrier Capacitance vs Fault Level

Isolator RA-3-2

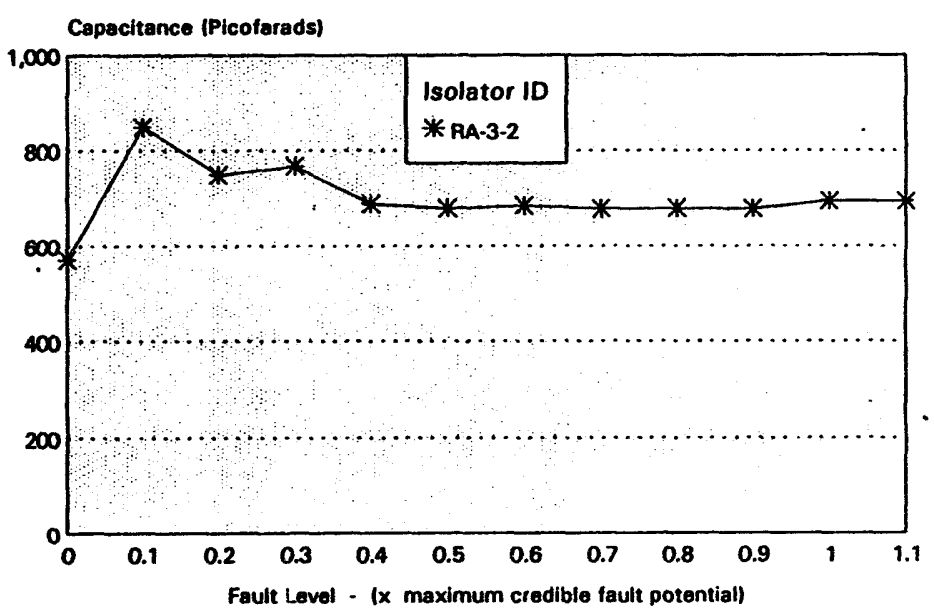

Capacitance as measured after epplication of indicated fault level. 
Figure D.13 Reach-Through Energy vs Fault Level Isolator VD-3-1

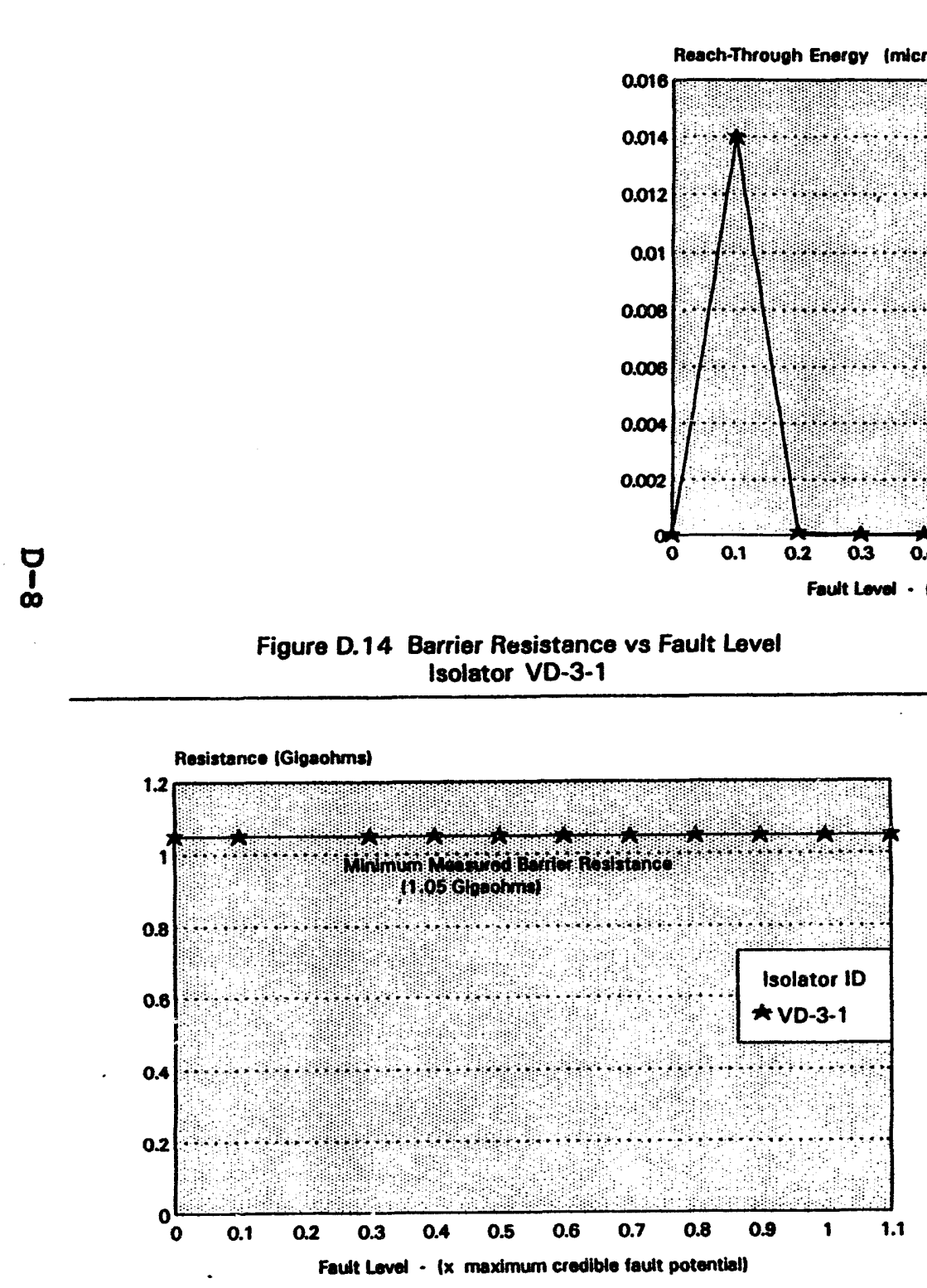

Figure D.15 Barrier Capacitance vs Fault Level Isolator VD-3-1

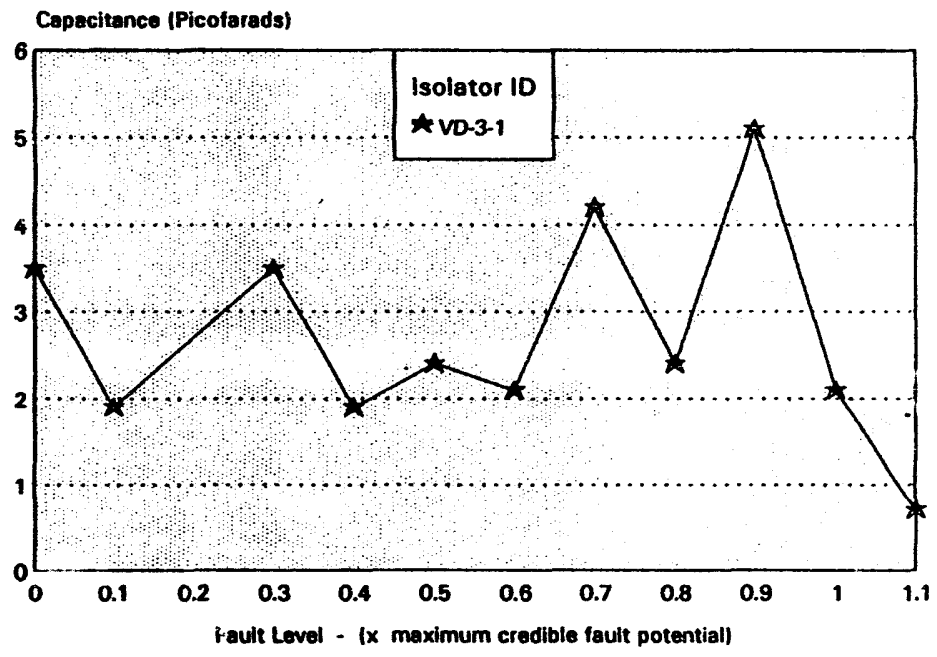

Carsecitance as measured after application of indicated fault level. 
Figure D.16 Reach-Through Energy vs Fault Level Isolator WA-3-1

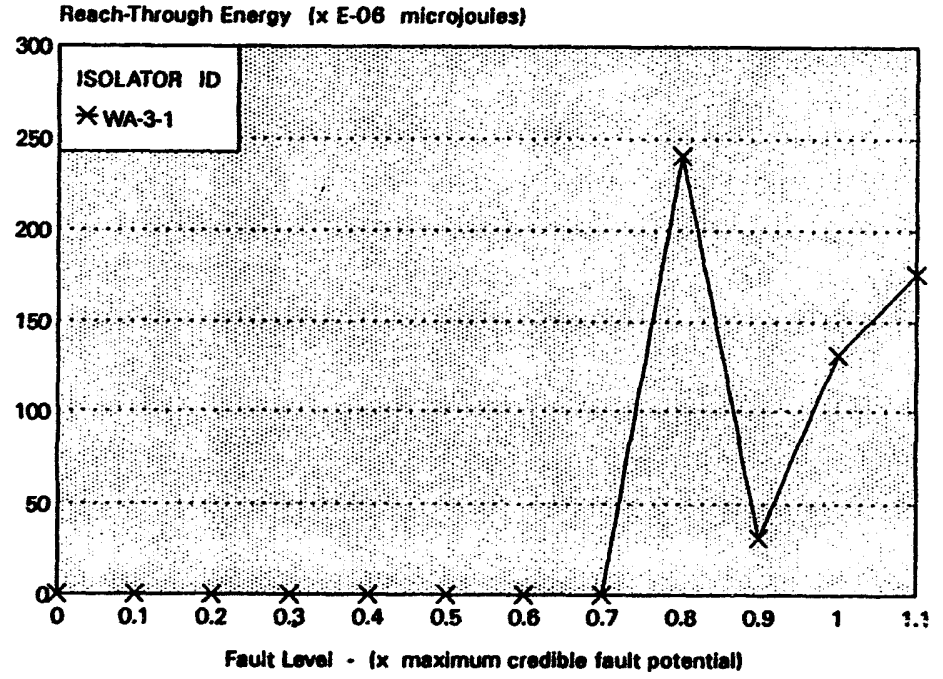

Figure D.18 Barrier Capacitance vs Fault Level Isolator WA-3-1

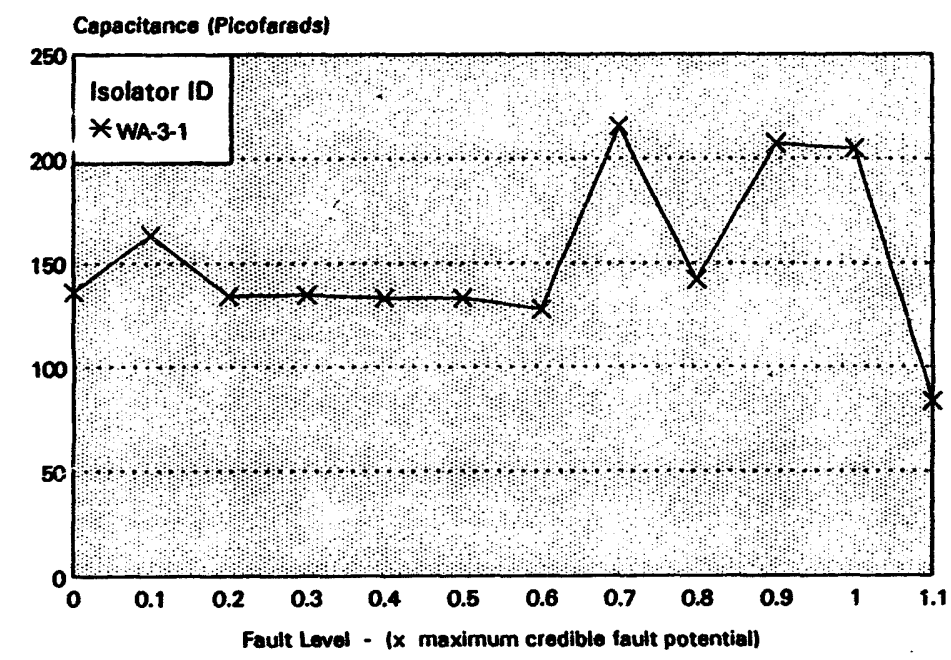

Capacitance as measured after application of indicated fault level.
Figure D.17 Barrier Resistance vs Fault Level Isolator WA-3-1

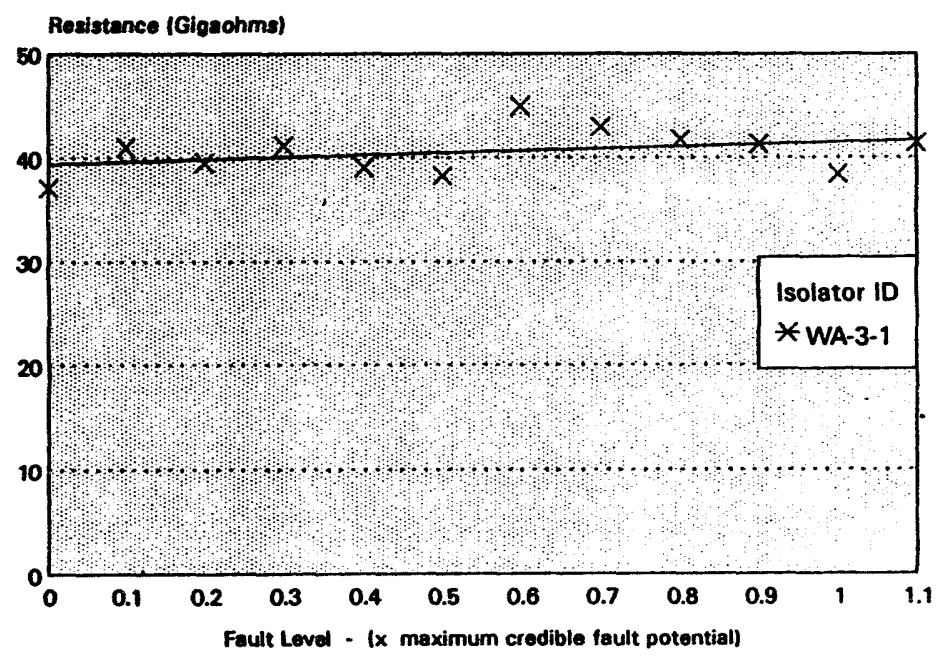

Resistance as measured after application of indicated fault level. 
Figure D.19 Reach-Through Energy vs Fault Level Isolator DA-2-3

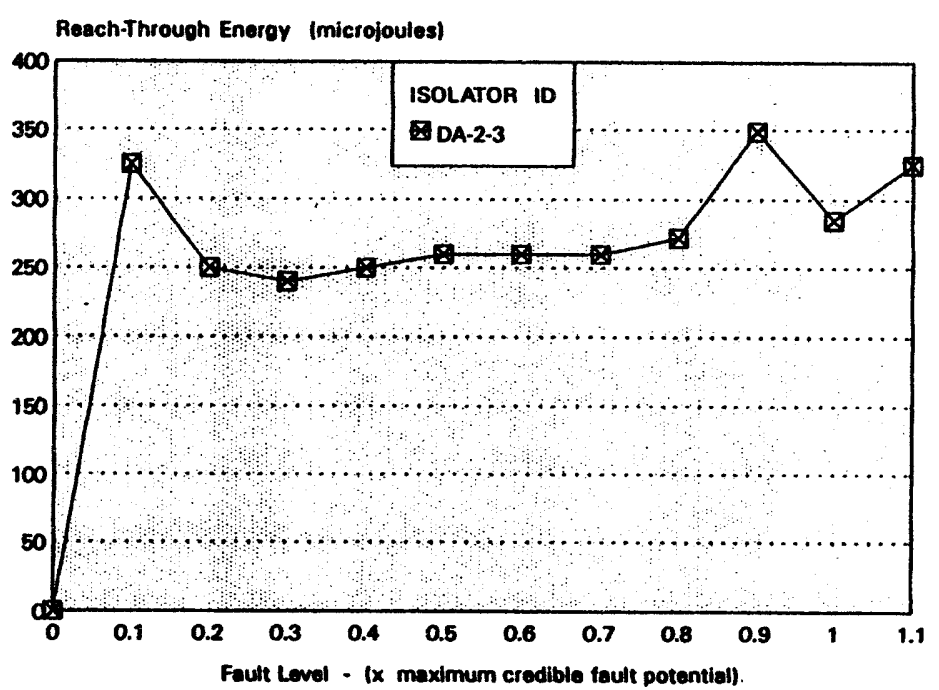

Figure D.20 Barrier Resistance vs Fault Level Isolator DA-2-3

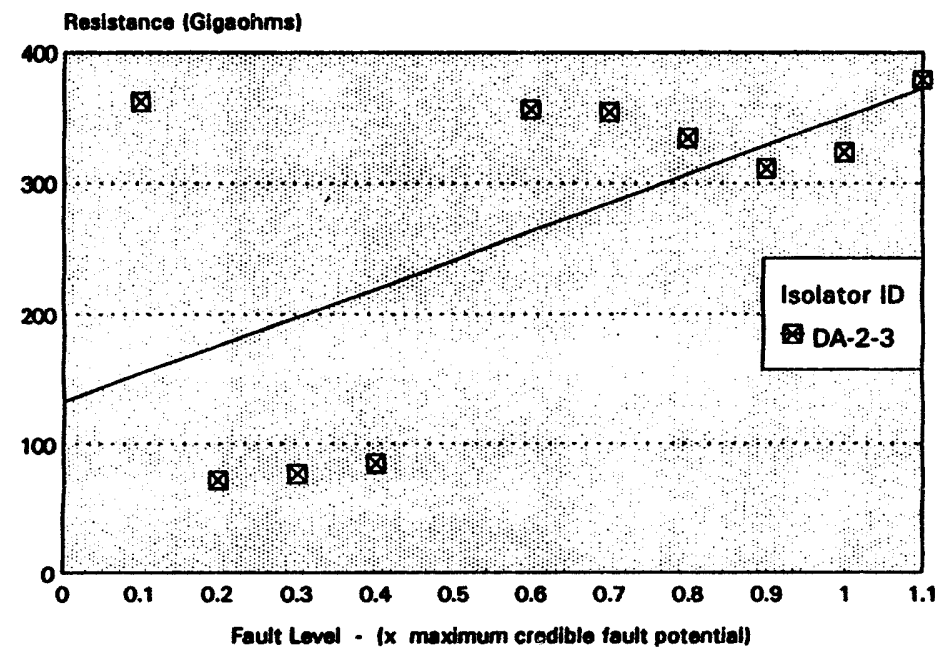

Resistance as measured efter application of indicated fault lovel.
Figure D.21 Barrier Capacitance vs Fault Level Isolator DA-2-3

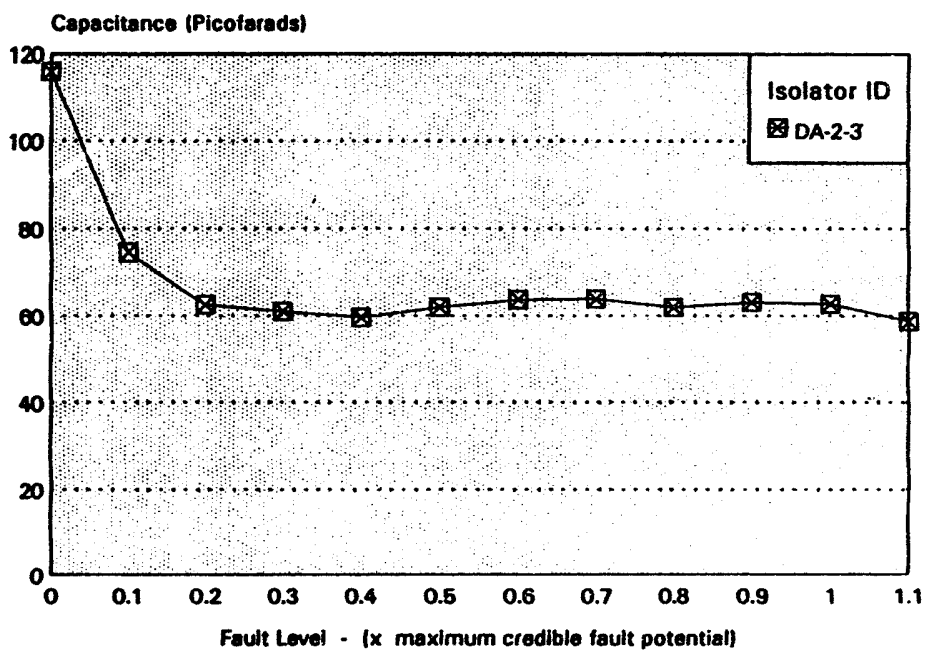

Capscitance as measured after application of indicated fault level. 
Figure D.22 Reach-Through Energy vs Fault Level Isolator HNA-2-1

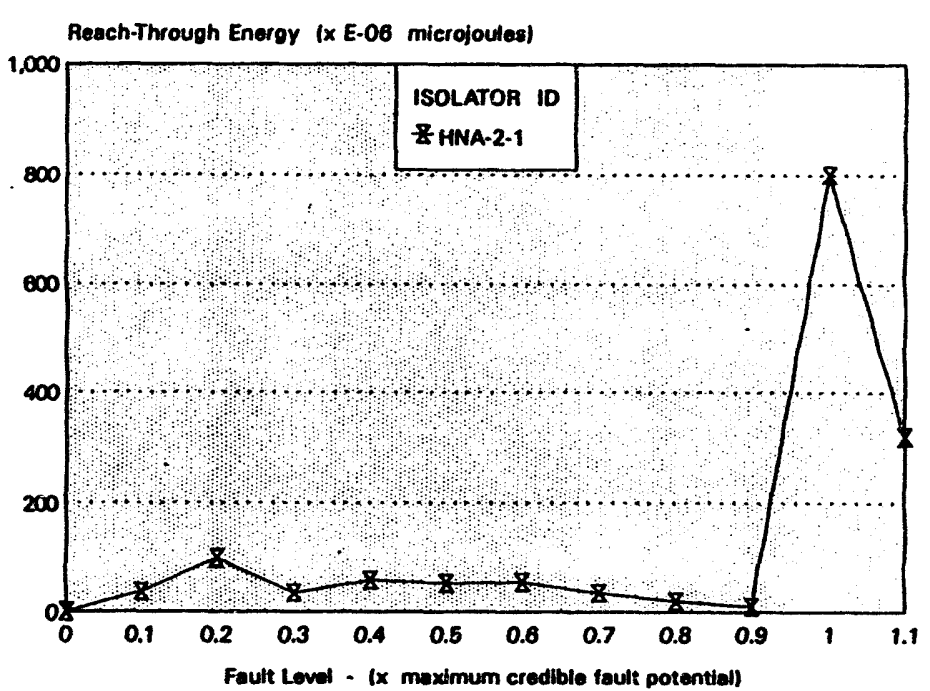

Figure D.23 Barrier Resistance vs Fault Level Isolator HNA-2-1

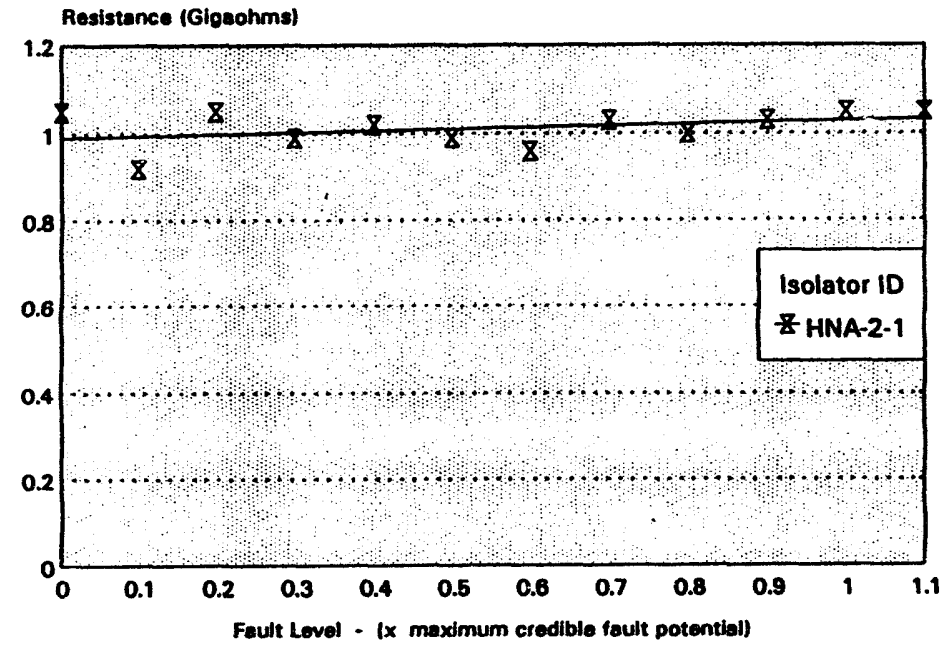

Resistance as measured after application of indicated fault level.
Figure D.24 Barrier Capacitance vs Fault Level Isolator HNA-2-1

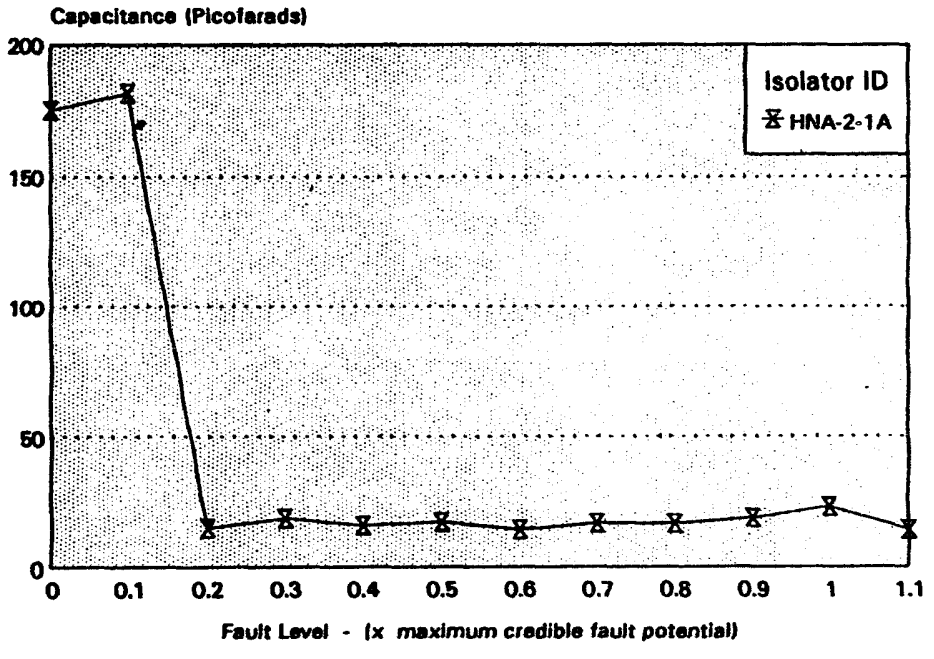

Capacitance as measured after application of indicated fault level. 


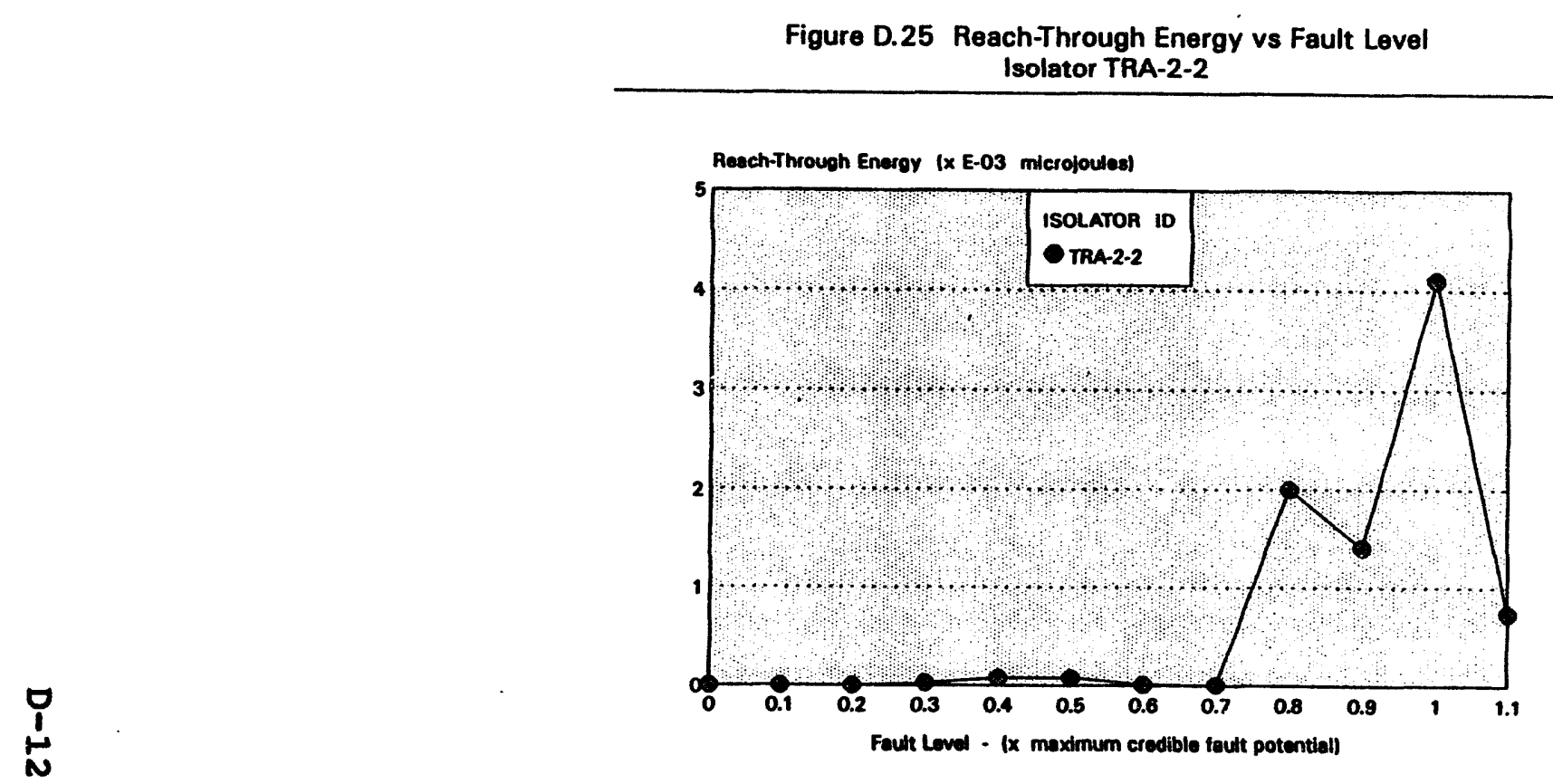

Figure D.26 Barrier Resistance vs Fault Level Isolator TRA-2-2

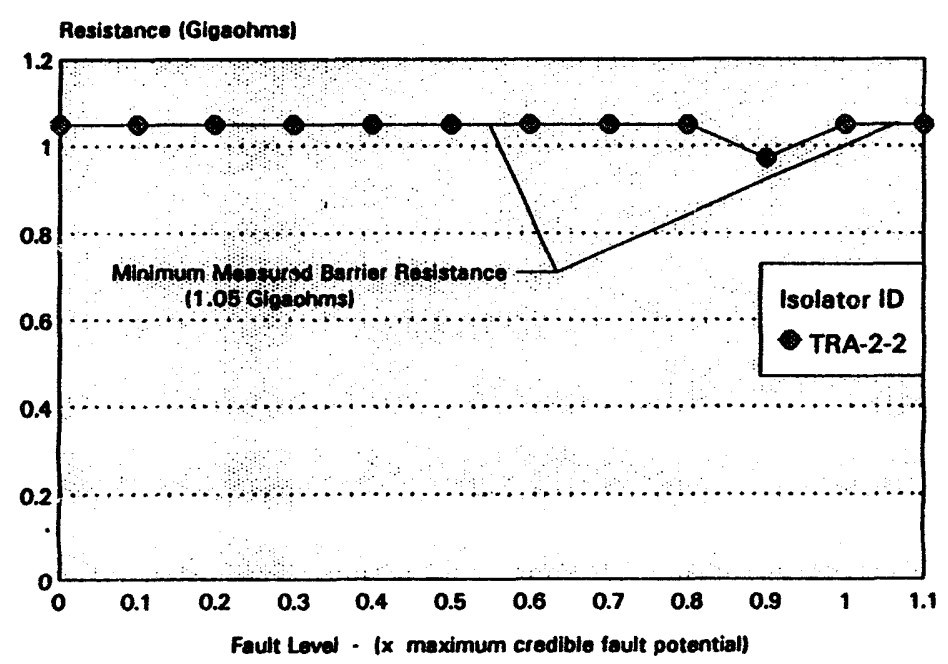

Resistance as measured after application of indicated fault level.
Figure D.27 Barrier Capacitance vs Fault Level Isolator TRA-2-2

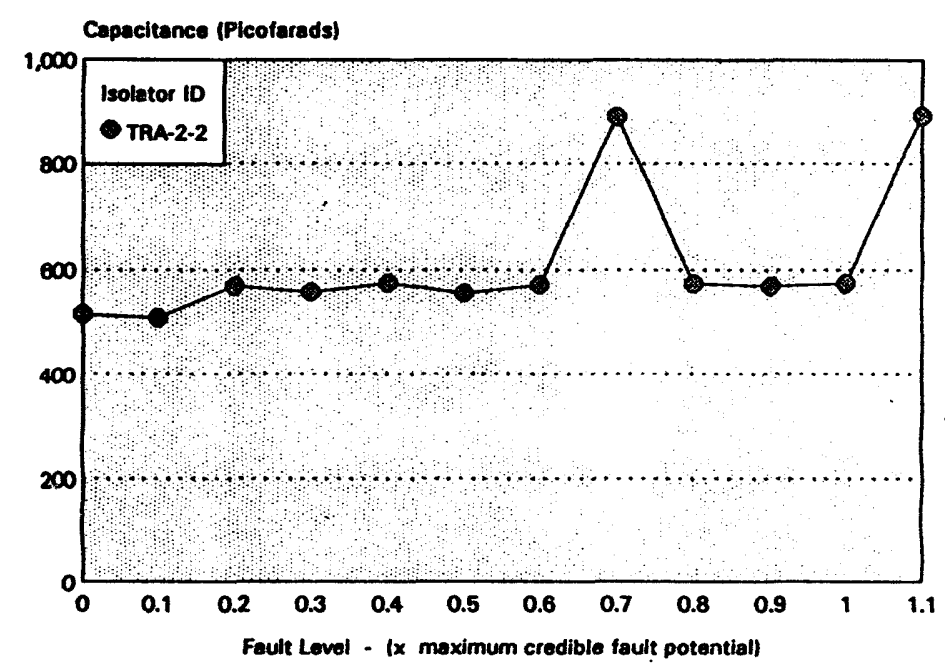

Capacitance as measured after application of indicated fault level. 


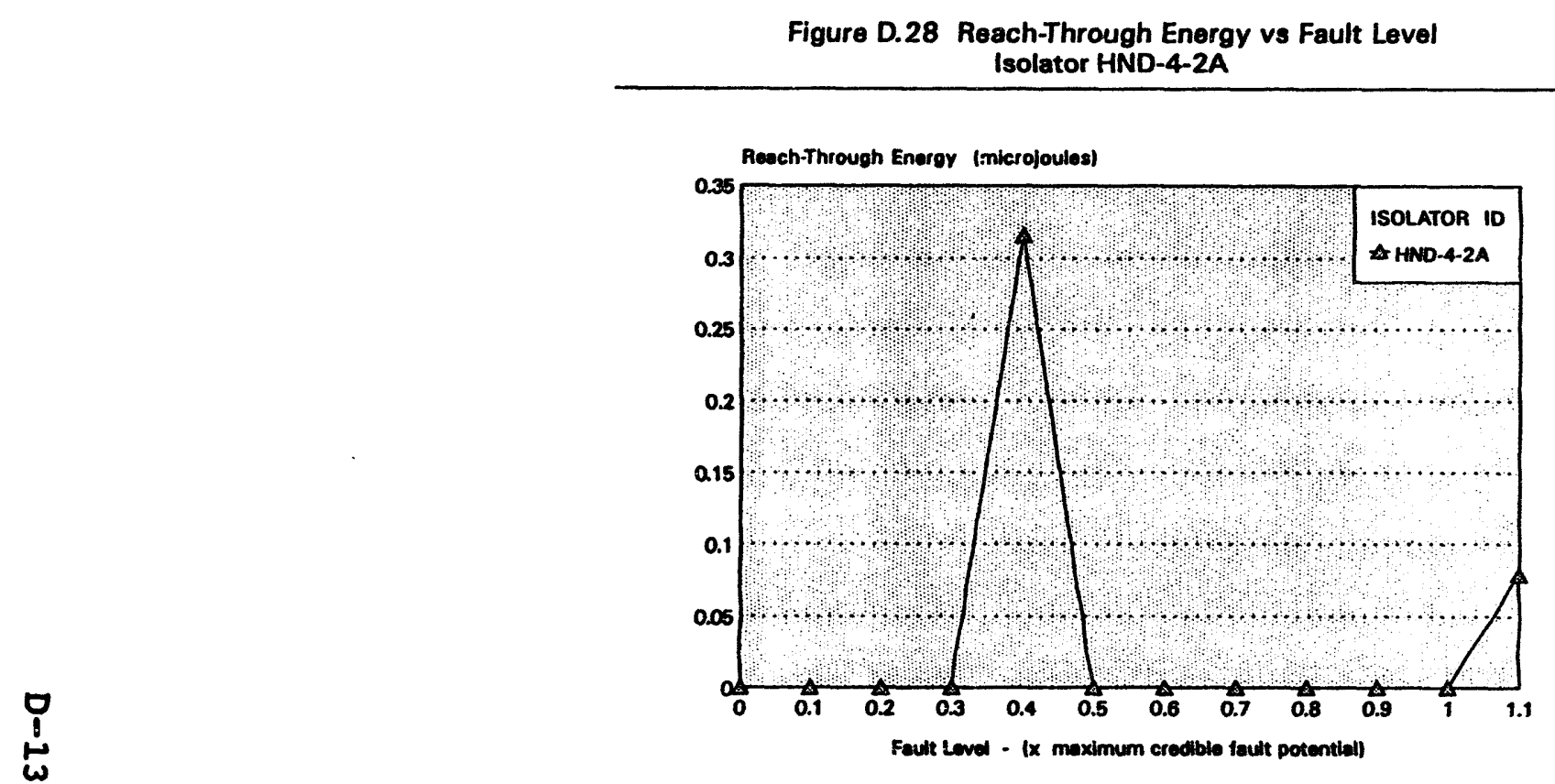

Figure D.29 Barrier Resistance vs Fault Level Isolator HND-4-2A

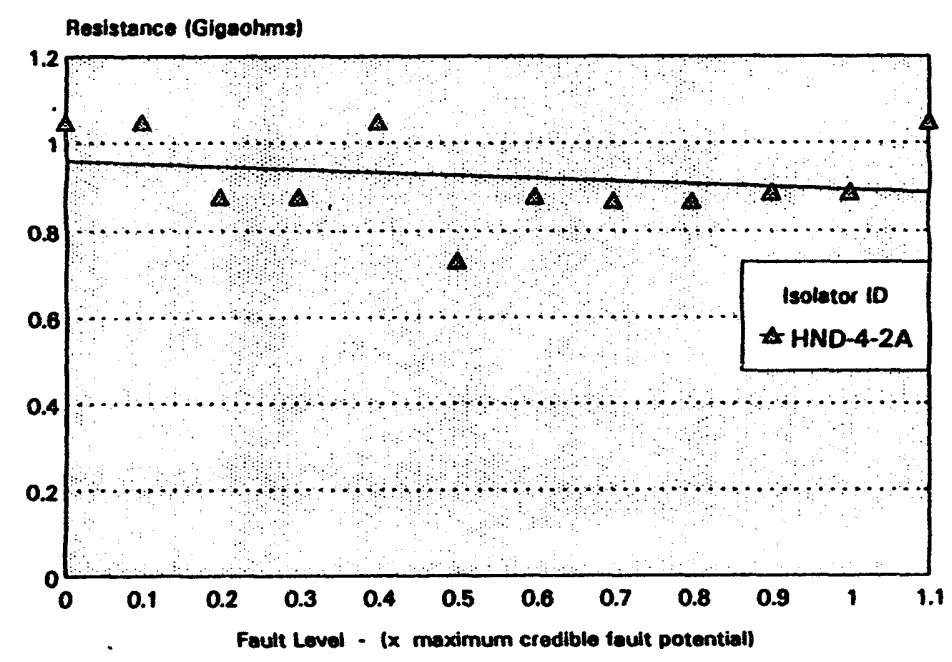

Resistance as measured after application of indicated fault level.
Figure D.30 Barrier Capacitance vs Fault Level Isolator HND-4-2A

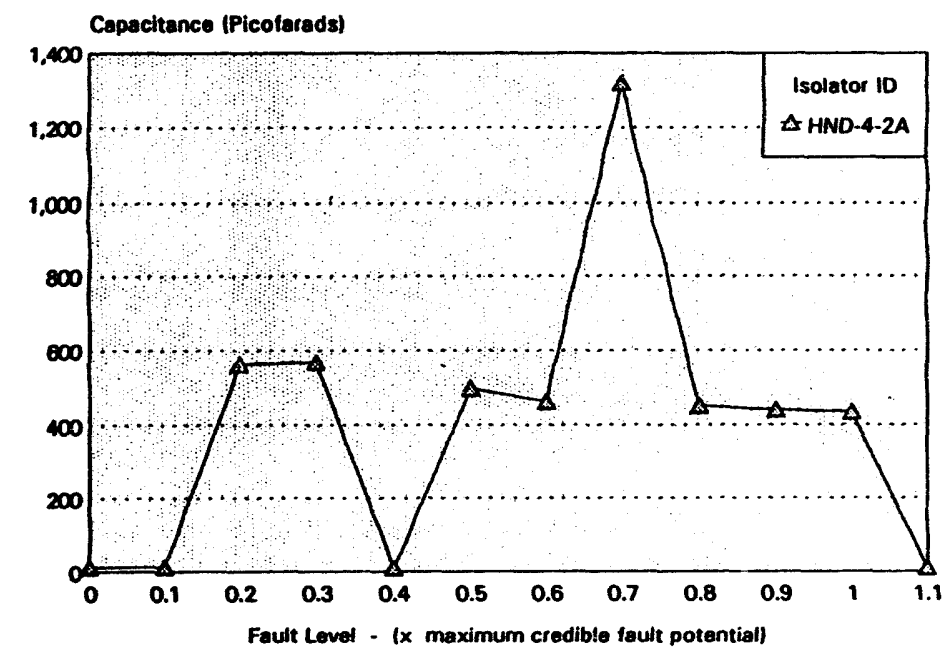

Capacitance as measured after application of indicated fault level. 
Figure D.31 Reach-Through Energy vs Fault Level Isolator TD-4-1

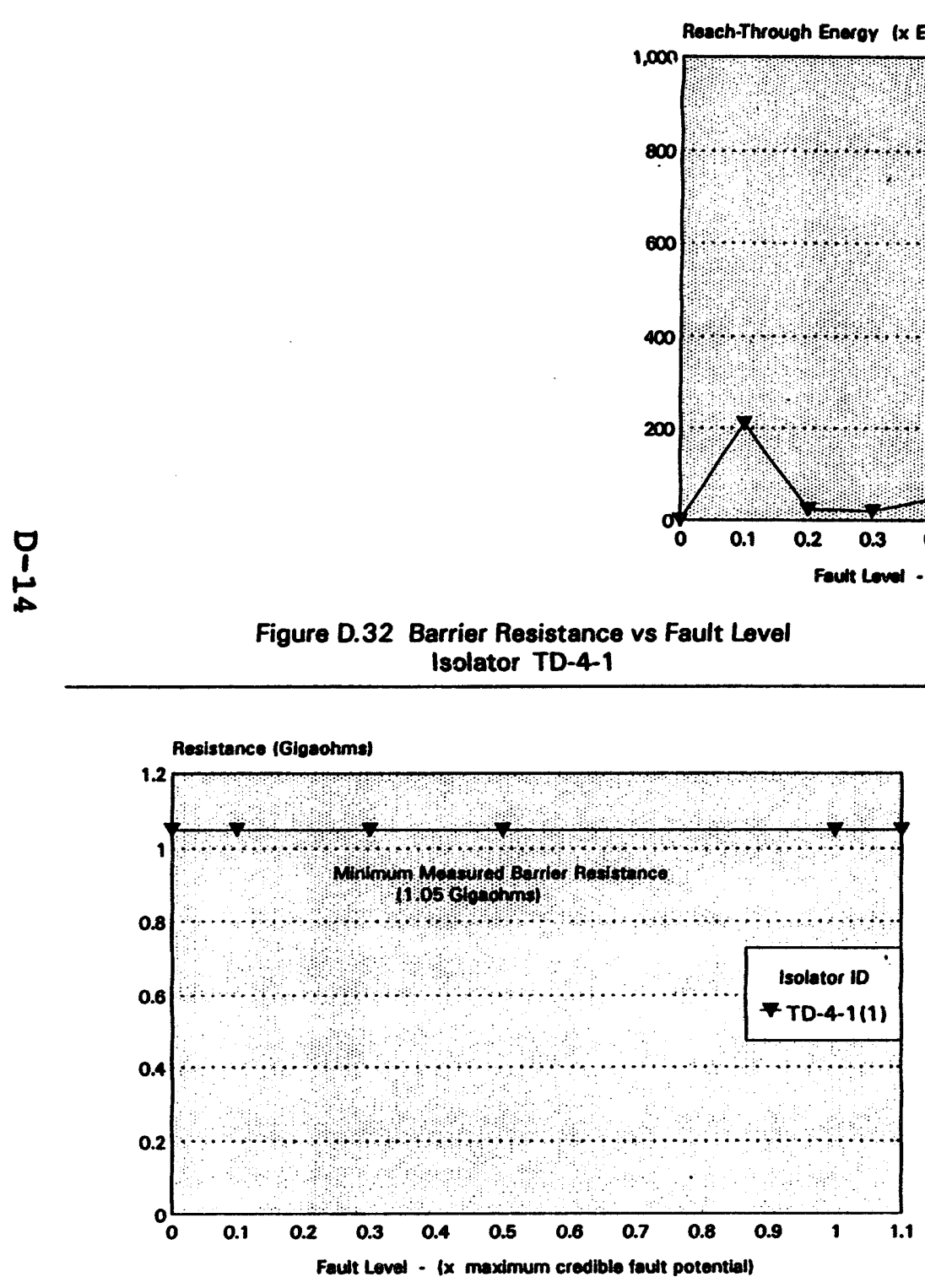

Figure D.33 Barrier Capacitance vs Fault Level Isolator TD-4-1

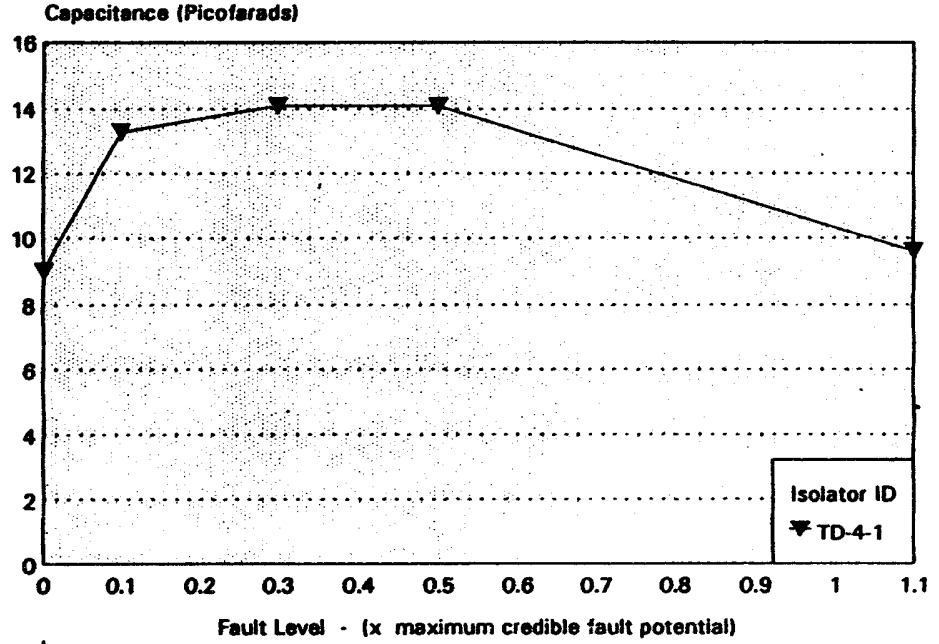

Capacitance as measured after application of indicated fauti level. 


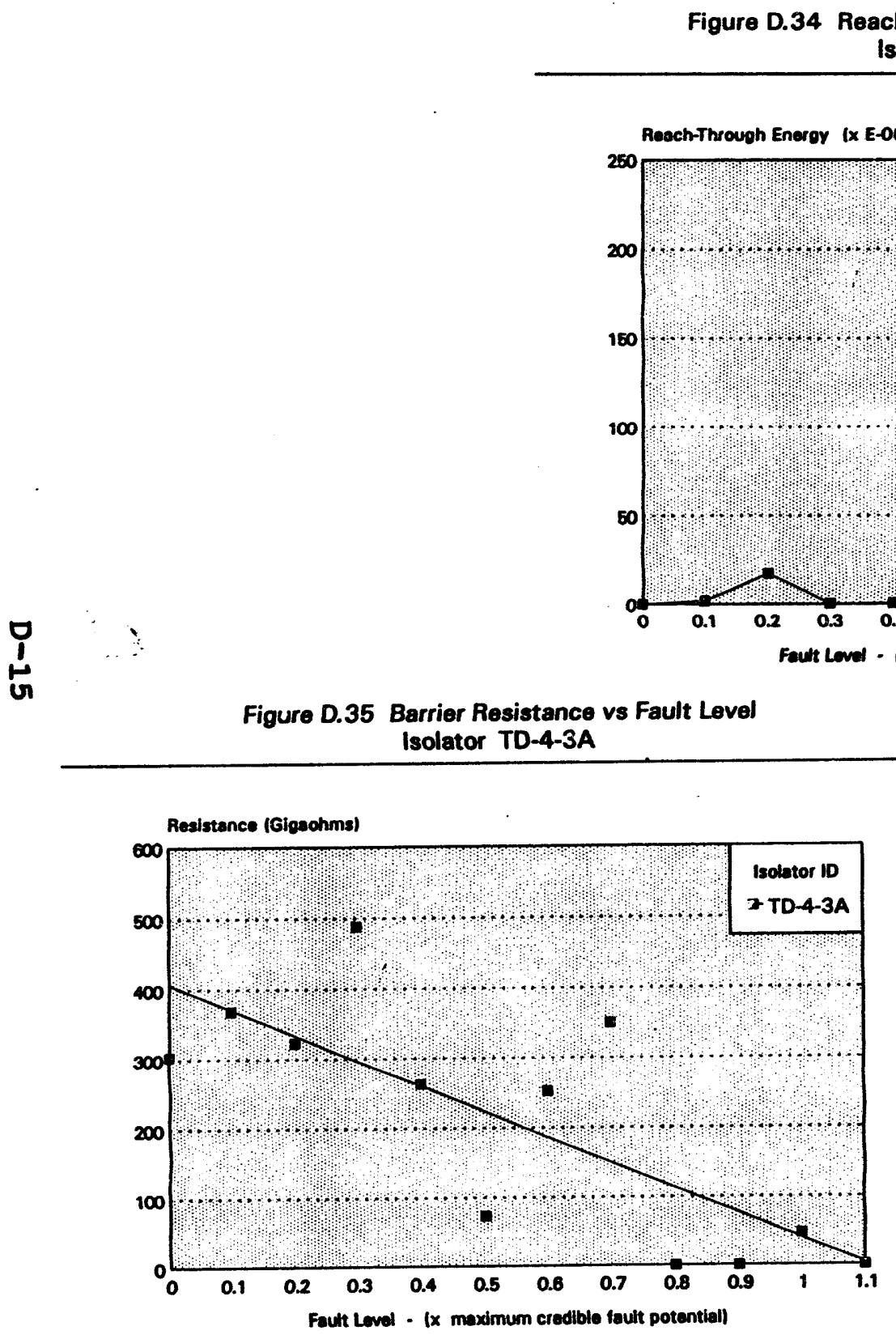

Resistance as measured after application of indicated fault level. vs Fault Level solator TD-4-3A

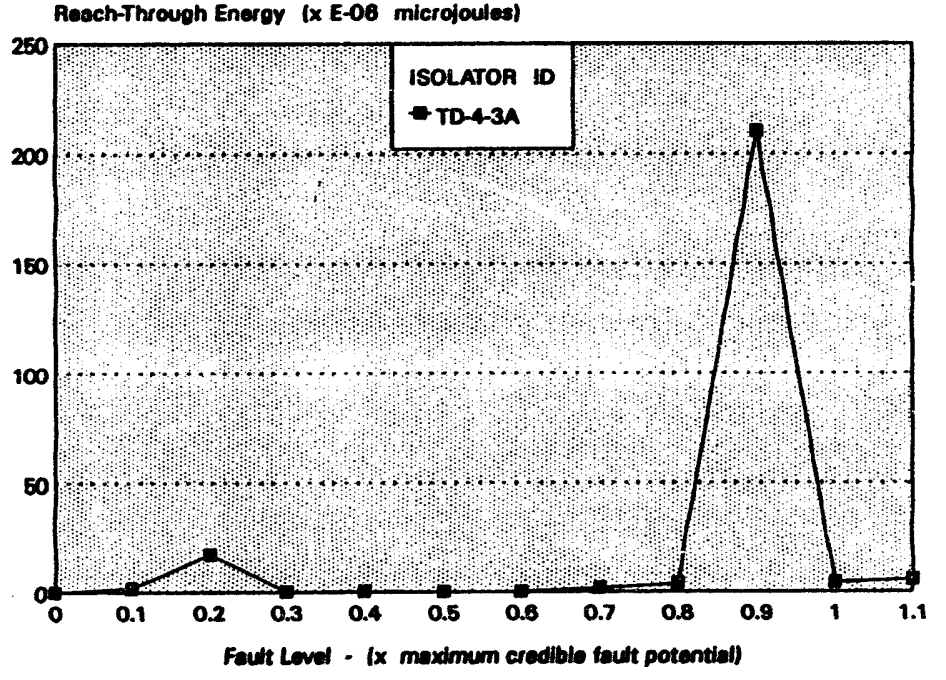

Figure D.36 Barrier Capacitance vs Fault Level Isolator TD-4-3A

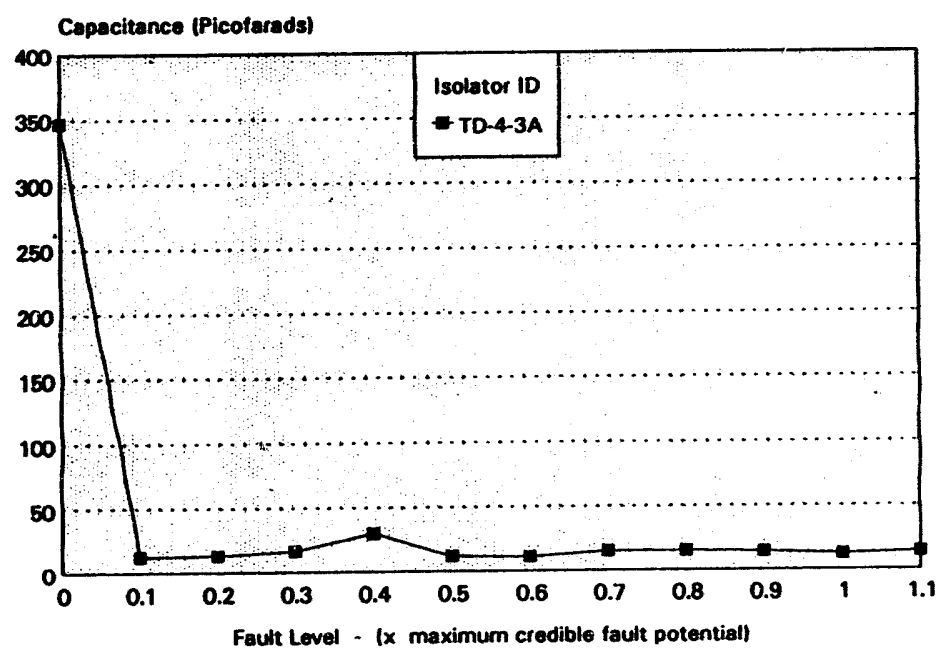

Capacitance as measured after application of indicated fault level. 
Selected Fault Testing of Electronic Isolation Devices

Used in Nuclear Power Plant Operation

M. Villaran, K. Hillman, J. Taylor, and J. Lara, Brookhaven

National Laboratory

DATE REPORT PUBLISHED

MONTH

May 1994

4. FIN OR GAANT NUMBER

T2158

6. TYPE OF REPORT

Technical

w. Wilhelm, Consultant

7. PERIOD COVERED IIne/usim OATES)

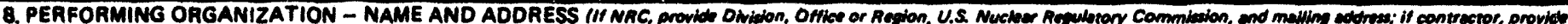

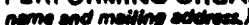

Brookhaven National Laboratory

Building 130

Upton, NY 11973

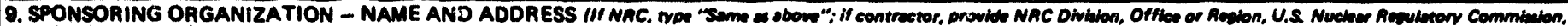

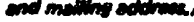

Division of Engineering

Office of Nuclear Regulatory Research

U.S. Nuclear Regulatory Commission

Washington, DC 20555-0001

10. SUPPLEMENTARY NOTES

11. ABSTAACT (2000 mond or now

Electronic isolation devices are used in nuclear power plants to provide electrical separation between safety and non-safety circuits and systems. Major fault testing in an earlier program indicated that some energy may pass through an isolation device when a fault at the maximum credible potential is applied in the transverse mode to its output terminals. During subsequent field qualification testing of isolators, concerns were raised that the worst case fault, that is, the maximum credible fault (MCF), may not occur with a fault at the maximum credible potential, but rather at some lower potential. The present test program investigates whether problems can arise when fault levels up to the MCF potential are applied to the output terminals of an isolator. The fault energy passed through an isolated device during a fault was measured to determine whether the levels are great enough to potentially damage or degrade performance of equipment on the input (Class 1E) side of the isolator.

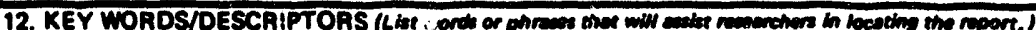

Electronic circuits - performance testing

Electronic circuits - failures, electrical faults

Nuclear power plants - engineered safety systems, reliability, electrical equipment, electric currents, benchmarks, testing
13. AVAILABILITY STATEMENT

Unlimited 14. SECUAITY CLASITICATION Trasperl

Unclassified IThm Reporl

Unclassified 15. NUMBEA OF PAGES 

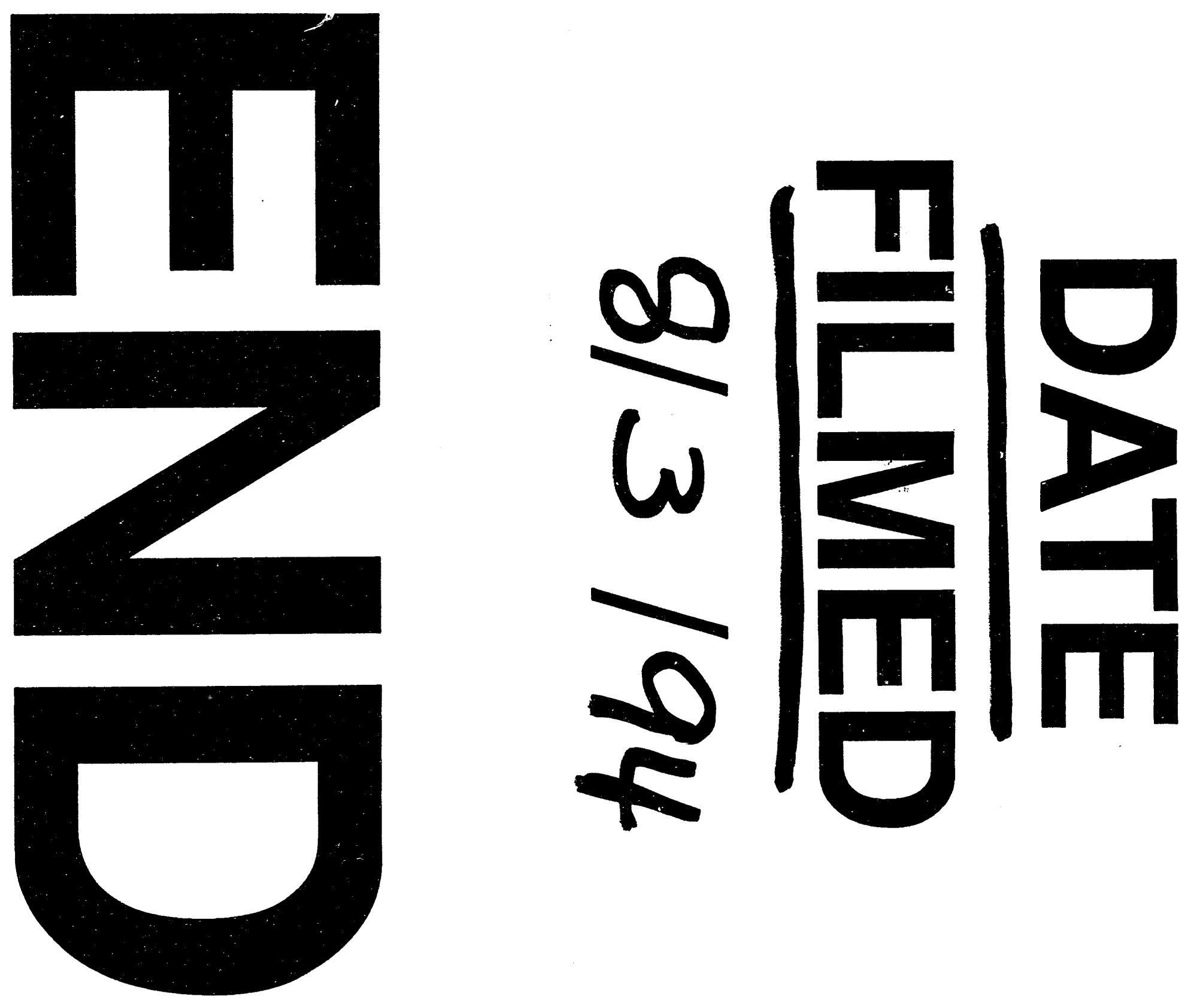
